Florida International University FIU Digital Commons

FIU Electronic Theses and Dissertations

University Graduate School

7-2-2015

\title{
Decentralization and Citizen Participation in Mexico
}

Ilyana Albarran

Florida International University, ilyana_albarran@hotmail.com

DOI: 10.25148 /etd.FIDC000076

Follow this and additional works at: https:// digitalcommons.fiu.edu/etd

Part of the Public Affairs, Public Policy and Public Administration Commons

\section{Recommended Citation}

Albarran, Ilyana, "Decentralization and Citizen Participation in Mexico" (2015). FIU Electronic Theses and Dissertations. 2223.

https://digitalcommons.fiu.edu/etd/2223

This work is brought to you for free and open access by the University Graduate School at FIU Digital Commons. It has been accepted for inclusion in FIU Electronic Theses and Dissertations by an authorized administrator of FIU Digital Commons. For more information, please contact dcc@fiu.edu. 


\section{FLORIDA INTERNATIONAL UNIVERSITY}

Miami, Florida

\section{DECENTRALIZATION AND CITIZEN PARTICIPATION \\ IN MÉXICO}

A dissertation submitted in partial fulfillment of the

requirements for the degree of

DOCTOR OF PHILOSOPHY

in

PUBLIC AFFAIRS

by

Ilyana Albarran

2015 
To: Dean Michael R. Heithaus

College of Arts \& Sciences

This dissertation, written by Ilyana Albarran, and entitled Decentralization and Citizen Participation in México, having been approved in respect to style and intellectual content, is referred to you for judgment.

We have read the dissertation and recommend that it be approved.

Eduardo Gamarra

Milena Neshkova

$\begin{array}{r}\hline \text { Milena Neshkova } \\ \hline \text { Sukumar Ganapati }\end{array}$

Jean-Claude Garcia-Zamor, Major Professor

Date of Defense: July 2, 2015

The dissertation of Ilyana Albarran is approved.

Dean Michael R. Heithaus

College of Arts \& Sciences

Dean Lakshmi Reddi

University Graduate School 


\section{DEDICATION}

I dedicate this dissertation to my husband, John Berry. Without his support, patience, understanding, and most of all love, the completion of this work would not have been possible. I would like to give thanks to my mother and father, who encouraged me to pursue a doctoral degree. I would also like to acknowledge the Mexican activists in the two communities examined in this dissertation — their selfless hard work to develop their communities has been a great inspiration to me throughout the research process. 


\section{ACKNOWLEDGMENTS}

I wish to thank the members of my dissertation committee for their guidance throughout the dissertation process. I would like to acknowledge the financial support of the Dissertation Evidence Acquisition Fellowship from Florida International University, which made possible the data gathering phase of my dissertation. Lastly, I would like to recognize the institutional support from the Institute for Public Management and Community Service (IPMCS) at Florida International University, without which I could not have completed this dissertation. 


\section{ABSTRACT OF THE DISSERTATION \\ DECENTRALIZATION AND CITIZEN PARTICIPATION \\ IN MÉXICO}

by

Ilyana Albarran

Florida International University, 2015

Miami, Florida

Professor Jean-Claude Garcia-Zamor, Major Professor

During the past few decades, decentralization efforts in México have coincided with efforts to democratize the administrative decision-making process. Adopted in 1988, the Programa Nacional de Solidaridad (National Solidarity Program; PRONASOL) required citizen participation in decisions involving the use of federal resources for regional development and poverty alleviation projects. In 1998, Section 33 of the Ley de Coordinación Fiscal (Fiscal Coordination Law; LCF) placed Social Infrastructure Funds (SIF) directly under the supervision of municipalities and retained the requirement that citizens participate in decisions involving the allocation of funds.

The present study seeks to understand the factors that affect the participation of citizen committees (composed of community members; organized to address a particular cause) in SIF allocation decisions and assess the impact of this form of citizen participation on government performance. To pursue this objective, the study analyzes the implementation of LCF with respect to the role of citizen committees in SIF allocation decisions at two different locations: the township of Santa Maria Tonantzintla, 
located in the municipality of San Andrés Cholula, in the state of Puebla, and the rural municipality of Tenango Del Aire, located in El Estado de México (the State of México).

The study finds that gender, church participation, and personal economy play major roles in the formation of citizen committees. Although the citizen committees have been instrumental in getting their SIF projects prioritized, they have had little effect on the quality or efficiency with which the projects were carried out. In general, the municipal decision-making process in both municipalities lack mechanisms to guarantee citizen participation and thus to ensure consideration of the broader public interest beyond the interest of organized groups. Because SIF can be used for various economic development projects, such as water, sewage, electrification, emergency clinics, and schools, it was of particular importance to determine whether the participatory mechanism was functioning correctly. Given the nature of the projects carried out by municipalities, flaws in the implementation process, including failures to include the broader public, could hinder not only local economic development, but also the economic growth of the nation. 


\section{TABLE OF CONTENTS}

CHAPTER

PAGE

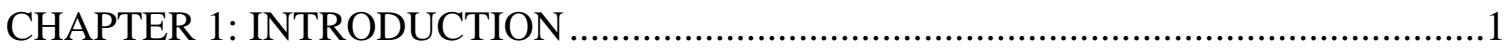

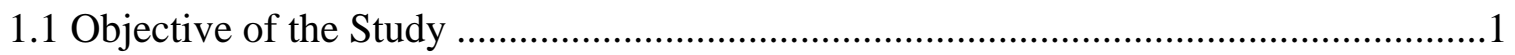

1.2 Research Problem .............................................................................................2

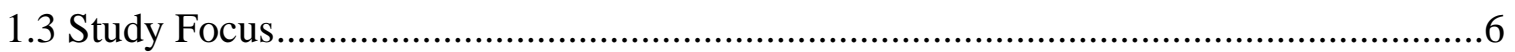

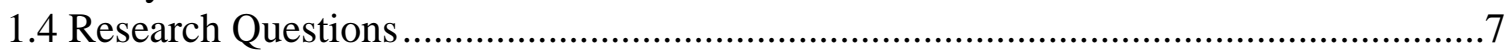

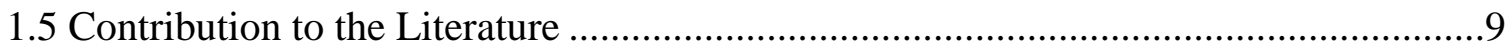

CHAPTER 2: THEORETICAL FRAMEWORK AND LITERATURE REVIEW ...........11

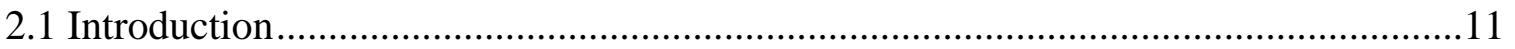

2.2 Shifting Idealogies: From Centralization to Decentralization .....................................11

2.2 Citizen Participation in Bureaucracy: A Theoretical Framework..................................23

2.4 Institutionalization and Incorporation of Decentralization Policy and Participative Planning and Management (PPM) Practices......................................................................33

2.5 Solidarity Committees in México: The Legacy of PRONASOL..................................49

2.6 Determinants of Citizen Participation in México ..........................................................55

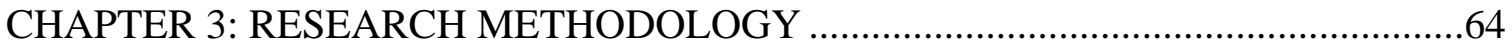

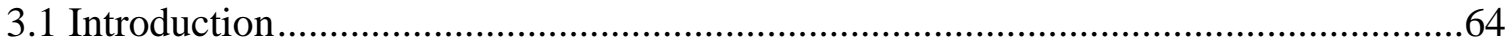

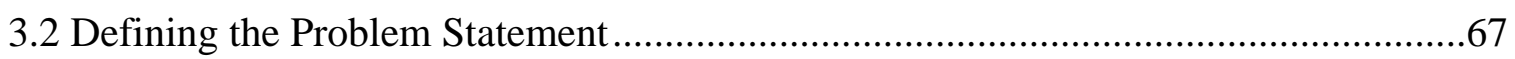

3.3 Selection of Research Sites ..................................................................................69

3.4 Selecting Participants and Obtaining Data .............................................................73

3.5 Data Analysis .....................................................................................................

3.6 Reliability, Validity, and Potential Limitations ..........................................................81

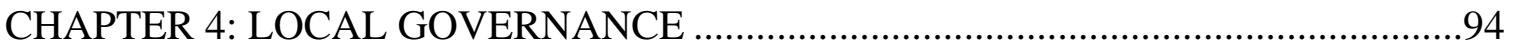

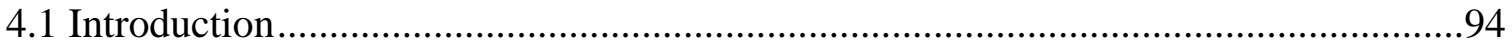

4.2 Structure of the Decision-Making Process ...................................................................95

4.3 The Mayors' Description of the Municipal Decision-Making Process .......................103

4.4 The Role of Administrative Discretion................................................................110

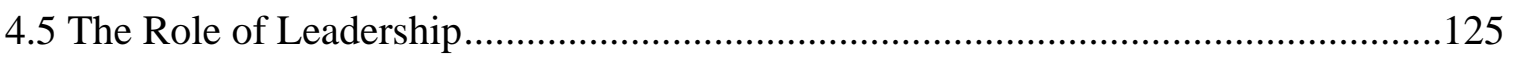

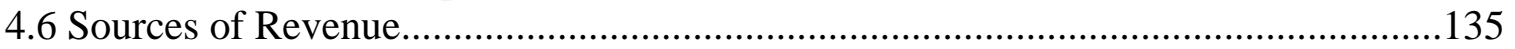

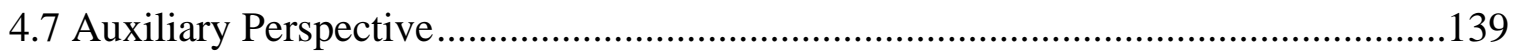

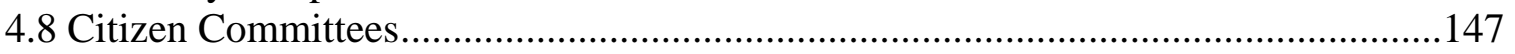

4.9 Function and Treatment of Citizen Committees in Each Municipality: A

Preliminary Typology of Citizen Committees ...............................................................152

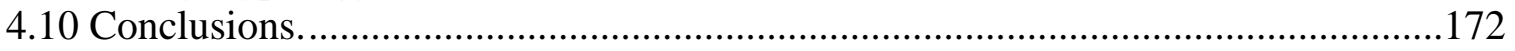

CHAPTER 5: CITIZENS COMMITTEES: Formation and Involvement; an

Evaluation of the Participatory Mechanism...............................................................176

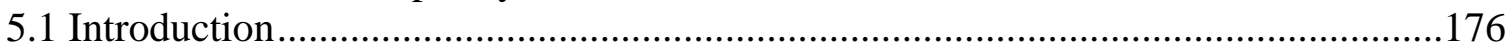

5.2 Santa María Tonantzintla Comités de Obra................................................................177 
5.3 SIF and Public Schools; Padres de Familia

5.4 Determinants of Citizen Participation in San Andrés Cholula ...................................212

5.5 Tenango del Aire's COCICOVIs..........................................................................216

5.6 Determinants of Citizen Participation in Tenango del Aire.........................................223

5.7 Evaluation of the Participatory Process: Conclusions .................................................225

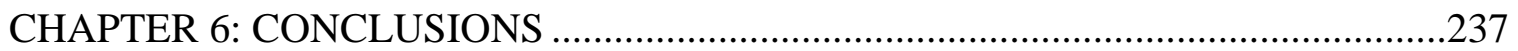

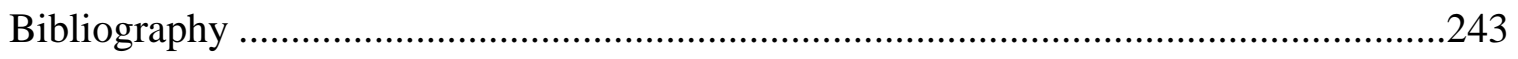

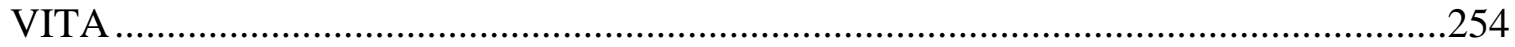




\section{CHAPTER 1: INTRODUCTION}

\subsection{Objectives of the Study}

The objective of this dissertation is to analyze critically the implementation of decentralization policies that required the incorporation of citizen participation and the impact of these policies on the governance of rural Mexican municipalities. The study seeks to provide a better understanding of the development and operation of citizen committees in rural areas, and their influence on the governance/decision-making process of municipalities. The findings of the research will contribute to at least three bodies of literature. First, they will shed additional light on decentralization processes in rural México. Second, by assessing the extent and impact of citizen committees on allocationdecisions involving infrastructure funds, the dissertation will contribute to the research literature on public participation in administrative decision-making. Finally, by focusing on México and the processes of democratization of administrative processes at the local level, the work will ultimately contribute to the literature on comparative public administration.

Specifically, the present study analyzes the formation of citizen committees and their impact on allocation-decisions involving Social Infrastructure Funds (SIF) in two municipalities in México. It traces several citizen committees in their attempt to obtain SIFs for potable water projects, road pavement, and the creation and expansion of schools. In pursuing its main objective, the study answers a number of interrelated questions: What is the current governance structure of municipalities? How are SIF allocation decisions made? What role do citizen committees have on the allocation of SIF? Do citizen committees vary from one municipality to another? What affects the 
formation of citizen committees? Have decentralization policies that require the creation of citizen committees met their objectives? By answering these questions, I hope to contribute to the literature on participatory democracy and decentralization, and simultaneously enhance knowledge about the performance of municipalities. It is important to understand the effects of these reforms, if any, and their implications for the performance of municipalities. The broad value of this work lies in the interplay between decentralization and citizen participation and how this affects good governance.

\subsection{Research Problem}

Over the past decades governance has become a popular topic of discussion and study. Authors, such as Box, have preferred to use the word governance rather than government or administration because the term "include[s] the entire range of activities of citizens, elected representatives, and public professionals as they create and implement public policy in communities” (1998). However, the definition of governance varies. For example, according to the World Bank, governance is "the process and institutions through which decisions are made and authority in a country is exercised" (n.d.: 3 cf. Grindle 2007: 556-557). According to the United Nations Development Program, governance "comprises the mechanisms, processes and institutions through which citizens and groups articulate their interests, exercise their legal rights, meet their obligations and mediate their differences” (1997: 12, cf. ibid.). Other definitions of governance include:

'how the institutions, rules, and systems of the state-the executive, legislature, judiciary and military —operate at central and local level and how the state relates to individual citizens, civil society and the private sector' (DFID 2001:11, note a, cf. ibid.). 
'The ability of government to develop an efficient, effective, and accountable public management process that is open to citizen participation and that strengthens rather than weakens a democratic system of government' (USAID 2005: 1 cf. ibid.).

'The formation of stewardship of the formal and informal rules that regulate the public realm, the arena in which state as well as economic and societal actors interact to make decisions' (Hyden et al. 2004: 16 cf. ibid.).

Although Huillet-in the forward of the book "Participatory governance: planning, conflict mediation, and public decision-making in civil society"-explains that the term governance describes an intricate composite of organizational mechanisms, administrative processes, and ever-changing relations and interactions between government and non-profit organizations, citizens, and the general private sector, put simply, governance can be defined as being "about processes of making decisions" (Lovan, Murray and Shaffer 2004, xvi). "In other words, [governance] is concerned with processes focusing on the distribution of public responsibilities across multiple stakeholders" (ibid.). Furthermore, governance is a term that focuses on the "fundamental question of how the processes of democracy (citizen involvement, decision-making procedures and administrative functions) can be adapted to help countries resolve the complex issues with which they are challenged” (ibid.).

Although, non-profit organizations and the private sector influence the decisionmaking process of government, increasingly, studies have begun to focus more on the role of citizens. However, until recently, citizen participation in government has been limited to indirect participation through voting (Nabatchi 2012). In democratization efforts, the "focus of citizen participation was on gaining and guaranteeing the rights of all citizens to vote for representation in government” (Keyssar 2000 cf. Nabatchi 2012). 
However, after those rights were secured, "the focus shifted from an emphasis on 'the representative nature of government' to an examination of 'direct participation by citizenry in day-to-day activities of the state”" (Stewart 1976 cf. Nabatchi 2012). The more recent shift in ideology encouraging decentralization has shifted the conversation on the impact of citizen participation and good governance from the national to the local level.

Unfortunately, studies on the current governance of rural Mexican municipalities and the impact that decades of decentralization policies has had on the role of citizen participation in the decision-making process are lacking detail and substance. Few works (e.g., Goldfrank, 1998) have analyzed the links between decentralization, democratization, and the promotion of good governance. In Goldfrank (1998), the focus was on a general comparative analysis of several countries in South America. In the case of studies conducted in México, the literature analyzing the links between decentralization and improved governance were available but focused mostly on large cities (Cabrero, 1996; Guillen, 1996; Habers, 2007; Ramirez Saiz, 1998; Ziccardi, 1995). Moreover, of these studies, only Habers (2007) was conducted in México City and integrated democratization—specifically defined as increases in the level of citizen participation in the administrative decision-making process. The work of Beneria and Mendoza (1995) examined the role of citizen committees in the decision-making process but focused on the regulations of an outdated program no longer in operation.

Few works, including that of Bazdresch Prada, 1994; Diaz Montes, Zafra, and Gonzalez Menchor, 1994; Cabrero, 1995; Rodriguez and Ward, 1995 mentioned small municipalities in México (c.f., Rowland, 2001). Of these studies, only Rowland (2001) 
was conducted in rural México, integrating all three areas of interest-decentralization, democratization, and governance. However, Rowland's work accounted for the democratization of administrative decision-making through municipal use of COPLADEMUNs (Comités de Planeación para el Desarrollo Municipal), local planning meetings carried out with representatives of local non-governmental organizations (NGOs) as well as neighborhood organizations and other civil associations. Moreover, although Rowland (2001) mentioned that "in México there is no single law which delineates the scope of citizen participation in local government, and each state may have its own mechanism to encourage it in its Constitution” (p. 1380), he made no reference of municipal use of citizen committees as a means of incorporating citizen input into decision-making processes. According to the literature, decentralization efforts in México were undertaken to democratize the government process and promote good governance. By devolving decision-making authority to the municipalities and increasing citizen participation in the administrative processes, it was hoped that the needs of society would be better met. However, several questions remained unanswered, such as: Are these groups composed of a representative sample of the community they represent? Are the legal mandates regulating the formation of citizen committees accessible for community representatives? What kind of citizen committees do most resemble in practice: advisory, supportive, put-off, or put-on committees? In other words, what exactly is the role of citizen committees in the municipality's decision-making process for SIF allocation? Does the current participatory process promote good governance? 


\subsection{Study Focus}

This present study focuses on two major policy shifts occurring in México that are the result of decentralization efforts. The first is the inclusion of citizen participation in the process for determining SIF allocation. The second is the devolution of authority over SIF allocation to the municipal level. By devolving decision-making authority to the municipal level of government, and passing legislation to institutionalize citizen participation, it was hoped that the needs of marginal groups in society would be effectively met. However, several questions remained unanswered, such as: How successful have municipal governments been at institutionalizing citizen participation? And does the current participatory process promote accountability, improve governance, and deliver all the benefits promised by decentralization reform?

The aim of the research is to understand the formation of citizen committees and examine their impact on rural municipal decision-making. The dissertation specifically examines municipal decisions regarding Social Infrastructure Fund (SIF) allocation for potable water projects, road pavement, and the creation and expansion of schools. In carrying out the research, the theoretical arguments for decentralization and direct participatory democracy are critically analyzed. The outcomes of the legislation are compared with the desired impacts, specifically: the promotion of accountability and improved governance — ethics, efficiency, effectiveness, and responsiveness — as well as the establishment of cost recovery mechanisms for certain infrastructure/service provision projects.

The evolution of the research interest arose as follows. After several years of dedicating themselves to the situation involving potable water in the community of San 
Isidro Buenos Aires in Santa Maria Tonantzintla, México, the citizen committee of potable water was finally able to capture the attention of their representatives and add the project to the long list of public works to be completed by 2006. It was by no means a simple process to prioritize this public project. The steps needed to obtain some of the paperwork were complicated, requiring time and money from the citizen committee. I became interested in understanding what the process of obtaining potable water was and how it fell into the general scheme of what is intended according to the new legislation that emerged from the decentralization process. However, it became apparent that in order to make generalizations about the process, more case studies needed to be included. As a result, this research analyzed the story of two additional citizen committees in the area as well as the story of three schools that continually battle to obtain SIF. In addition, the present study compared the experiences of these three citizen committees with the experiences of additional citizen committees in another rural municipality, Tenango del Aire, in the State of México. Through process tracing for each case and in-depth interviews with municipal authorities, citizen committee members, and community members, I aimed to understand the mechanisms through which SIF allocation occurs and is affected by citizen committees.

\subsection{Research Questions}

Little is known about the impact of this form of citizen participation in the administrative process on government performance in rural México. Scholars argue that incorporating citizen participation in the administrative decision-making process can improve overall government performance (Bringham, Nabatchi and O’Leary 2005; Dahl 1989, 1992; Ebdon and Franklin 2004, 2006; Habermas 1996; Kernaghan 1992; Roberts 
1997; Stivers 1990; Olsen 1986; Urbinati and Warren 2008; Neshkova and Guo 2009; Garcia-Zamor 1985). However, not all authors agree that direct citizen participation in the administrative process is necessary or conducive to better policy outcomes. Traditional representative and bureaucratic governments advocate a more "decisional" approach to policy setting through technocrats (Waldo 1948). From the theoretical perspective, lack of citizen participation is justified because the public lacks the knowhow to implement policy effectively (Dahl 1989, Stivers 1990). Moreover, there is the concern that participation outside the electoral process represents the narrow interest, rather than the established general interest (Boyton, Patterson, \& Hedlund 1969, cf. Riedel 1972, Ebdon \& Franklin 2004, c.f. Neshkova \& Guo 1990). The present study aims to contribute to the current debate by investigating the following questions:

1. What factors affect the formation and involvement of citizen committees in México?

2. What is the impact of citizen committees on the governance of municipalities, specifically, government performance: the promotion of accountability and improved governance, ethics, efficiency, effectiveness, responsiveness, and the establishment of cost recovery mechanisms for certain infrastructure/service provision projects?

3. What factors determine the degree to which municipalities will adapt the new mechanisms for incorporating citizen participation in SIF allocation decisions? 
The main hypotheses are:

1. The formation of citizen committees in rural México will be a function of individual characteristics such as gender, income, religious affiliation, political participation, and the feelings individuals have about the responsiveness and efficiency of the government administration at the local level, as well as factors pertaining to the municipal willingness to collaborate with citizens.

2. If municipalities operate under the traditional representative and bureaucratic government perspective (which advocates a "decisional” approach to policy setting and implementation through the use of technocrats), it is not likely to observe improvements in accountability, governance, or the establishment of cost recovery mechanisms for infrastructure/service provision projects.

3. Municipalities belonging to a state with a history of social movements and controlled by opposition will be more likely to introduce participatory mechanisms than those with a history of social movements but controlled by the majority party and aligned with the central government.

\subsection{Contribution to the Literature}

In México, the political decentralization process has succeeded in democratizing every level within the government structure. Ranging from the executive to the local level, elections are held to select the nation's president and municipal presidents, respectively. The current debate over citizen participation is, thus, not about gaining the right to elect citizens' representatives. Rather, the debate concerns the impact that increasing citizen participation in the administrative decision-making process has on the 
establishment of economic development policies. The present study will analyze the implications of Section 33 of the Fiscal Coordination Law (LCF), which regulates the process through which citizens participate in the municipal decision-making process. Through Section 33, citizen participation is channeled through citizen committees. This study investigates the process through which citizen committees affect decisions regarding Social Infrastructure Fund (SIF) allocation. The SIF can be used for diverse economic development projects such as water, sewage, electrification, and the construction of emergency clinics and schools. If the process is not functioning correctly, it can hinder not only the local economic development, but also the economic development of the nation.

My research will shed light on efforts to promote economic development at the local level by decentralizing control over SIF allocation decisions to the municipal level. In particular, I will focus on decentralization efforts designed to increase citizen participation in the municipal decision-making process. The present study will elaborate on a possible typology that can be used by researchers to describe expected municipal reactions to citizen committees under particular circumstances. By doing so, the study will directly contribute to the comparative administration literature on decentralization and participatory democracy. Moreover, the current study will analyze the advantages and disadvantages of the current participatory process contributing to the creation of more effective, equitable, and efficient policies. 


\section{CHAPTER 2: THEORETICAL FRAMEWORK AND LITERATURE REVIEW}

\subsection{Introduction}

This chapter traces the development of decentralization policies and assesses their impact on the governance of rural Mexican municipalities-specifically, the impact of the policies requiring citizen participation in the allocation of Social Infrastructure Funds (SIF). The literature review in this chapter is divided into several sections. The first offers

a theoretical analysis of the main arguments behind decentralization reform. It posits the suggested links between decentralization and citizen participation. The second section offers a debate on the pros and cons of citizen participation in bureaucratic processes. The third section reviews the institutionalization and incorporation of decentralization policy and participatory planning and management (PPM) practices in México. Moreover, the third section identifies potential determinants affecting the incorporation of citizen participatory mechanisms at the local level. The fourth section offers a highlight of the decentralization policy that gave rise to citizen committees in México. The last section of this chapter is dedicated to describing the determinants of citizen participation as posited in the research literature.

\subsection{Shifting Ideologies: From Centralization to Decentralization}

The liberal doctrines of the Enlightenment, which fueled the French Revolution, also influenced the wide range of administrative reforms and institution building that transformed Europe, North America, East Asia, and other parts of the world during the late nineteenth and early twentieth centuries. The convergence of the ideologies and reforms of that time culminated in the emergence of bureaucratic model as we know it today (Argyriades 2010). 
“The bureaucratic model was manifestly a composite of many diverse elements. The model represented an early response to the emerging problems of complexity and scale in government, the quest for cost-effective service delivery, but also for legality, objectivity, integrity, consistency and coherence in the discharge of the functions of public management.” (ibid.: 277)

As noted by Argyriades (2010), the process of "bureaucratization" can be linked to the decline of patrimonial states secured on prescriptive rights, the transition from an agrarian to an industrial society and the conversion from a feudal aristocracy to capitalist democracy. A product of its time, the bureaucratic model pushed for reason in the structuring of organizations and their scientific management thereafter. In such a manner, bureaucracies, like machines, could secure speed, predictability, accuracy, and efficiency (Argyriades 2010). Bureaucracy, the ideal-type configuration of an organization proposed by Weber, was characterized by a hierarchical structure with unity of command at the apex, a division of labor based on task specialization, the merit-based appointment and promotion of employees, formal rules and regulations, formal communication systems, and proper access to records for informed administrative decision-making (Farazmand 2010). Bureaucratic centralism was an unmistakable part of the scientific claims of the classical management doctrines (Argyriades 2010). For example, the twentieth century 'classical' management literature such as; C. I. Barnard, The Functions of the Executive (Cambridge, MA: Harvard University Press, 1938, repr. 1968); H. Fayol, General Industrial Management (London: Pitman, 1949); L. Gulick and L. Urwrick, eds., Papers on the science of administration (New York: Institute of Public Administration, 1937); 
and F. W. Taylor, The Principles of Scientific Management (New York: Norton, 1911) all advocated centralization through scientific management as a way to organize private and public organizations (Albarran and Garcia-Zamor 2010).

After World War I, the pursuit for unity and standardization through scientific management was followed by the push to advance centralized public service management (Argyriades 2010: 279). In the United States for example, during the Great Depression, scientific management was utilized to strengthen the administrative capacity of the country (Albarran and Garcia-Zamor 2010). World War II—and its wartime administrations managing evacuation schemes, propaganda campaigns, production battles, etc.-required countries to centralize government functions even further (ibid.). "The economic boom that followed the war created a consensus over the efficiency of centralized systems of management" (ibid.: 133). Thus, "beginning in the 1920s, the establishment and strengthening of central management agencies continued unabated well after World War II, becoming in this process one of the most abiding features and commonest concerns of public service reform, for more than half a century" (Argyriades 2010: 279). Because centrally managed mixed economies promoted growth, organizations like the Organization of Economic Co-operation and Development (OECD) endorsed centralization in the developing world well into the 1970s (Albarran and Garcia-Zamor 2010).

The promotion of centralized bureaucracies was not thought to conflict with democratic principles. According to classical management doctrines-the traditional representative and bureaucratic government perspectives—politicians/elected officials would establish policy through democratic means and technocrats/bureaucrats would 
execute policy faithfully and in accordance with pre-determined directives. In other words, there would be a politics-administration dichotomy. The perspective has its origins during what Waldo called the classical orthodox period in public administration (1968). Wilson advocated a politics-administration dichotomy in government, along with authors such as Goodnow (Waldo 1968) and Weber (Kweit and Kweit 1984, c.f. Neshkova \& Guo 2009). According to these perspectives, there was no room for public involvement in the administrative/bureaucratic process (Neshkova and Guo 2009, Peters 2010). From this theoretical perspective, lack of citizen participation in administrative process was justified because the public lacked the understanding of how to implement policy effectively. On the other hand, bureaucrats were seen as possessing specialized knowledge and skills—which they gained through the tenure of their career-allowing them to gain expertise on the best way to execute policies "effectively" (Meier 2000). In other words, bureaucrats gained legitimacy as executors of public will on the basis of their expertise (Dahl 1989, Stivers 1990, c.f. Neshkova and Guo 2009). Implicit in the classical management perspective was a trade-off between democratic and purely administrative decision-making; mainly efficiency. Citizen involvement was thus limited to the democratic process of election of representatives who would then establish policy.

As stated by Peters;

"The public was involved at the level of selecting (albeit indirectly) the minister through the electoral process [...] but even the clients would be excluded from any direct involvement in designing the services. This model of governing assumed that the public had little of importance to say about the policies being delivered to them, and that their involvement actually might undermine both the 
technical quality and the legality of the services being rendered” (Peters 2010: 214).

However, no contradiction was seen between democracy and centralized bureaucracies. In assuming a well-functioning representative government, policy would represent the broad interests of the people who elected representatives that would select policies to meet their needs. Moreover, by having bureaucracies follow policies explicitly, and administer the law, one guaranteed that policies democratically decided on would be safeguarded (Peters 2010).

Therefore, the linkages between democracy and bureaucracy could be viewed as complementary. Expanding on the work of Suleiman (2003), Peters explains how both effective democracy and effective bureaucracy are required for good governance (2010). Specifically, he explains how "the responsiveness of democratic governing must be balanced with the predictability and impartiality assumed to reside within bureaucratic institutions” (Peters 2010: 210). In addition, expanding on the work of Day and Klein (1987), Peters points out that the "linear relationships between voters, ministers, their civil servants, and the service delivered made enforcing accountability over programs relatively easy” (2010: 212).

The complimentary relation of bureaucracy and democracy is not surprising when one recalls that bureaucratic structures were "developed in the wake of the Age of Enlightenment, [...] with strictly limited purposes in mind. One such primary objective was the rule of law and protection against arbitrariness (d'état de droit). [... In fact] it would be fair to argue that, more than other values, legality, objectivity, regulation, and 
accountability presided over the shaping of bureaucratic structures” (Argyriades 2010: 281). Nonetheless, the bureaucratic hierarchical process, central planning, and integration gained escalating pressure for change in and after the 1980s. As noted by Argyriades, the shifting of ideologies were to a great extent the outcome of declining faith in organizational structures as a result of the crises confronted during the period.

"Sharp economic downturns in certain parts of the world, student and labor unrest, and political convulsions in others have greatly undermined the credibility of the institutional framework. Events in Eastern Europe, culminating in the implosion of the USSR, the emergence of kleptocracies and 'failed states', the current global crisis, and failure of some countries to keep their competitive edge compounded by growing indebtedness; all in different ways occasioned a reordering of national priorities, accompanied at times by pressures for retrenchment in light of perceived scarcity” (2010: 281).

In Latin America for example, top-down military and bureaucratic governments were unable to adjust to changing conditions. According to North (1990), centralization undermined a country's ability to escape path dependency. As the feeling that "adaptation to new social conditions [... became] the sine qua non of survival” (Argyriades 2010: 292) centralized governments began experimenting with decentralization. For many governments, decentralization policies were adopted as a way of establishing service delivery on a "demand led" basis versus following a national established provision of entitlements with secured expenditures from the center (Levaggi and Smith 2003). The view assumed that information asymmetries are reduced when administrative agencies 
with the most contact with the citizenry take responsibility for determining the "bundle of services" that would be provided. Because of proximity, the assumption was made that sub-national governments are better positioned to gather information on local preferences and respond more efficiently to variations in demand than the remote national agency/government (e.g., Albarran and Garcia-Zamor 2010, Hayek 1945, Musgrave 1959).

However, the view is not without its critics. For example, Oats warns that allowing sub-national governments to determine the "bundle of services" that will be provided can lead to statewide inequalities, as variation across jurisdictions is not only because of differences in local preferences but also to cost differentials (1999). Thus, in the presence of regional inequalities, if there is a component of the service provision that is mandated from the top, states will undercut their spending to match federal funds in an attempt to keep benefits "more or less constant" across states. As a result, overall benefits of welfare are reduced (Peterson 1999). Thus, concentration of certain types of services in certain locations will only lead to welfare gains as constituents are able to vote with their feet in accordance with their preferences (Tiebout 1956). However, there may be factors that limit mobility, giving rise to concerns over equity.

Behind the push for institutional decentralization were several considerations. Among these was an attempt to increase allocative efficiency by improving the government's ability to absorb and adapt to changes in local preferences for development, but also an effort to maintain legitimacy and faith in the system (Manor 1999). By bridging the gap between government and civil society, it was believed that greater political accountability could be achieved and marginal groups would be better served (e.g., Nickson 1995, 
Rondinelli 1998). Following the humanist perspective, allowing for citizen participation in administration should help validate the premise and effectiveness of programs. Some authors believed decentralization could help promote accountability and reduce corruption as a result of constituent pressure on government because of their newly gained awareness of subnational governments' actions versus the remote national government (e.g., Ostrom, Schroeder, and Wynne 1993). As mentioned above, although counterarguments presented in the work of Olson (1993), McGuire and Olson (1996), and Schleifer and Vishny (1993) indicate that coordination from the center reduces misgovernance and corruption, not decentralization, Latin American countries began decentralizing $^{1}$ in the 1980s (Montero and Samuels 2004).

As noted by Argyriades, decentralization was part of a larger world trend of "debureaucratization"-a shifting of managerial ideologies from closed to open systems (2010). Bureaucracies were no longer seen as isolated machines operating in a vacuum. Rather, they were seen as being affected by outside environments. Unable to adapt to

\footnotetext{
1 "James Manor (1999) identified three different processes that could be taken individually or conjunctly to achieve decentralization: de-concentration or administrative decentralization, fiscal decentralization and devolution or democratic decentralization. In order to achieve these goals within a political system, James Manor identified three different processes that could be taken individually or conjunctly to achieve decentralization: de-concentration or administrative decentralization, fiscal decentralization and devolution or democratic decentralization. The first process, de-concentration, was defined as the dispersal of agents from higher levels to lower levels within the government structure. However, James Manor noted, when defining de-concentration as simply the relocation of agents, it is easy to see that this process, occurring alone, without the transfer of power to the lower administrative levels, can result in further centralization, with the agents simply re-enforcing the demands/desires of the higher authority. Fiscal decentralization was defined as the downward fiscal transfer over budget and financial decisions from higher levels to lower levels within the government structure and the third process, devolution, was defined as the transfer of authority and resources to independent lower level authorities. However, a consensus has further specified the categories into deconcentration, delegation and devolution (Cohen and. Peterson 1999). And, as in James Manor's analysis of decentralization, decentralization by default (a reaction by non-governmental organizations to supply goods and services as a result of the lack or under provision by the government) and inadvertent decentralization (occurs when a new policy accidentally grants resources and power to lower levels of government as an unforeseen by-product) have been omitted as valid processes that lead to institutionalized decentralization” (Albarran and Garcia-Zamor 2010, p. 135).
} 
changing economic conditions centralized/hierarchal/closed bureaucracies received continued attacks for being unresponsive. With the rising number of "think-tanks, consulting firms, universities," etc. who knew as much as those in the bureaucracy, public officials could no longer claim that their views carried special weight (Argyriades 2010: 285).

"Under these new conditions, openness, consultation, and participation [...became] essential daily facets of organizational life [... and] policymaking. No longer [could] decisions be reached, as in the past, by managers or 'experts' acting in isolation, and then communicated to a passive body of underlings. Staffmanagement relations, but also the conditions for sound policy-planning $[\ldots$ changed] so much that, in most present-day successful organizations 'Collegial not command structures' become the natural basis for the mandatory modes of getting things done' (Cleveland 1985: 188). Inclusion, social dialogue, participative management, and consultation, [... became] widely accepted facets of public administration and good governance” (Argyriades 2010: 285).

Although the term "participation" began to gain currency in the decision-making processes of bureaucracies in industrialized societies in the 1930s, "it is only since the late 1960s and the 1970s that the concept started to be used in the context of the newly developed sub-discipline of 'development administration'” (Garcia-Zamor 1985:5).

Again, it is important to note that in addition to the promised benefits that decentralization could afford to adaptability, efficiency, and accountability, 
decentralization policies were also carried out because of their potential to promote 'participatory' development and democracy more generally. ${ }^{2}$ According to the United Nations; "More than increasing efficiency, decentralization seeks to bring government back and closer to the citizen, a feature that has made it one of the critical facets of the transition processes and administrative reform.” (2000:7 cf. Argyriades 2010: 290). Moreover, as noted by Goldfrank;

"Scholars with a democratizing approach [...] appreciate that decentralization may open the way for popular participation [...] in making decisions about policy design and implementation, not just consultation. [...] For democratizers, the emphasis is on transferring responsibilities, resources, and participation in decision-making to the lower levels of government because of the value they place on participation itself as an extension of citizenship (Felicissimo 1994: 501; Perez Pierra 1992)" (1998: 9).

The push for increasing citizen participation within the processes of a decentralized bureaucratic structure directly challenged the assumptions behind classical management theories. Moreover, they bring into question the linear yet complimentary relationship between democratic process and administrative compliance with predetermined directives.

Nonetheless, local municipal bureaucracies have increasingly become the locus point for public involvement (Peters 2010). By allowing citizen participation in bureaucratic processes, Peters—expanding on the work of Rothstein (2008)—posits that "the nature of democracy itself may be shifting away from concern with making political inputs into decision-making towards more direct control over outputs” (Peters 2010: 211). The view is not without merit; two decades earlier, Garcia-Zamor noted that "with the emergence

${ }^{2}$ Other works advocating decentralization because of its purported effects on levels of democracy and development are Putnam, 1993; Rondinelli, 1990; Smith, 1985; World Bank, 1997, 2000. 
of the issue of participation, [... conversation] moved away from an input orientation to program management and towards an output emphasis, where the recipient of program benefits occupies a focal role” (1985:5). Moreover, drawing from the work of Paharr and Putnam (2000), Peters notes that the trend toward output oriented democracy coincides with the declining levels in traditional political participation and the resulting increase in “disaffected democrats" (2010). In other words, there is a decreasing number of people who turn out for elections and a decreasing level of party membership while citizens are simultaneously being expected to participate more in bureaucratic processes (ibid.). Moreover, Peters (2010) notes that the nature of political parties is also shifting from a representational role to a single-issue status. In addition, he notes that the "floating nature of parties" is becoming more prevalent. Within this context, he contends that there is an immediate threat to accountability (ibid.). Peters bases his claim on the fact that:

"Parties and party leaders that come and go will tend to be less effective [...] in enforcing accountability over public bureaucracies than will more established parties that have an electoral incentive. [Moreover] the single issue parties maybe interested in accountability in that single policy area, but generally not in broader policy issues nor in the continuing effective operation of democratic accountability considered very broadly” (Peters 2010: 213).

In either case, Peters is quick to expand on a point made by McFarland (2007) and claim that this new form of citizen "involvement will not, of course, be done by the average citizen acting autonomously but rather will be done by organized groups, 
whether in network structures or through a more pluralistic manner requiring some competition for access” (2010:215). ${ }^{3}$

Although scholars like Truman (1971) viewed interest groups in the American political system as a feature innate to its democratic process, explaining how early writers such as Madison —in the federalist papers_-and de Tocqueville, viewed the presence of such groups as not only "the essence of the political process," but also a positive element of American democracy, direct participation in the administrative process has been viewed from two very different theoretical perspectives. The participation of "citizen committees” or interest groups in administrative decision-making can be predicted to have a positive or a negative impact on program/government efficiency depending on what theoretical perspective one is using. Some authors (e.g., Peters) warn that this “output oriented version of democracy is more individualistic, non-deliberative, and nonmobilizational. Thus, this style of democracy shifts away from aggregating interest and collective decision-making toward merely responding to the demands of each individual (very much like the general conceptions of New Public Management)” (2010: 211).

\footnotetext{
${ }^{3}$ On the subject of organized groups, authors such as Lane (1959), Almond and Verba (1963), Milbrath (1965), Olson (1970) and others, have attempted to explain why citizens participate in the political process. Most of these case studies have been based on surveys measuring attitudes that will or will not be likely to lead to active participation (Riedel 1972). However, the work of Truman (1971) helps explain interest group formation in complex societies and how they can achieve their goals effectively. Truman not only provides us with a definition for interest group as "any group that, on the basis of one or more shared attitudes, makes certain claims upon other groups in the society" (p. 33) but he provides us with a typology for classifying groups. Moreover, Truman puts claims on the theory "that the rate of association formation can serve as an index of the stability of a society" (p. 57), placing interest groups in a positive light. In addition, this author emphasizes the increasing need for interest groups to work through intermediary institutions (government), and how the extent to which these groups can achieve their goals depends on " 1 ) factors relating to a groups strategic position in the society, 2) factors associated with the internal characteristics of the group, and 3) factors particular to the government institutions themselves” (p. 506). Lastly, by placing emphasis on the non-structural characteristics of interest groups, Truman validates future studies focusing on the role of leadership and other criterion under which group member selection might occur.
} 
Without broad mobilization, one cannot guarantee that the general interests of the population are being represented.

\subsection{Citizen Participation in Bureaucracy: A Theoretical Framework}

As noted in the previous section, while citizen participation in the decentralized bureaucratic processes can serve as an avenue for increased accountability over outputs, replacing traditional hierarchical and political accountability mechanisms, the viability of such approaches is highly contentious.

For those advocating the use of models of organization using a participatory state or what has been called an "empowered state” perspective, greater citizen involvement in the administrative decision-making process is encouraged (Kernaghan 1992). Corporate pluralist literature also represents a theoretical perspective that seeks to encourage innovative ways in which to incorporate the special knowledge of social groups (Olsen 1986). In addition, authors such as Linder and Peters have advocated a "dialogical" process that would permit citizens to play a more substantial role in the policy setting process (1995). Through the dialogical process Linder and Peters advocate, citizens would bargain directly with each other in attempting to set policy.

For these authors, as with others-Dahl (1989, 1992), Stivers (1990), Habermas (1996), Roberts (1997) Bringham, Nabatchi \& O’Leary (2005), Ebon \& Franklin (2004, 2006), Urbinati \& Warren (2008) and Sirianni (2009), Neshkova \& Guo (2009), Garcia-

Zamor (1985) etc.- - there are several reasons why governments embrace the concept of 
citizen participation and citizen involvement in the decision-making process. One reason for engaging the public in technical policy matters is to establish procedural justice in accordance with democratic ideals and basic human rights (e.g. Laird 1994; Perhac 1998, cf. Rowe \& Frewer, 2000). In the case of Dahl (1989) and Urbinati and Warren (2008), for example, the need for enhancing citizen participation stems from the principle that in order to be fair, those affected by policy outcomes should have an equal voice in the process. For authors such as Roberts (1997) and Salomon (2002), the desire to increase citizen engagement stems from the belief that there are benefits associated with the participatory process itself—in particular, educating the citizenry on the inner workings of government. Through education, the populous not only becomes empowered, but they also build capacity to innovate and create new and better solutions that will invigorate the bureaucracy (Roberts 1997). By participating, citizens not only gain knowledge of the trade-offs associated with the policy process (Halvorsen 2003, Kathlene and Martin 1991), but they gain appreciation for administrators' work (Ho and Coates 2006). Put another way, government can resist protest and increase legitimacy by obtaining information on the public's preferences and establishing service delivery on a demand basis through direct citizen participation (e.g., Kasperson, Golding, and Tuler, 1992, cf. Rowe and Frewer 2000).

However, not all authors agree that direct citizen participation in the administrative process is necessary or conducive to better policy. According to the "classical management" traditional representative and bureaucratic government perspectives, a more "decisional" approach to policy setting through technocrats is advocated. Contemporary authors also argue against direct public participation in the 
policy process for several additional reasons. For starters, there is said to be a problem with attempting to motivate citizens to participate in a task that requires energy, commitment, time, and inconvenience (Bollens and Schmandt 1965, cf. Riedel 1972). Others state that our political system favors well-organized groups (coalitions, parties) (Lowi 1969, Riedel 1972), leaving direct citizen participation groups disadvantaged, even if they chose to participate. Moreover, there are concerns that participation outside the electoral process represents the narrow interest of a single perspective, rather than the established general interest (Boyton, Patterson, and Hedlund 1969, cf. Riedel 1972, Box 1991, Curry, 2001, Ebdon \& Franklin 2004, c.f. Neshkova and Guo 1990). Some believe that polarization in society might increase as a result in public deliberation (Fiorina 2005, Stasavage 2007, cf. Neshkova and Guo 1990). In addition, there is also an increasing recognition that there are monetary costs associated with citizen participation (Robbins et al. 2008, Ebdon and Franklin 2006, Irvin and Stansbury 2004, Thomas 1990, c.f. Neshkova and Guo 2009). There is cost associated with the time required to educate the public on the policy at hand, but also, "the per-decision cost of citizen participation groups is arguably more expensive than the decision-making done by a single administrator" with the appropriate experience and experience (Irvin and Stansbury 2004, 58, c.f. Neshkova and Guo 2009). As noted by Nabatchi (2012), “empirical evidence does little to resolve this debate, suggesting at least one reason why more and better evaluation of citizen participation processes is needed,” (p.4) especially because citizen participation in public administration has become a reality in many countries.

In an effort to redefine and expand the boundaries of participative planning and management (PPM), Garcia-Zamor (1985) summarized the promises and concerns of 
PPM in the development context-specifically, the experience of international donor organizations in applying such techniques. A synopsis of Garcia-Zamor's points on PPM is provided bellow:

1. PPM is used for its ability to promote the integration of local community interests and the goals set forth by development projects. It provides a space for dialogue of various perspectives and thus helps prevent misinterpretations and conflict. However, it is important to confirm that beneficiaries have sufficient information to define their role in the participatory process and to make informed decisions.

2. By promoting the involvement of beneficiaries, project performance increases. This is because affected members of the community have an intrinsic stake in the functioning of the project and will thus have greater incentive to accept and meet the performance criteria. Moreover, because beneficiaries had their voices heard during the early stages of the project, they are more likely to accept the outcomes and promote project continuation.

3. PPM helps develop trust between project managers (outsiders) and community members. It provides a space for open communication, identification and resolution of community needs, and conflicting viewpoints. PPM empowers the community by providing members with a space to use their skills and creativity, thus avoiding problems associated with alienation and opposition to projects. It contributes to the sustainability of the projects because beneficiaries play an important role in allowing for the continuation of the project. 
4. By allowing for the input of citizen input, one increases the chance of developing more targeted, useful solutions to problems faced in the community. By creating a built-in feedback mechanism, PPM allows for the early identification of problems associated with the project and helps to open the gateway for identifying more effective ways of resolving quality output issues and promotion the longevity of the project.

5. PPM reduces information asymmetries between project managers and affected communities. By allowing dialogue, project managers can learn of the effectiveness of their practices in the field while simultaneously increasing the possibility that the outlook of beneficiaries on such practices will be positive-because they feel their concerns are being heard.

6. By allowing for the use of local human resources versus imported inputs, PPM reduces the cost of project operation. It helps promote self-sufficiency and avoid dependency on outside regions (Garcia-Zamor 1985).

Garcia-Zamor (1985) moved on to indicate that although PPM is now widely used as a management technique and it has excellent potential, it can fail if not applied properly. He then identified the potential dangers that can occur when applying PPM techniques. They can be summarized as follows:

1. The creation of a bias toward one group over others occurring for various reasons. The most obvious was that in identifying potential project beneficiaries, those who were most articulate in an open forum context would most likely get their concerns addressed while overshadowing the majority. Thus, PPM could result in 
the expression and pursuit of narrow individual interest rather than community interests. Moreover, the tendency in society to have one prominent group firmly in control while the rest are only moderately active was also noted as a potential pitfall for PPM practices. If the dominant group was not identified and measures were not taken to guarantee equal representation of all in society, PPM could simply reinforce the prestige and wealth of one group over the rest, overrepresenting the interest of those with power positions in society and essentially giving them the power to manipulate local residents to accept their will. However, Garcia-Zamor (1985) noted that even if all people were given the chance to participate, PPM practices may still lead to oligarchic dominance and a non-equal distribution of benefits. This is because citizens vary in their ability to express their opinions.

2. The second potential pitfall to PPM practices noted by Garcia-Zamor (1985) was that this approach did not identify a way to motivate members of society to participate-specifically, those struggling with economic hardship. Because the PPM approach does not give out immediate financial rewards, it is difficult to motivate beneficiaries that are at or near the subsistence level. The poorest of local residents often find it the most difficult to take time away from work because the economic impact of doing so is harder felt. Thus, they often feel content to allow the more educated local elites negotiate such projects for their community.

3. Garcia-Zamor (1985) noted that for the PPM approach to be successful, one needs to hold prior educational campaigns to gain confidence of local residents and 
educate poor and apathetic members of society on the importance of participation. These practices can be time consuming.

4. Lastly, it was noted that PPM requires institutional restructuring that is exogenous to most political and administrative systems in place within developing countries.

Identifying the benefits and potential drawbacks of PPM is useful program implementation. Garcia-Zamor's framework is useful because the concerns about participatory mechanisms have not changed much over the last three decades. Moreover, the "values" for the practice of public participation are long-standing and agreed upon. For example, if one analyzes the list of core values from the International Association for Public Participation (IAP2), the seven points outlined below (all points are quotes from Tina Nabatchi's Manager's Guide to Evaluating Citizen Participation, Fostering Transparency and Democracy Series, 2012 IBM Center for the Business of Government) sum the pro arguments stated previously in this chapter advocating for increased citizen participation in public administration.

1. "Public participation is based on the belief that those who are affected by a decision have a right to be involved in the decision-making process."

2. "The participation of those who are potentially affected by or interested in a decision should be sought out and facilitated.”

3. "Public participation should seek input from participants in designing how they participate.”

4. "Public participation includes the promise that the public's contributions will influence the decision.” 
5. "How public input affected the decision should be communicated to participants."

6. "Public participation should recognize and focus on the needs and interest of all participants, including decision-makers.”

7. "Public participation should provide participants with the information they need to participate in a meaningful way” (Nabatchi 2012:6-7).

The values for the practice of public administration have not changed; however, participatory programs do vary in their ultimate purpose and the level of empowerment or shared decision-making authority granted to participants (Nabatchi 2012). In addition to offering a list of core values for the practice of public participation, the IAP2 provides a five-point Spectrum of Public Participation indicating the variance in design, assumptions, and levels of shared decision-making authority granted to citizens in a program (ibid.). The points or levels on the spectrum are outlined below (all are quotes from the IAP2 2007 with adaptations by Nabatchi cf. Nabatchi 2012:10-12).

1. "Inform: At the first level of the spectrum are processes that inform, or 'provide the public with balanced and objective information to assist them in understanding the problem, alternatives, opportunities, and/or solutions.' At this level the public has virtually no shared decision-making authority; thus the promise made by government to the public is simply, 'We will keep you informed.' Some examples of informational processes include static websites, mailings, bill stuffers, fact sheets, 311 call centers, and open meeting webcasts. Social media tools such as Facebook and Twitter are also sometimes used to inform the public.” 
2. "Consult: At the second level are processes that consult with the public, or 'obtain feedback on analysis, alternatives, and/or decisions.' Consultation processes provide minimal, if any, shared decision authority, and promise only to 'listen to and acknowledge [citizens'] concerns and aspirations, and provide feedback on how public input influenced the decision.' Some face-to-face examples include traditional public meetings and focus groups. Other consultation processes are done remotely through citizen surveys or various public comment devices; still others are done through specific interactive websites such as SeeClickFix.com, FixMYStreet.com, or LoveLewishman.org, as well as through numerous other general websites that use social media and Web 2.0 technologies.”

3. "Involve: At the third level are processes that involve the public, or 'work directly with the public through the process to ensure that public concerns and aspirations are consistently understood and considered.' Involvement processes promise that public 'concerns and aspirations are directly reflected in the alternatives developed;' thus, they have an inherent level of shared decision authority, though this can range from low to moderate. Public workshops are a general example of face-to-face involvement processes, and National Issues Forums (e.g., Melville, Willingham, and Dedrick 2005) are a specific example. Deliberative Polling (e.g., Fishkin and Farrar 2005) is a specific example that may be done face-to-face or online, and Wikiplanning (www.wikiplanning.org) is a specific online example.”

4. "Collaborate: At the fourth level are processes that collaborate with the public, or 'partner with the public in each aspect of the decision including the development of alternatives and the identification of the preferred solution.' Collaborative 
processes promise that public 'advice and recommendations' will be incorporated 'into the decisions to the maximum extent possible;' thus, they have a moderate to high level of shared decision authority. Some citizen advisory committees may be structured as collaborative processes. The AmericaSpeaks $21^{\text {st }}$ Century Town Meeting (Lukensmeyer, Goldman, and Brigham 2005) and the Citizens Jury (Crosby and Nethercut 2005) are specific examples of face-to-face collaborative processes.”

5. "Empower: At the highest level are processes that empower the public, or 'place final decision-making in the hands of the public.' Empowerment processes have the highest level of shared decision authority because the promise made is that the government will implement what the public decides. Participatory budgeting, which may be done online or face-to-face, can be an empowerment process, particularly when done in the style of Porto Alegre, Brazil, where citizens make neighborhood-level decision on budgeted items (see, Abers 1998; Baiocchi 2001; Wampler 2007). Other processes that guarantee delegated decision authority can also be considered empowerment processes” (Nabatchi 2012:10-12).

Different levels of engagement characterize different public participation methods. Moreover, as noted by Rowe \& Frewer (2000), and indicated above, at the lowest level of engagement, the public may be targeted with enhanced information about the particular risks associated with a project or service that the government is providing. At higher levels of engagement, the government might actively solicit, through consultation exercises, focus groups, and questionnaires the public's opinion on a particular service or 
project the government has completed. At the highest level of engagement, members of the public can be selected to take part in exercises that provide them with a degree of decision-making authority. It is this level of citizen participation, the highest level of engagement, which in theory describes the participatory process for service delivery of Social Infrastructure Funds (SIF) in México.

\subsection{Institutionalization and Incorporation of Decentralization Policy and Participative Planning and Management (PPM) Practices}

The degree to which countries have successfully decentralized and incorporated PPM practices varies significantly. Rowland argued that the degree to which decentralization reaches its stated goals will vary among and within countries depending on the characteristics of the country and the area where power and responsibility is devolved (2001). Moreover, Rowland posited that within countries the variability in the "success" of adoption of decentralization reform is related to the population size of the local jurisdiction. Specifically, she posits that while the benefits of decentralization policies have been felt in urban areas in México, small towns and rural municipalities- which suffer from concentrated poverty—have not benefitted from decentralization reforms (2001). The present study is specifically interested in analyzing the effects of

decentralization reforms in rural municipalities where implementation may have faced more difficulties.

In addition, the successful adoption of participative mechanisms by municipalities has varied according to the nature and history of interaction among political parties within a country. Specifically, while summing the works of Abers (1996), Schonwalder (1998), 
Nylen (1996), and Berry et al. (1993:50), Goldfrank suggests that "the strategies the ruling parties use and the degree to which conflict among and within parties is played out within participatory programs [... can] explain their relative success” (1998:10). For Goldfrank, accounting for the local history of social movements and political parties in municipalities and their relationship with the ruling parties at the national level is imperative when accounting for the success or failure of municipalities attempting to incorporate participatory mechanisms in their administrations. In conclusion, Goldfrank posits that in municipalities "where social movements operate in an oppositional, revindicative mode (or "expressive-disruptive” rather than "integrative-corporatist”) and are strongly allied with the party in local government, participation will be more difficult to institutionalize" (1998: 11-12).

In the case of México, an understanding of México’s history of political parties and social movements may be reached by analyzing the developments stemming from the Mexican Revolution (1910-1920). The 1917 Mexican Constitution presumed a multiparty system and despite the Institutional Revolutionary Party's (Partido Revolucionario Institucional, PRI) control of the presidential seat for 70 consecutive years prior to the year 2000 — which characterized Mexico politically as a single-party state—the façade of free elections was maintained throughout the $20^{\text {th }}$ century. The National Revolutionary Party (Partido Nacional Revolucionario), the predecessor of the PRI, was founded in 1929. It was founded after the execution of president-elect Álvaro Obregón in 1928, which threatened the stability of the country and institutional changes made after the revolution. In 1936, during the presidency of leftist president Lázaro Cárdenas (1934 to 1940) the National Revolutionary Party changed its name to Party of the Mexican 
Revolution and eventually, the party settled on its present name (PRI) at the end of Manuel Ávila Camacho presidency (1940-1946).

Founded to safeguard the revolutionary cause, the PRI hegemony saw the centralization of economic and political resources as a requirement for the autonomous decision-making required to transform the nation (Mainwaring \& Scully 2003). In other words, "in the scheme of things established by the revolutionary experience, political parties and party competition threatened to get in the way of the overriding goals of [the revolution. Moreover,] the existence of an alternative system outside the PRI, through which particular interest could be represented—trade unions, business organizations, religious associations, and other pressure groups—rendered parties unnecessary" (ibid. 199). Thus, for decades, PRI carried out fraudulent elections and created its own “opposition” political parties (Mainwaring \& Scully 2003). As a result, "the right of opposition could not be exercised because other parties were either not 'real,' having been sponsored by the government, or being 'real,' that is, independent, they were too weak to be considered useful instruments of political participation" (ibid. 200). Thus, the PRI's commitment to promoting the façade of a multiparty system, combined with their exercised political unanimity, resulted in the creation of short-lived political parties subordinated to the state that "worked as limited interest groups, without either the ability or the desire to widen their horizons” (ibid 200).

The main goals of the National Revolutionary Party (the PRI predecessor) had been to provide lay education and agrarian reform, and to secularize the state. As mentioned above, most political parties served to either disseminate the main political views upheld by the party, having been created by the party itself, or served as interest groups 
promoting a particular short-term goal. It was not until 1938, during the presidency of Lázaro Cárdenas, that the development of a cooperative government—which unified workers, peasants, and the military—was seen the advance of socialism and raised enough fear to trigger the creation of the first long-lived political party, the Political Action Party (Partido Acción Nacional, PAN) (Mainwaring \& Scully 2003: 209).

Although, from the beginning, PAN opposed the secularization of the state and liberalism, its institutionalization was mostly "a response to President Lázaro Cárdenas economic reforms, which included the nationalization of the oil industry, a far-reaching agrarian reform, and the expansion of the role of the state in regulating every aspect of economic activity” (ibid.: 256). The party strongly held that industrialization should be promoted but not through extensive government intervention outside the realm of regulating social antagonisms (Mainwaring \& Scully 2003). Moreover, although from its inception the teachings of the Catholic Church had inspired the party's doctrine, it was not until 1987 that the party joined the Christian Democratic Organization of Latin America (Organización Democrática Cristiana de América Latina) and not until much later (1998) that the party became a full member of the International Christian Democratic Organization (ibid.). Because the party formed as a rejection to the key achievements of the revolution (the provision of lay education, agrarian reform, and the secularization of the state), it was perceived to be a "real" opposition party compared to those that were created by the state or those that simply co-opted for collaboration with the state to meet the demands of a particular interest group (ibid.). Moreover, the 'reactionary' party strongly denounced the antidemocratic electoral practices of the ruling party. 
Put simply, “PAN was born afflicted by a 'dilemma of participation'—a dilemma that all opposition parties face in choosing between co-government and opposition. The former involves contributing to the workings of the institutional arrangements of which it is part, thereby supporting the functions of government through 'loyal opposition'; the latter involves blocking the functions of government—at times even those of political institutions-with a view to achieving power” (Mainwaring \& Scully 2003: 201). Although the party was seen as possessing an ideology in opposition to that of the PRI predecessors, giving it legitimacy as a "real" opposition party, its commitment to the electoral process and its lack of action to block government functions in protest, gave the PAN the label of what Linz coined in 1978 as "loyal opposition” (ibid.). The party's lack of active protest or contention for power outside the electoral system led to its survival during the PRI hegemony while many other parties failed to survive the reappraisal from PRI during the same period (ibid.).

The main actions of PAN focused on gaining votes. By the 1964 parliamentary elections, PAN won 20 seats in parliament and did not label the elections fraudulent, focusing instead on pressing for new legislation and creating more space for itself in the press (Mainwaring \& Scully 2003). By 1977 some of PAN's initiatives relating to the composition of political parties in the Chamber of Deputies were included in the constitutional changes made by PRI through the Ley Federal de Organizaciones, Partidos y Processos Electorales (1977 Electoral Law, LOPPE) (ibid.). The law gave a proportional number of seats in the Chamber of Deputies to oppositional parties. By 1979, PAN was established as the "second largest force in Mexican politics [... moreover,] PAN was the only opposition party that obtained majority seats in the 
Chamber” (ibid. 221.). Its strategic position within the Chamber of Deputies (gained by its role as "loyal opposition," focusing only on gaining ground through the electoral process) gave the party a degree of legitimacy and a great degree of influence over the legislation that could be passed to pursue its neoliberal ideology.

In the interim, during the 1970s, under the leadership of Luis Echeverría, and with recommendations of international institutions such as the World Bank and the InterAmerican Development Bank, the highly centralized federal State of México began the arduous process of decentralization (Mizrahi in Chapter 5 of the book by Tulchin \& Selee 2004). The initial steps toward decentralization included a series of attempts at spatial, economic, and administrative decentralization. Under the presidential administration of Luis Echeverría (1970-1976), polos de desarrollo (development poles) were established in order to spur development away from central cities and into poorer areas. Under the presidency of José López Portillo (1976-1982), efforts to achieve spatial and economic decentralization became more targeted. By 1978, the Plan Nacional de Desarrollo Urbano (National Urban Development Plan, PNDU) was announced, formalizing the effort to re-orient growth away from the capital city and into designated "zones," middlesized cities demonstrating potential for economic and social advancement (Rodriguez 1997). In addition, progress toward administrative decentralization was made. Programs such as the Desconcentración de la Administración Pública Federal (Deconcentracion of the Federal Public Administration) were passed, promoting, as the name implied, the deconcentration of the federal public administration (ibid.).

However, despite the previous efforts to achieve spatial, economic, and administrative decentralization in the 1970s, efforts to achieve political 
decentralization—often equated with democratization and the granting of decisionmaking authority to citizens and their elected representatives—did not begin until the 1980s (Rodriguez 1997). As noted previously, political decentralization policies have been formulated with several goals in mind, such as increasing allocative efficiency, accountability, and legitimacy. In México, attempts at reform, in particular efforts to achieve political decentralization in the 1980s and 1990s, have been viewed as being primarily focused on regaining the legitimacy of the administrative and political process (Rodriguez 1997). After all, decentralization reforms during that period were "formulated in response to the problems and realities that surfaced during the 1980s: macro-economic adjustment, negative economic growth, the fiscal crisis of the state, the collapse of the tacit alliance between the state and corporative-bureaucratic groups, the globalization of the economy, growing inequalities in the distribution of resources, the decomposition of social classes and class alliances, and the demands of new social movements to participate in decision-making procedures” (Beneria and Mendoza 1995:65-66).

Nonetheless, some authors have stated that in México, because the Institutionalized Revolutionary Party (PRI) ${ }^{4}$ functioned mainly to serve elite party supporters, and attempts to reform would have threatened the establishment, reforms were merely superficial. They were designed primarily to appease workers and the masses by creating the impression of change. For example, Coleman and Davis argue that reforms in México would be "preemptive in nature, designed to do what seems necessary to avert the threat of uncontrolled mobilization, [and would] probably stop short of producing sufficient change to induce gratitude among intended beneficiaries”

\footnotetext{
${ }^{4}$ PRI dominated the political process for 80 years, characterizing the country as a single-party state. Not until the year 2000 was a president from a different political party elected into office.
} 
(Coleman and Davis 1983, p. 22). For this reason, it is important to note the impact, if any, political decentralization efforts have had on local government functions.

As mentioned above, attempts to achieve decentralization prior to the $1980 \mathrm{~s}$ focused on fostering spatial, economic, and administrative decentralization. It was during the presidency of Miguel de la Madrid that the rhetoric of political decentralization became official and thereafter its transition into policies self-evident. Rodriguez (1997) has cited several statements from the president exemplifying the official rhetoric of political decentralization, such as; “'Descentralizar es democratizar y democratizar es descentralizar (To decentralize is to democratize, and to democratize is to decentralize) and 'La modernización de México avanzara por el camino de la descentralización. La fortaleceremos... para ampliar la democracia’ (México’s modernization will advance by means of decentralization. We shall strengthen it in order to increase democracy)" (Rodriguez, 1997 p. 7). Thereafter, the presidency of Miguel de la Madrid and the later presidencies leading up to Vicente Fox formalized the rhetoric into concrete policies, advancing the country toward becoming a decentralized polyarchal democratic state. Moreover, decentralization efforts became increasingly focused on establishing an institutionalized process through which to incorporate citizen participation in the development of economic development policies/projects/initiatives. The social policy of the 1990s followed a demand-driven approach that accompanied the neo-liberal economic policies of the last decade (Beneria and Breny 1995). "This approach represent[ed] a shift in social policy orientation: from one that views the state as being responsible for redistributive mechanisms and social services affecting all citizens, to one that targets only specific groups and projects [Stahl, 1994]. It also represent[ed] a shift in 
the responsibility for policy implementation from state institutions to local governments, community groups and non-governmental organizations” (ibid.:55).

During the presidency of Salinas de Gortari (1988-1994), El Programa Nacional de Solidaridad (the National Solidarity Program; PRONASOL), was announced as a new program requiring citizen participation to implement a wide range of economic development programs such as infrastructure for potable water, roads, schools, electrification, and hospitals. "The objectives of the new social policy therefore had to be compatible with the ongoing processes of modernization, privatization, deregulation, and liberalization. They also had to (a) build a new solidarity with the have-nots; (b) foster co-responsibility between the state and the beneficiaries of the new social policy; (c) fit in with the requirements for a high-quality and efficient state sector; and (d) build impartiality in the delivery of social services" (Beneria and Breny 1995:66). PRONASOL was a section of the Ley de Coordinación Fiscal (Fiscal Coordination Law, LCF), a law that hoped to achieve greater efficiency in government operations through the coordination of national and state affairs. The allocation of resources directly from this Social Infrastructure Fund (SIF) to the projects stipulated by the Planning Committees for Development (COPLADES) $)^{5}$ and approved by the federal executive in Social Development Agreements (in Spanish, CDS) was said to resolve the problems created by a lack of community support (Tulchin \& Selee, 2004). The PRONASOL approach to determining service delivery of economic development projects required the

\footnotetext{
${ }^{5}$ COPLADES had been formed during the presidency of Lopez Portillo (1976-1982) as one of the first steps toward decentralization. They are composed of all the municipal presidents in the country and presided by the governors of each state. The projects proposed by the COPLADES were to come directly from the request of the Solidarity Committees, which in turn were composed of ordinary civilians organized at the local level (Tulchin \& Selee, 2004).
} 
highest level of citizen participation. Community members had to organize themselves into Solidarity Committees and channel their requests to the COPLADES. However;

"critics of PRONASOL have repeatedly claimed that the program is shaped more by political concerns than by a serious intention to eliminate poverty. It has been accused of being aimed at recovering the votes lost in the 1988 elections by the governing party (PRI) [...]. In this sense, PRONASOL is viewed as attempting to waken the opposition by concentrating its projects in areas of dissatisfied groups, even if they are not among the poorest. It has also been pointed out that the official message seems to be that the PRONASOL is made possible by the privatization and liberalization processes tied to structural adjustment, thereby making more acceptable an economic program that has impoverished or intensified the poverty of a large portion of the population” (Beneria and Breny 1995: 69-70). That said, Beneria and Breny indicate that the defenders of PRONASOL exalt the program's political nature because of its ability to facilitate democratization of the state and civil society and democratization in turn is a requirement for poverty alleviation (ibid.).

During the presidency of Ernesto Zedillo (1994-2000), “New Federalism” was announced as the strategy that would reform intergovernmental relations in the country. It intended to reduce the power of the president, promote transparency in the election process, and strengthen the local (e.g. state and municipal) governments (Rodriguez, 1997). The process of fiscal decentralization that occurred under the banner of New Federalism increased the transfer of funds from the national government to states and municipalities. Up to this point, " $80 \%$ of all resources collected by the federation remained in the center, while $17 \%$ went to the states and $3 \%$ went to the municipalities. 
In 1998, the federal government reduced its share by almost 10 percentage points, reserving $70.9 \%$ of all resources for itself, and allocating $24.4 \%$ to the states and $4.7 \%$ to the municipalities” (Martinez \& Ziccardi 2000, c.f. Tulchin \& Selee 2004, p. 154). More importantly, the modification of Article 115 in the Constitution granted discretionary power over the use of these finances to the municipalities such that "powers exclusive to the municipality that before were held concurrently with the state, such as public works, the preventive police, and potable water, were recognized" (Guerrero and Guillen 2000, cf. Martinez \& Ziccardi 2000, Tulchin \& Selee 2004, p. 154).

By 1998, Section 33 officially replaced Section 26 (formally PRONASOL). Through this new program, Section 33, SIF resources were transferred directly to the municipalities, bypassing the state governments. From 1998 to date, no modifications to Section 33 have been made. The new program, like PRONASOL, dictates the use of SIF resources by municipalities (Martinez \& Ziccardi 2000, Tulchin \& Selee 2004, p. 154). The responsibility over the allocation of SIF-used to provide the public with economic development projects such as potable water, sewage, expansion and construction of schools, and other basic services—-was devolved to the municipalities and decentralized to include citizen participation in the process.

A keystone of the PAN ideology was its promotion of the municipality as the "natural community," which in turn translated into support of decentralization policies implemented by the de la Madrid (1982-1988) administration in the 1980s (Mainwaring \& Scully 2003) and those implemented thereafter. The decentralization policies implemented granted new sources of income and autonomy to the municipalities as well as increased inlets for citizen participation in the decision-making process of the local 
administrations. The new spotlight placed on the municipality resulted in increased involvement of PAN in local elections. "Between 1966 and 1982, the party participated in elections in less than $20 \%$ of municipalities nationwide; after 1982, this rose to between $31 \%$ and 58\%. In 1993, it presented candidates in $88 \%$ of all municipalities, in 1997 in 96\% of them” (ibid. 224). The PAN's support for decentralization policies implemented at the national level by the PRI administration leads one to speculate that PAN municipalities might be more inclined to comply with the implementation of participatory mechanisms as mandated by federal decentralization legislation during this period than municipalities controlled by other opposition parties.

In any case, the main base of support for the party during the 1980s was from the wealthier states and groups with high income and status who brought to the table "their own resources for electoral campaigns” (ibid. 223). In addition to supporting the decentralization policies implemented by the de la Madrid administration, PAN showed support for the administration's role in decreasing the role of the state in economic affairs. Thus, during this decade, PAN lost support from México City—whose support was shifting to left-wing leaning candidates (ibid.). The presidential administration of de la Madrid (1982-1988) signaled a period of congruence in ideology on economic policy between PAN and PRI, however despite the similarities in economic ideology, the leading role of PAN as the opposition party remained. However, the earthquake of 1985 marked the emergence of a new opposition that would institutionalize itself soon after and usurp PAN's role as the leading opposition party during the 1988 presidential elections. 
The inadequate response of PRI in the aftermath of the devastating earthquake caused civil society groups to organize themselves to aid in the rescue process in México City (Harbers 2007). These civil society groups were tied to the individuals, groups, and smaller political parties that were to unify themselves to form the Partido de la Revolución Democrática (Democratic Revolutionary Party, PRD) in 1989 (ibid.). The founders of PRD (i.e., Cuauhtémoc Cárdenas, Heberto Castillo, Marco Rascón Córdova, Gilberto Rincón Gallardo, Porfirio Muñoz Ledo, etc.) were former left-wing PRI members who unified many smaller parties, such as: the Partido Comunista Mexicano (Mexican Communist Party), Partido Socialista Unificado de México (Unified Socialist Party of México), Partido Mexicano Socialista (Socialist Mexican Party) and Partido Mexicano de los Trabajadores (Mexican Workers' Party) into one, the coalition of centerleft parties called National Democratic Front (Frente Democrático Nacional). After the 1988 election, the National Democratic Front became the Democratic Revolutionary Party (PRD). As mentioned previously; “one of the PRI's defining characteristics [in the $20^{\text {th }}$ century] was its ability to undermine, accommodate and co-opt social movements in order to prevent mobilized citizens from challenging the party. Fear of co-option ha[d] led many social movements to be distrustful of political parties and avoid alliances, even with parties of the opposition (Davis, 1997, p. 178; Gilbert and Gugler, 1992, p. 185; Ward, 1990, p. 91). [Thus,] during the PRI regime almost all access to the political system was channeled through party-affiliated corporatist organizations. Under these conditions most participation was either regime-supportive or compromised of petitioning and contacting of public officials to influence the allocation of public goods (Cornelius and Craig, 1991.) (Harbers 2007: 43). Thus, the unification of left-wing 
opposition into PRD, as a result of the frustration with PRI's inability to deal with crisis, changed the political dynamic and the ability of the PRI hegemony to monopolize the electoral process. Moreover, it affected the role of PAN in the process.

On October 14, 1987, Cárdenas was nominated to run for president in the 1988 elections representing the predecessor of the PRD, the National Democratic Front (FDN). Poll figures recognized that FDN had received 31\% of the vote, almost double PAN's share (Mainwaring \& Scully 2003). "Moreover, the share of votes that went to the FDN were enough to win the election, however, through fraudulent means, the PRI declared their candidate, Salinas de Gortari, victorious” (ibid.: 235). FDN had become the new leading opposition party. Both PAN and FDN rejected the presidential election results. Cardenas, the FDN candidate, organized street protests and pushed for the annulment of elections. The PAN, who had for years authored and advocated electoral reforms, recognized irregularities in the electoral process, but settled for their role as 'interlocutor' for the government (ibid.). While rejecting the legitimacy of the presidential results, PAN "defended the advances it had made in the Chambers of Deputies [and] thanks to its participation in all the procedures of the electoral process-and to [...] not follow[ing] the protest movement orchestrated by Cardenas—-the new congress could be inaugurated and so comply with the timetable prescribed by the Constitution” (ibid.). "During the Salinas government, the [PAN] party gained an unprecedented capacity of influence. Not only did it have real strength in the Chamber of Deputies, but also the ill will between the president and the followers of Cuauhtémoc Cardenas opponents afforded the PAN the privileged position to act as an arbiter between irreconcilable adversaries. It thus assumed 
functions of political leadership and created the conditions for negotiation and dialogue” (Mainwaring \& Scully 2003:235).

Through concertaciones, a term coined for the compromises between PRI and PAN in resolving the irregularities of the electoral process, PRI recognized the victories of PAN candidates in various states without having to annul elections (ibid.). Moreover, "between 1988 and 1994, the PAN was a party to many government decisions" (Mainwaring \& Scully 2003: 236) including constitutional amendments that impacted rural collectives and the relationship between church and state as well as the promotion of market-oriented reforms and policies that further pushed for fiscal decentralization. "In fact, during those years, many PAN politicians themselves used to claim that the president had actually stolen their party's economic platform and was implementing most of the economic policies and reforms the PAN had long ago proposed" (Mainwaring \& Scully 2003: 257). While PAN worked within 'the institutional arrangements' strengthening its role as "loyal opposition," PRD worked to block functions of government through protest. In 1994, PRI won the presidential seat with no apparent fraud being committed; in 2000, the first non-PRI candidate was elected president. The presidency went to Vicente Fox from PAN. However, the 2006 and 2012 elections for president were labeled as fraudulent by PRD and organized protests occurred in the aftermath of both elections.

These two different strategies for contesting power, "co-government and opposition [...] the former [which] involves contributing to the workings of the institutional arrangements of which it is part [and] the latter [which] involves blocking the functions of government $[\ldots]$ with a view to achieving power" can be observed in the PAN and 
PRD strategies designed to deal with perceived electoral fraud (Mainwaring \& Scully 2003: 201). Following Goldfrank (1998), one could argue that PAN's ability to compromise with PRI and adopt a co-government position would make it more likely to incorporate participatory mechanisms in the municipalities it controls. Moreover, the ability of PAN to work slowly through the electoral process, gaining control of positions of power, in order to effect change through the institutional arrangements of which it is part, utilizing Goldfrank's (1998) framework, would also lead to the conclusion that it might be more likely to incorporate participatory mechanisms in the municipality it controls. On the other hand, PRD's adoption of an opposition strategy in dealing with the PRI administration in the $20^{\text {th }}$ century and PAN after the election of 2000 would indicate that the municipalities governed by PRD would be less likely to incorporate participatory mechanisms.

During the study period of this dissertation, PAN presidents controlled the executive branch of government. While the decentralization doctrine of promoting municipal autonomy, promulgated by PAN leadership, flowered in municipalities and states controlled by PAN, during the same period, municipalities and states controlled by opposition parties (PRD and PRI included) fought against the ideological tide to gain or regain control. This dissertation attempted to shed light on how the political reality shaped the formation and involvement of citizen committees in the areas under study.

Summarizing the arguments presented in this section, the suggestion that the historical relationship between opposition parties and local government administrations should affect the willingness of municipalities to incorporate citizen participation in the administrative processes is not farfetched. In México, the Institutional Revolutionary 
Party (Partido Revolucionario Institucional, PRI) controlled the presidential seat for 70 consecutive years, essentially characterizing México’s political system as a single party state prior to the year 2000. The slow political opening was a result of continual pressure by the people who were represented by two major opposition parties, the Political Action Party (Partido Acción Nacional, PAN) and the Democratic Revolution Party (Partido de la Revolución Democrática, PRD). These two political parties had and continue to have very different political agendas and historical relationships with the Institutional Revolutionary Party (PRI). The presence of each political party, with its unique political platform and relationship to the ruling party at the executive level, could indeed impact a municipality's incorporation of participatory mechanisms. More recently, Rowe and Frewer have considered the process through which citizen participation has been channeled to account for a certain degree of participation (2000). In particular, they have established two criteria for evaluating citizen participation methods, the acceptance criterion and the process criterion; the acceptance criterion concerns features of a method that make it acceptable to the wider public, and the process criterion concerns features of the process that is liable to ensure that it takes place in an effective manner (Rowe \& Frewer 2000).

\subsection{Solidarity Committees in México: The Legacy of PRONASOL}

As noted by Rowland, "in México there is no single law which delineates the scope of citizen participation in local government” (2001:1380). States can encourage participation in their municipalities by creating mechanisms that allow for it in their Constitutions, municipal laws, urban planning laws, etc., but they are not obliged to do so 
(ibid.). However, "the PRONASOL [National Solidarity Program] program (1988-94) imposed its own scheme for citizen participation in local government” (see Cornelius, Craig \& Fox, 1994; Dresser, 1991) (ibid.). As noted by Brenia and Breny (1995), PRONASOL was created to promote decentralization and citizen participation. Specifically, the goals were to:

“a) to institutionalize the principles and methods of PRONASOL at the level of municipalities for the purpose of strengthening local governments; b) to facilitate a major institutionalization and coordination of activities linking the federal, state and municipal actors; and c) to energize local social organizations” (Beneria and Breny 1995: 67).

To promote these objectives, PRONASOL allowed for NGO representatives or other neighborhood associations to become part of a COPLADES (Planning Committees for Development) whose stipulated projects had to then be approved by the federal executive in Social Development Agreements (in Spanish, CDS). Moreover, "PRONASOL's methodology [...] emphasized the creation of solidarity committees (SCs), democratically elected by members of a possible community to project beneficiaries at the micro-regional level” (Beneria \& Breny 1995: 67). This was the first instance in México where citizen committees were legislated to form part of the decisionmaking process. "The SCs [were to] formulate the demands of their communities and prioritize projects, thus beginning at this point what PRONASOL has called a process of 'participatory planning'” (ibid.) The process involved in PRONASOL's “participatory planning" were the following: 
- "First, the SCs evaluate social demands through direct participatory methods.

- Second, representative interlocutors (that is, SCs and official members of the Planning Ministry and SEDESOL) prepare a technical document specifying the nature of projects.

- Third, SCs and representatives of regional and local planning agencies of SEDESOL plan public works and estimate cost. At this stage, the federal, state, municipal and community contributions and commitments are stipulated. The community contribution may take the form of money, materials or labor.

- Fourth, the final stage deals with the implementation, control, and evaluation of the projects. To these activities, one must add the supervision of the project at the community level, which involves overseeing the selection of a contractor, the quality and cost of materials, and time schedules” (Beneria and Breny 1995: 67).

As noted by Beneria and Breny, “an interesting feature of PRONASOL’s discourse is that it relie[d] heavily on ancient cultural practices of Indian communities, such as solidarity and mutual aid, and on notions of social justice associated with the Mexican Revolution” (1995:66). Thus, promotion of co-responsibility for projects funded through PRONASOL would be thus facilitated in areas where participants already had a culture of solidarity.

"Under co-participation schemes, program beneficiaries are encouraged to participate in defining program priorities and to co-finance projects with 
their own resources, particularly labour. As such, poor rural and urban organizations enter into a new relationship, involving partnership, with governmental institutions. By placing co-participation at the center of the new social policy, PRONASOL's intellectual authors claim not only that they are leaving behind past practices that favored the exchange for political support for social favors; but also that they are struggling against old practices of paternalism, bureaucratization, and corruption. In this respect, they speak about a new political equation that includes the state and civil society and about the creation of a new political culture” (ibid.)

The assumption behind co-participation, or what is the active involvement of affected citizens aiding in the improvement of their own communities, was that it eradicates paternalism, boosts the dignity of the poor, and contributes to co-responsibility of raising communities out of poverty and promoting the sustainability of efforts to combat poverty (ibid). “According to PRONASOL, the new social policy not only democratizes relations between state and society, it also strengthens the social organization of the poor. [... Thus], PRONASOL can be viewed not only as a channel through which social demands can be articulated, but also as a space where the poor gain civil consciousness and thus become real subjects of civil and economic rights” (Beneria and Breny 1995:69). According to Tiburcio (1992), co-participation in PRONASOL "resulted in a high level of community identification with the projects, so that the communities themselves [were] more likely to take responsibility for the quality and sustainability of projects” (c.f. Beneria and Breny 1995:71). 
As mentioned above, PRONASOL was a section of the Ley de Coordinación Fiscal (Fiscal Coordination Law, LCF), a law that aimed to achieve greater efficiency in government operations through the coordination of national and state affairs. Currently, "the closest thing in México to national legislation on citizen participation in local government is found in the National Democratic Planning System (Sistema Nacional de Planeacion Democratica), which was established in 1982 as part of the [LCF] Planning Law. The system [which regulated PRONASOL] provides the basis for citizen participation in local planning $[\ldots$ but, the] precise rules $[\ldots]$ vary from state to state, as to their duties and prerogatives. Under such circumstances, it is difficult to know exactly what procedures, if any, are actually followed at the municipal level” (2001:1380). Moreover, in 1998, Section 33 replaced Section 26 (formerly PRONASOL). Through this new program, Section 33, SIF resources were transferred directly to the municipalities, bypassing the state governments. However, because "the Solidarity Program [PRONASOL] received a great deal of attention from the international development community and from national governments” (Beneria \& Breny 1995:54), its effects, as we will see in the next chapter, had a lasting influence in shaping municipal decisionmaking and the inclusion of citizen committees in the allocation of SIF resources.

Currently, at the municipal level, elections are held every three years. Once elected, the municipal president selects, at his/her discretion, a group of "technocrats" who will compose part of his/her cabildo (city council). Section 33 of the Fiscal Coordination Law (LCF) allows this city council to make decisions on SIF allocation. Decisions on allocation can also be made by the coplademun (Municipal Development Planning Committee) or by citizen committees (as interest groups/citizen committees). In 
a study by Hernandez-Trillo and Jarillo-Rabling (2008) on SIF allocation in about 2,429 municipalities, $69.2 \%$ of decisions examined in the study were made by cabildos, $29.5 \%$ by coplademun, and $.7 \%$ by other participatory forms, including citizen committees (the descendants of Solidarity Committees). After conducting their study, Hernandez-Trillo and Jarillo-Rabling also noted that SIF is subject to elite capture and that it is positively related to population size, a proxy for voter registration. The bigger the municipality, in terms of population, the larger the share of funds it receives. Moreover, the study also found that "SIF is disbursed toward communities with larger populations within the municipality, regardless of the social infrastructure level of coverage” (Hernandez-Trillo \& Jarillo-Rabling 2008, p. 1556).

As mentioned above, of particular interest to the present study is the allocation of SIF resources through citizen committees in rural municipalities. According to Hernandez-Trillo and Jarillo-Rabling (2008), SIF allocation decisions made by citizen committees [which, as described in the next section of this chapter, are included in the category "committees for community improvement" in the 2010 Latin American Public Opinion Project (LAPOP) and whose members could also have indicated in the study that they solicited or demanded a service at the local level] living within rural areas are the least likely to occur. Under current legislation, in order for SIF resources to be allocated through Section 33 by citizen committees, households have to prioritize the work, households have to organize themselves to form the citizen committees, and the municipality must prioritize the project in response to the request of the citizen committees. Due to lack of research, it is not clear how these citizen committees operate in different regions, what role these interest groups have in the municipal decision- 
making process, and what impact they have on SIF allocation decisions. In other words, what kind of advisory committees do these solidarity committees most resemble in actuality; do they resemble the advisory, supportive, put-off or put-on committees as described by Riedel (1972)?

\subsection{Determinants of Citizen Participation in México}

Authors such as Lane (1959), Almond and Verba (1963), Milbrath (1965), Olson (1970) and others, have attempted to explain why citizens participate in the political process. Most of these case studies were based on surveys measuring attitudes that may or may not be likely to lead to active participation (Riedel 1972). During the 1960s and 1970s, studies that analyzed the civic culture and political attitudes in México found an apathetic, cynical, and at times antidemocratic attitude predominating among Mexican adults (see, for example, Scott 1965; Hansen 1971; Needler 1971; and Segovia 1975). Almond and Verba (1963) found that two-thirds of the participants in their study were “subjects,” one-quarter “parochial,” and “participants” seemed to be almost non-existent. A study by Fromm and Maccoby $(1970,89-90)$ on political culture in village life found that only $7 \%$ of participants had a democratic orientation while the predominant sociopolitical relations present among villagers were of authoritarianism, with submissiveness toward traditional authority being quite common. Moreover, in a study designed to question the pre-established "authoritarian nature" of political culture, Fagen and Tuohy concluded that political attitudes that predominated in their study were characterized by apathy and indifference to democratic principles, in particular among women of lower classes (Fagen \& Tuohy, 1972). A later study found that "the prevailing 
political culture in México expresses comparatively low support for democracy and relatively high support for non-democratic government, on the one hand, and low interpersonal trust, low levels of tolerance, and a strong emphasis on deference, on the other” (Mendez \& Moreno 2002: 350). These attitudes were viewed as resulting in a lack of participation in the electoral process and thus the persistence of a less than democratic government.

More recently, in a study of citizen participation from 2004-2010, investigators Paras García, López Olmedo, Vargas López, \& Seligson, of the 2010 Latin American Public Opinion Project (LAPOP 2010), found three main significant variables that affect citizen participation in the Mexican electoral process. The first is age. Older individuals are more likely to vote. ${ }^{6}$ The second variable is political interest. However, as mentioned in the LAPOP study, although one would believe that this relationship would be positive — the more interested an individual is in politics, the more likely he/she will vote—-that is not always the case (2010). As the authors of the LAPOP study indicate, sometimes not voting is a form of protesting or politically manifesting one's opinions (ibid.). ${ }^{7}$ The third variable is gender. However, in contradiction to other studies (Almond \& Verba, etc.) the data obtained by the Barometer of The Americas and utilized by the LAPOP 2010 study, women are more likely to vote than men (ibid.). ${ }^{8}$ Of lesser statistical significance, the

\footnotetext{
${ }^{6}$ This positive relationship between age and voting is also present among the variables age and participation in civic organizations (ibid.).

${ }^{7}$ The study found that one in four Mexicans interviewed disclosed that they had no interest in politics vs. one in ten who said they were very interested.

${ }^{8}$ It is important to note that the LAPOP 2010 study did not consider urban vs. rural women participating in the electoral process, which might have produced different results.
} 
level of education was shown to have a positive effect on participation in the electoral process (ibid.).

The authors of the LAPOP 2010 study found that political participation did not change significantly from 2004 to 2010 (ibid.). Authors such as Crow (2009) indicate that the less than enthusiastic participation in elections is a result of citizen disenchantment with politics. Crow argues that citizen disenchantment with politics in México "is widespread: Mexicans profoundly distrust parties, politicians, and parliament. [...He argues that] widespread and deep dissatisfaction with democracy may jeopardize the survival of some new democracies, but the more immediate concern raised by dissatisfaction is its detrimental impact on political participation” (2009: xiii). In addition to the work of Crow (2009), "there has been a lot of focus on the role that 'social capital', and in particular the degree of trust—interpersonal and institutional—in society has on citizen participation. Utilizing Fukuyama’s (1997) definition of social capital as "norms and values that permit cooperative behavior in groups," investigators Paras García, López Olmedo, Vargas López, \& Seligson of the 2010 LAPOP study elaborate and comment that participation is dependent on the existence of channels for participation, as well as the disposition of individuals to collaborate. Moreover, they theorize that citizens who participate in civil society learn to work together and to trust one another but that a minimal amount of interpersonal trust is needed to allow for collaboration in the first place. They conclude that a strong civil society, as measured by its citizen's trust and participation in the system, contributes to the establishment of democracy.

\footnotetext{
${ }^{9}$ English translation of Fukuyama (1997) in Pablo Paras García, Carlos López Olmedo, Dinorah Vargas López, \& Seligson 2010 work in Spanish.
} 
Expanding on the analysis of the degree of interpersonal trust to México, the LAPOP study found that an estimate of $60.5 \%$ of the national population feels that the people in their area are very trustworthy (2010). However, compared to other countries in the region, México has an aggregate low level of interpersonal trust (LAPOP 2010). The LAPOP study found that the most statistically significant determinant of interpersonal trust is the perception of public safety. When the perception of public safety decreases, so does interpersonal trust (ibid). However, according to this study, despite the increasing levels of violence and the worsening economic conditions since the global financial crisis, the level of interpersonal confidence has remained statistically constant since 2004 (ibid.). The second determinant, according the authors of the LAPOP study, is the level of education of the individual — the higher the level of education, the higher the level of interpersonal trust. Lastly, age also influences the level of interpersonal trust, as older individuals have a higher level of individual trust (ibid.)

According to the above noted LAPOP study, most citizen participation in México in 2010 occurred within religious organizations; all religions taken into consideration, approximately $44.2 \%$ of Mexicans participate in this kind of civic organization. The second most popular form of public participation in civic organization in México, being comprising roughly $24.4 \%$ of the population, is participation in school-related parent groups. This level of participation varies among schools, but occurs in both public and private schools. The next most popular form of public participation occurs in “committees for community improvement." Around 13\% of the Mexican population participates in this kind of civic organization. Committees for community improvement can include citizen committees, which form to promote a particular public infrastructure 
project and are of particular interest to this study, and any other type of committee that forms to resolve specific problems in neighborhoods and can come to be controlled by political parties as part of a clientelistic strategy to control popular zones in large urban locations (LAPOP 2010). It is participation in these "committees for community improvement" that this study is interested in. The present study hopes to analyze their operation in rural areas and their influence on the governance/decision-making process of municipalities and ultimately create a typology of citizen committees that would contribute to the comparative administration literature on the topic.

In any case, monitoring the variations of participation in the above noted civic organizations from 2004-2010, the LAPOP study indicates that although participation in religious organizations has dropped during the period, it is not likely to be a sign of the reduction of participation; it continues to be the primary form of participation in the country, but rather a result of secularization (ibid.). In the case of participation in schoolrelated parent groups, participation was similar from year to year and the measures for 2004 and 2010 were also nearly identical (ibid.). However, unlike the participation in the above-noted civic organizations, which remained very similar during the period noted, participation in committees for community improvement, which is the area this particular study is interested in, changed dramatically during the time in question. In 2004 participation in committees for community improvement was $16.9 \%$ and by 2010 it was $13 \%$. As noted in the LAPOP study, the decrease in participation was not oscillatory, with sharp ups and downs, but rather signaled a clear downward trend in participation through time (ibid.). The downward trend is important to note because the purpose of 
decentralization policies was to distribute funds for infrastructure projects dictated by the input of these groups.

In addition to citizen participation in civic organizations, citizen participation in local government is very important. As stated by Paras García, López Olmedo, Vargas López, \& Seligson of the 2010 LAPOP study, "it is the local municipal governments who are in charge of receiving the majority of the demands from the population and who are responsible for responding to a good portion of those demands, especially those related to public services like transportation, security, maintenance of public spaces, etc., in summary, they are immediately responsible for the quality of life in society" (English translation of LAPOP 2010: 139). Decentralization efforts hoped to bring the government closer to the people by transferring decision-making authority to municipal governments who are "closer to the people." In an attempt uncover how close Mexicans are to their local government, the LAPOP 2010 study asked if they had participated in any municipal meeting/assembly or session - the study found that México placed below half of the other countries in the Americas. Only one out of ten Mexicans stated that they had participated in local government during the year (LAPOP 2010). Participation in local government meetings/assemblies etc. have remained stable at around 9\% since 2006, having dropped from 2004 when $12.8 \%$ of the population had participated in local government (ibid.).

To contrast participation in local government-an indicator of cooperation between citizens and government officials in the decision-making process-with the oneway exertion of pressure from citizens on government officials to carry out their demands, the LAPOP study analyzed how often citizens sought out, solicited, or petitioned local government officials/functionaries during 2010. The study found that 
$16.4 \%$ of those interviewed solicited help or presented a petition to the local government. This finding contrasted with the level of participation in local government meetings/assemblies/sessions, which was around 9\% (ibid.). In other words, a significant number of Mexicans engage with their local municipal government soliciting services. However, the percentage of people who petitioned or solicited a service to the local government had decreased from 2004 to 2010 (ibid.). The next question asked by the LAPOP 2010 study was who was more inclined to seek help or solicit local government in México. The variables considered were the size of the municipality, wealth quintiles, age, gender, education, the perception of economic situation of the family, whether the individual assisted local government meetings, and the degree of trust the individual had in his/her local government. The study found that the significant determinants to whether an individual sought out the local government's assistance or made a petition was whether or not the individual participated in local government meetings/sessions, age, and, to a lesser extent, level of education (ibid.). Interestingly enough, one in every two people who assisted a local government session/meeting presented a petition. The LAPOP analysis of the data from the Barometer of the Americas 2010 concluded that there is a lack of participation in local government and that, in general, the population mostly decides to participate in local government solely to solicit or demand a service (LAPOP 2010:147). Unfortunately, the study found that only approximately four out of ten Mexicans who presented a petition to local authorities had their petition resolved (ibid.).

With regard to citizen satisfaction with local government services, the LAPOP 2010 study found that one in every two individuals interviewed felt that services rendered 
in their municipality were neither good nor bad, but rather satisfactory in quality (41.3\% of Mexicans) (ibid.). On the other hand, 29.4\% believe that the services are good and $22.4 \%$ believe the services rendered are low quality or bad. "The percentages in the extreme categories, very good or very bad, make up less than $10 \%$ and represent $1.4 \%$ and 5.5\% respectively" (Translated LAPOP 2010: 147). Compared to other countries in the Americas, whose citizens were asked to rate their satisfaction with services rendered by local governments, México scored worse than half of the other countries in 2010 (LAPOP 2010). Moreover, average level of satisfaction with services rendered by local governments in México from 2004-2010 has not changed significantly over the period (ibid.).

After conducting a multiple regression, LAPOP researchers found gender to be a determinant of satisfaction in local government services, finding that women are more satisfied than men (ibid.). Moreover, there is a significant relationship between satisfaction with government services and citizen support of that system (ibid.) Crow argues "that a main cause of political dissatisfaction is a citizen concept of democracy, 'substantive' democracy, emphasizing economic improvement and social equity, combined with poor government performance in just those respects. [In other words,] for citizens who conceive of democracy as an instrument of economic equality, their governments' failure to ameliorate poverty leads to disengagement from politics. These citizens vote and engage in institutional participation less often. Dissatisfaction also predisposes a small but significant minority of citizens to contentious political participation" (2009: xiii). The hope of decentralization efforts was to increase citizen participation in the decision-making process and thus channel citizen demands through 
official channels. Moreover, the hope was to bring the government closer to the people to decrease the more 'contentious' political participation. In any case, most studies analyzing citizen participation in México have been quantitative in nature. Although the aggregation of data to find predictors of participation is very useful, in depth qualitative case studies_-focusing on the formation of groups and their experience with petitioning the local government-provide us with the opportunity to improve official channels of participation. Qualitative studies also provide us with an opportunity to find the missing determinant variables to participation and identify the location specific information that affects the channels for participation available at the local municipalities. Case studies also help us understand the inner workings of local governments, the governance of municipalities. The present study aims to fill this particular gap in the literature. 


\section{CHAPTER 3: RESEARCH METHODOLOGY}

\subsection{Introduction}

The present study aims to model the complex pattern of roles and interactions that comprised the municipal decision-making process, the creation of citizen committees, and ultimately the involvement and impact of these groups in SIF allocation decisions of rural Mexican municipalities. In order to answer the questions set forth in the study, and understand the "governance" of rural municipalities in México, it was necessary to conduct field research where the events were occurring. The behavior and beliefs of the public officials, citizen committee members, and citizens interviewed in the selected municipalities were studied as they occurred naturally. Prior to arriving at the study sites, I assumed that there are multiple realities represented in the perspectives of study participants. Participant perspectives would thus build on each other, defining what was “real.” Situational context was a key, necessary element to understanding the behavior of study participants.

Data were collected directly from the source, through observation, interviews and document analysis, to describe and answer questions on the how and why behavior occurred during the process of interaction among participants. The goal of the interviews was to obtain rich narrative descriptions of the interaction between residents of the municipality, citizen committee members, and government officials. The emerging research design was flexible, allowing research questions to change and evolve as data were collected, analyzed, and brought to an understanding of how SIF is allocated. Thus, several of the assumptions made in the preliminary study design classified the intended 
methodology as qualitative in nature. Moreover, the study is exploratory, aiming to utilize both inductive and deductive reasoning to contribute to theory building.

The use of a qualitative methodology was justified because it would provide an in-depth description of the decentralization reforms in México, specifically the implementation Section 33 of the Ley de Coordinación Fiscal (Fiscal Coordination Law, LCF). As noted in the previous chapters, Section 33 placed Social Infrastructure Funds (SIF) directly under the supervision of municipalities. Moreover, Section 33 introduced citizen committees into a municipality’s decision-making process, allowing citizens to voice their demands and potentially gain access to SIF through Section 33. The present research set out to examine the decentralization policies and evaluate the specific outcomes. Moreover, I set out to provide an analysis of the factors that affect the impact of citizen committees on the decision-making process for SIF allocation.

A non-experimental qualitative approach was favored because it allows for an indepth inquiry into the role of "context” in a selected number of cases (Neuman 2000). The emphasis on context helps determine the unique elements that pre-determine a specific outcome for a specific policy under a particular situation. By highlighting the role of "social context," qualitative methods give meaning to "social action” (ibid). In this particular study, a preliminary analysis of the literature indicates that decentralization reforms in México were implemented in the context of increasing pressure to re-gain legitimacy in the system (Rodriguez 1997). In other words, the context of the situation played an important role in the administrative decision to devolve authority over SIF allocation to the municipalities. Because of the need to understand the social context behind the decentralization reform, a qualitative methodology would need to be 
employed. In other words, a qualitative methodology would be utilized to link social context to the implementation of specific decentralization policy and later, to the specific policy outcomes.

Although quantitative methods utilize a large sample of cases, and as a result, conclusions can be generalized to the broader population without regard to context, a qualitative approach was favored for this study because of its ability to produce detail and context specific information. According to Rosenbloom (1995), when studying reform implementation, case study methods are particularly useful because they provide information and details within a policy that are—and are not—effective under particular circumstances. In other words, the contribution to the literature made by this research, which will describe the specific details of the participatory process that facilitates/hinders SIF capture through Section 33 in rural México, can only be made through qualitative analysis. The current study analyzed the advantages and disadvantages of the current participatory process in two rural municipalities. It highlights the best practices regarding citizen involvement in economic development policies. By doing so, it contributes to the creation of more effective, equitable, and efficient policy.

The study design incorporated elements and assumptions of ethnographic methodology, phenomenology, and case study analysis. The following chapter is divided as follows: Section 3.1 re-iterates the problem statement, Section 3.2 describes the process behind the selection of research sites, Section 3.3 describes the process behind the selection of participants for the study, Section 3.4 describes the data analysis process, and Section 3.5 defines the steps taken to improve the external and internal validity of the study. 


\subsection{Defining the Problem Statement}

In México, states are divided into municipalities, which are roughly equivalent to counties in the United States. If a particular municipality extends over a large area and contains more than one city or town (collectively called localidades), one of the cities or towns is selected to become the cabecera municipal (head city, the seat of the municipal government). The rest of the localidades become juntas auxiliares (auxiliary juntas; roughly equivalent to townships in the United States). These auxiliary juntas are not considered a third-level administrative division because they depend fiscally on the municipalities in which they are located. However, residents elect, every three years, representatives to lead their presidencia auxiliar or junta auxiliar (auxiliary presidency or town council) within the municipality.

As noted by Rodriguez (1997), there was, and I would add that there continues to be, an urgent need for new systematic research initiatives that examine the decisionmaking procedures of rural Mexican municipalities. The small and mostly rural municipalities, which continue to be a significant portion of the 2,412 municipalities in México, remain neglected by most researchers. Moreover, the population of medium- and large-sized municipalities tends to be concentrated around the municipal seat of government (ibid.). So, while this immediate area may be urban, the municipality may contain some auxiliary juntas that are rural. Thus, there is a need not only to focus on the decision-making processes of small and overall rural municipalities, but also the decision-making process of the larger more populated municipalities, particularly those decisions that concern their rural auxiliary juntas. The present study aimed to fill this gap in the literature. 
The major question of the study was how rural municipalities make decisions on how to allocate SIF in the decentralized context in which they operate. Because, as mentioned above, some medium-sized municipalities are comprised of rural auxiliary juntas, this study was also interested in understanding how larger-sized urban municipalities make decisions regarding how to allocate SIF in their rural auxiliary juntas. Moreover, this study was interested in the impact that citizen participation through citizen committees had on that process.

The sub-questions and hypotheses that arose are the following:

1. What factors affect the formation and involvement of citizen committees?

2. What factors determine the degree to which municipalities will adapt the new mechanisms for incorporating citizen participation in SIF allocation decisions?

3. What is the impact of citizen committees on government performance, specifically: the promotion of accountability and improved governance, ethics, economy, efficiency, effectiveness, responsiveness, and the establishment of cost recovery mechanisms for certain infrastructure/service provision projects?

The a priori hypotheses were:

1. Socioeconomic factors such as sex, income, and religious and political affiliation, as well as factors pertaining to the municipal willingness to collaborate with citizen committees, affect citizen committee formation in rural México.

2. Municipalities belonging to a state that has a history of social movements who operate in an opposition mode to the political party in control of the central government will be more likely to incorporate participatory mechanisms than those 
with a history of social movements that are aligned with the central government (Abers 1996, cf. Goldfrank 1998, p. 14).

3. Taking the traditional representative and bureaucratic government perspective (which advocates a more "decisional” approach to policy setting through technocrats), one would not expect improvements in accountability, improved governance, or the establishment of cost recovery mechanisms for certain infrastructure/service provision projects (Huntington 1975, Moynihan 1969).

The focus was on in-depth description and understanding of the single major question and the several sub-questions.

\subsection{Selection of Research Sites}

The present study aimed to understand SIF allocation decisions made by overall rural municipalities as well as those decisions affecting rural auxiliary juntas within urban municipalities. The major sources of data for this research were thus drawn from the rural auxiliary junta of Tonantzintla, located in the municipality of San Andrés Cholula in the state of Puebla, and the municipality of Tenango del Aire in the Estado de México (State of México). Both locations were considered to be rural according to the 2010 Institute of Geography and Statistics (INEGI, 2010). However, the municipality in charge of the presidencia auxiliary of Tonantzintla and the municipality of Tenango del Aire are very different. These municipalities belonged to states with very different socio-political histories; Puebla has had a strong alliance with the PAN (National Action Party) political party, which has controlled the presidential seat since 2000; and, the State of México has and continues to have a strong alliance with the PRI (Institutionalized Revolutionary Party) party, which controlled the presidential seat for 70 years prior to the year 2000. As 
such, an analysis of citizen committee involvement in both municipalities provides an interesting comparative study. Through this study, I aimed to understand if the political history of a state's municipality affects the experiences of citizen committees attempting to obtain SIF allocations through Section 33 of the LCF.

The municipality of San Andrés Cholula, located in the state of Puebla, is composed of six auxiliary juntas. Among the most important is the cabecera municipal of San Andrés Cholula. The other five auxiliary juntas are Santa María Tonantzintla, San Francisco Acatepec, San Luis Tehuiloyocan, San Rafael Comac, and San Bernardino Tlaxcalancingo. San Andrés Cholula is the eighth most populated municipality within the state of Puebla (INEGI, 2010). Its annual growth rate of approximately $6.5 \%$ is the largest growth rate in the state. In 2000, San Andrés Cholula had 56,066 inhabitants, and by 2005 the population had grown by $42.90 \%$. By 2010, the population had expanded to 100,439 inhabitants (INEGI, 2010). According to population growth projections calculated by CONAPO, by 2015, the municipality will have a total population of $126,127$.

The cabecera municipal of San Andrés Cholula, San Andres, comprises 43.9\% of the total municipal population, or what is equivalent to 35,206 inhabitants (Programa del Ayuntamiento de San Andrés Cholula 2005-2008, Program for the Municipality of San Andrés Cholula 2005-2008). Unfortunately, the information available in the 2010 census of the population of Santa Maria Tonantzintla was not consistent. According to the INEGI, the population of Santa Maria Tonantzintla in 2010 was 135 inhabitants (Octubre, 2011). The same number of inhabitants in 2010 was recorded by the Catálogo General de Localidades (SEDESOL, 2011). However, according to the Program for the Municipality 
of San Andrés Cholula 2005-2008 (the latest version available), there were 5,697 inhabitants in the township of Santa Maria Tonantzintla. Moreover, according to an interview conducted with the municipality's Director of Urban Planning in September 2010, the number of inhabitants was approximately 20,000. After visiting the township however, it is clear that the number of inhabitants is between 5,697 and 10,000 inhabitants—compared to the 135 individuals reported by both SEDESOL and INEGI.

Santa Maria Tonantzintla further divides into three principales (barrios): San Miguel, San Diego de Alcala, and San Pedro. Moreover, it contains two colonias—San Isidro Buenos Aires and San Martin Cuachitla—and one ejido: Cuachitla.

After earning a bachelor's degree in economics from Cornell University in 2002, I moved and lived in San Isidro Buenos Aires of Santa Maria Tonantzintla until 2006. During this time, I participated in township meetings until I became the treasurer of a citizen committee dedicated to obtaining potable water in the area. Moreover, I eventually became a hired consultant for the auxiliary junta working to promote specific public works in the area. This experience granted me insight into the cultural determinants that affected the implementation of public policy. After four years of dedication to prioritizing potable water in the community of San Isidro Buenos Aires in Santa Maria Tonantzintla, the citizen committee for potable water (in which I participated) captured the attention of representatives, who added the project to the long list of public works to be completed by the year 2006. It was by no means a simple process to prioritize this public project. The steps needed to obtain some of the paper work were complicated, requiring the time and money of the committee. This study arose from the desire to document, as a doctoral student, the perspectives and experiences of 
the other citizen committee members during the process of obtaining potable water. Moreover, my goal was to understand how the process of implementing this particular infrastructure project fell into the scheme of what was supposed to happen according to the new legislation that emerged from the decentralization process. As such, Santa Maria Tonantzintla became the projected township/study site, where in addition to retracing the steps of the potable water citizen committee, two additional citizen committees-in which I did not participate, but who achieved prioritization and completion of desired projects—-would be analyzed. In combination with the data obtained from the potable water committee, these additional citizen committees would provide information on the factors that affect the formation of these groups. Moreover, interviews with government officials at the auxiliary and municipal level of government would provide information on the decision-making process and the impact these groups have on it. The research took place four years after the citizen committee for potable water successfully completed its objective.

Because of concerns regarding limited ability to generalize findings on the decision-making process from only one site, and to understand and isolate the impact of an area's social-political history on the formation and involvement of citizen committees in municipal decision-making, a multi-site study of two very different municipalities was imperative. In order to contribute to theory development on the impacts of political history on municipal decision-making and use of participatory mechanisms, the study site of Tenango del Aire was chosen. As mentioned previously, the municipality of Tenango del Aire is distinctly rural; $39 \%$ of the population dedicate themselves to agricultural work and $51.37 \%$ of the municipal territory (38.09 $\mathrm{km}$ squared) is dedicated to 
agriculture. Moreover, the political history of the state in which Tenango del Aire is located, Estado de México, is very different from that of Puebla, the state where the municipality of San Andrés Cholula is located.

In Tenango del Aire, mining and other manufacturing activities comprise $10 \%$ of the economic activity and 34\% to commerce and tourism. As of the 2005 census, the total population was 9,432 (Conteo INEGI 2005). By 2010, the population was 10,578 inhabitants. It is the distinct rural character of this municipality in the State of México that makes it of particular interest to this study. The municipality governs over the following communities: San Juan Coxtocan, Santiago Tepopula, Rancho Aculco (El Paraíso), San Luis Aculco, Tecuatitla (Colonia Nueva Tecuatitla), Rancho el Paredón, Cerro de las Campanas, Rutilo Herrera, El Pedregal (Teotoxtipan), Rancho Chavarría (Paraje Puerta), Tecorral, Tlatelpa, Rancho San Isidro Labrador (El Piaje), Rancho Saturnino (Tepalcapa), Tres Platos, La Casa del Puente, Colonia el Mirador and Barrio San Miguel (Las Espinas). The present study aimed to identify citizen committees in Tonantzintla, and through process tracing and in-depth semi-structured interviews, determine the unique characteristics of citizen committees and the general role they play in the decision-making process for SIF allocation in their municipality.

\subsection{Selecting Participants and Obtaining Data}

Participants were identified as part of the study site and internal sampling, that is, the selection of specific participants, times, and documents within the two sites were conducted. The selection of cases and participants was comprehensive in each site-that is, all relevant individuals were chosen to be interviewed and all relevant "cases" were selected to draw data from. Participants selected to participate in the study belonged to 
one of three groups: community members, citizen committee members, and government officials. Citizen committees were treated as nested cases, cases from which information could be gathered to create a typology of the citizen committees present in rural México to elucidate the factors that affect citizen committee formation and involvement in rural Mexican administrative decisions. The cumulative information gathered from the interviews with community members, auxiliary and municipal government officials, and the citizen committees (treated nested cases) from each municipality would provide information on the decision-making process in the two cases, the municipality of San Andrés Cholula and the municipality of Tenango del Aire.

In obtaining the data from the research site of Santa Maria Tonantzintla, observation was comprehensive, continuous, and concluded over an extended period of time. The role of research varied from complete participant in one of the citizen committees (2002-2006) to complete observer of the two additional citizen committees. The data collection from the study site of Santa Maria Tonantzintla took place between August and November 2011. In obtaining data from Tenango del Aire, observation was less comprehensive, although continuous, because data collection occurred during a shorter period of time. The first visit to Tenango del Aire occurred in December 2011, and the first interviews conducted at this site were unstructured in nature. The goal of those initial interviews was to identify the key informants. Later interviews with community members, government officials, and citizen committee members occurred from January to March 2012. My role as researcher in Tenango del Aire was of complete observer. 
In selecting participants from both communities to interview, the snowball sampling (i.e., network) method, borrowed from ethnographic research techniques, was utilized. That is, initially selected participants, or key informants who were selected because of their reputation for being particularly knowledgeable about the setting and topic, were asked to recommend other members of the community to be interviewed. Interviews with key informants were unstructured in nature. They began with general questions about the municipality, their involvement in the community, the municipality, politics, etc. and progressed to more specific questions about the functioning of the government administration, the process required for SIF allocation in their community, the role of citizen participation, and the factors that affected the formation and involvement of citizen committees in the decision-making process, etc. The questions then moved to specific questions generated by interview responses. Audio-tape recording and use of extensive notes while the interviews were being transcribed provided the basis for elaborating more questions to be asked in the future as well as afforded the opportunity to study the data carefully. Information was gathered from descriptions of what occurred and reflections on what the descriptions meant (i.e., speculations, emerging themes, patterns, problems).

In the selection of participants from citizen committees, it was noted that because summative evaluations of a particular policy are best done after a policy has had time to stabilize (Patton 2002), only citizen committees formed after 2002 would be analyzed. The goal of this research is to evaluate the impact and effectiveness of incorporating this form of citizen participation into the decision-making process. By only studying citizen committees formed after 2002, the research allowed four years for the policy to stabilize 
before being evaluated. It granted four years since Section 33 of the LCF transferred decision-making authority over the allocation of all SIF to the municipalities and ultimately made them accountable to citizen committees before evaluating their performance.

When possible, citizen committees were treated as focus groups—as they would be treated in an ethnographic study—when all members are interviewed simultaneously. Ultimately, each citizen committee became a case within a case study of the formation, involvement, and treatment of citizen committees within two municipalities (our two cases). The each citizen committee was seen as a bounded system composed of interactions of group members and their environment. Participant observation and situational analysis of a specific event, experience, episode, or interaction—for example, a specific meeting with municipal authorities, a process required (paperwork needed to get a particular project carried out by the municipality), etc.—was recorded from multiple perspectives and analyzed to gain an in-depth analysis of reality. In interviewing citizen committee members, I maintained the phenomenological assumption that a single experience can be interpreted in multiple ways and the meaning of that experience is what constitutes reality. Participants were selected because they have lived or are living the experience of being citizen committee members and because they could articulate their feelings during semi-structured interviews.

In total, seven citizen committees were chosen from both municipalities. Three public works committees were chosen from the rural auxiliary junta of Santa Maria Tonantzintla, located in the municipality of San Andrés Cholula in the state of Puebla, and four citizen committees were chosen from the overall rural municipality of Tenango 
del Aire in the State of México. In addition, personnel from three different schools in Tonantzintla were chosen to be interviewed to understand the role that citizen committees play in the process of getting SIF allocated in their institutions. In-depth, semi-structured interviews and process tracing were carried out to understand the factors involved in the formation of citizen committees (factors such as an individual's frustration with elected representatives, sex, income, and religious affiliation). Factors within the legislative process that affect the ability of citizen committees to organize and get their demands heard by the municipality were also analyzed extensively. The resource allocation of the twelve cases was analyzed extensively and the reconstruction of the process of local capture by citizen committees will be carried out to fill the gap in the research literature linking policy to outcome.

Government officials were treated as key informants and selected according to their position and decision-making authority within the municipality and/or auxiliary junta. Municipal presidents from both municipalities were chosen to be interviewed as well as trustees and directors of specific departments related to public works, infrastructure, and citizen participation. Lastly, I analyzed the decision-making process municipalities use to determine allocation of SIF to understand the role of citizen committees.

\subsection{Data Analysis}

As in a phenomenological study, analysis of data emerging from interviews with the citizen committees was concerned with being able to reflect the shared meaning and consciousness of the participants. When analyzing emerging data, there was first the writing of a statement of a particular event and then a separation of what was experienced 
from who it was experienced. The records kept on the six citizen committees in the two municipalities were translated and ordered chronologically. Process tracing for the twelve cases was carried out and analyzed extensively. Open-ended interviews with the citizen committee members helped to understand some of the un-documented as well as some documented steps that need clarification. The interviews thus included a narration of the process utilized by group-members to form into citizen committees and accomplish their particular goal. Through the narration process, information on the key factors that determined the selection of members was revealed. Factors that were seen as affecting group formation were coded and documented. Moreover, detailed and varied information on the legislative process followed by these nine independent citizen committees was also gathered.

Through process tracing, the present study hoped to understand the factors within the legislative process that affect SIF capture by citizen committees. The process tracing step, therefore, required content analyses of various official government documents and the selection of pertinent material to record—both steps required by qualitative analysis (Neuman 2000). When completed, the steps taken by the citizen committees were compared with the legal procedures mandated by the municipality. It was important to verify if the steps taken by the citizen committees followed the legal mandates. If they did not, it was noted that one cannot draw conclusions on the effectiveness of the participatory process required by the municipality. If the two processes lined up, one could draw generalizations from the cases to the overall participatory process. Interviews were also conducted with municipal authorities to determine the legal participatory process required by the municipality. By combining the information gathered from the 
municipality and the citizen committees, this study was able to identify a causal relationship between a specific legislative procedure and specific outcome. Moreover, it allowed for the drawing of a causal relationship between a specific action taken by a committee, and a specific outcome.

To evaluate the participatory process, as mandated by each municipality, I used the two criteria established by Rowe \& Frewer (2000): the acceptance criterion and the process criterion. As noted above, the acceptance criterion concerns features of a method that make it acceptable to the wider public, and the process criterion concerns features of the process that are liable to ensure that occurs in an effective manner (ibid). The process of SIF capture by a citizen committee was deconstructed into the various steps needed for that process to be carried out. For example, in order for public work to be carried out, under current legislation, the following steps need to be taken: households must prioritize the work, the municipality must prioritize the project in response to household opinions, and local activism must translate into Legally Recognized Participation (citizen committees must be formed and they must follow certain steps to get their demands heard). In the present study, the process through which local activism is translated into Legally Recognized Participation was of particular interest. I analyzed how this step occurs and if this step satisfies the acceptance and process criteria as summarized in the work of Rowe and Frewer (2000).

Once the evaluation process was completed, data analysis took on a different route. Document analysis of primary data, minutes from meetings, articles and government documents were re-analyzed. New information was also gathered, transcribed, and analyzed extensively. Interviews conducted with municipal authorities, 
auxiliary government officials, citizen committee members, and other individuals from the community were re-analyzed. Information from each interview was divided into categories according to the various questions sought in the research-particularly, questions regarding the factors that influence the formation of citizen committees and questions regarding the municipal decision-making process, the treatment of citizen committees in the decision-making process, and information gathered regarding the views about the efficiency, effectiveness, and accountability with which SIF projects were carried out. My goal was to construct an overall description of the experience of each participant. As in an ethnographic study, data analysis occurred in three stages. The first stage was coding, that the organizing of data into reasonable, meaningful units that were coded with words or very short phrases that signify a category. The coding was done according to etic categories - that is, my interpretation of emic data or what is equivalent to information provided by the participants in their own language and organizational units. Coded data were then summarized by examining all similarly coded data and summarizing it with a sentence or two that conveyed its essence.

Pattern seeking and synthesizing occurred as follows. Relationships among the categories and patterns that suggested generalization were first identified. While pattern seeking occurred, findings were interpreted inductively, synthesizing the information and drawing inferences. Interpretation began by following informed hunches and ideas that led to the identification of tentative patterns and identified holes in the data that needed to be filled. That is, the identification of additional data that needed to be analyzed to determine if there was consistency in the patterns identified. By adding the new data from a different source, there was an enlarging, combining, subsuming, and a creation of 
new categories that made sense. I aimed to uncover how responsive the municipal cabildos were to the demand of citizen committees. By analyzing municipal response to citizen committees from the perspective of citizen committees and municipal authorities, I was able to construct a typology of 'motives' relating to municipal reaction to citizen committees in rural México.

This typology can be used by researchers to describe expected and probable municipal reactions to citizen committees under particular circumstances. By doing so, this study will directly contribute to the research literature on participatory democracy. Moreover, through the synthesizing of data collected, I was also able to determine how rural municipalities make decisions over SIF allocation and how the participatory process affects them. In addition, the research provided information needed not just to understand the decision-making process and how it is affected by including the participation of citizen committees, but also the impact of such participatory policy on government performance as preserved by its citizenry, that is the quality, efficiency, transparency, economy, and effectiveness of the completion of SIF projects in the eyes of its citizenry.

\subsection{Reliability, Validity and Potential Limitations}

Several steps were taken to guarantee the reliability of the data and validity of the study — that is, to guarantee the processes in question were indeed being studied. Drawing on the categorization schemes provided by McCall and Simmons (1969, p. 78) and Simon and Burstein (1985, p. 242-248) for classifying the main threats to validity and reliability in field studies, McKinnon (1988) designated four main types of threats: observer-caused effects, observer bias, data access limitations, and complexities and limitations of the human mind. In this section, I will discuss the definitions of the four 
threats, as defined by McKinnon (1988), and describe the application of the tactics and strategies recommended by this author, and others, to counteract some of the threats in the present study.

The first threat identified by McKinnon was observer-caused effects, or the altering of "natural behavior" by participants as a result of the presence of the researcher. As noted by McKinnon, "it is the role attributed to the researcher by the participants that is instrumental in producing or avoiding observer-caused effects” (1988, p. 37). Thus, McKinnon noted a need for constant monitoring and management of how the role of the researcher is being represented in the research setting.

The second threat, observer bias, was described as "the distorted effects of the researcher's selective perception and interpretation” (ibid.) of data obtained from the research setting. The threat of observer bias was noted by McKinnon to be present during the process of observation, interaction with research subjects, and document analysis, or simply put, the "registering, interpreting, and recording" events (Schwartz and Schwartz, 1955, p. 91, c.f. ibid.). A researcher's “cultural background, occupational and general training, and prior experiences of the specific phenomenon under investigation" (McKinnon, p. 38) were noted as factors that affect the formation of "political and philosophical" biases in the researcher, altering his/her intake of information as well as its interpretation. Because the "political and philosophical" views of an individual are thought to be part of the "psychological make-up" of the researcher, McKinnon describes that the biases cannot be eliminated but rather “managed” by accepting their presence and working to control for them in the study. 
Data access limitations, the third threat to the reliability and validity of a study identified by McKinnon, were elaborated from the work of Zelditch (1962). The threat of data access limitations was seen as arising from the time constraint imposed on the researcher as well as from the research hosts themselves. Firstly, because the researcher can only be present on the site for a limited time period, the researcher can only witness what is occurring at the moment and cannot travel in time to obtain the needed historical antecedents to the phenomenon under study. Moreover, the moment the researcher is present in the study site may "coincide accidentally with an exaggerated or abnormal instance of the phenomenon [...] Hence, although the researcher may have taken to choose a 'typical' site, they may in fact end up observing an 'atypical' period in the life of that site" (ibid.). Thus, the timing of the research might limit the data available and thus bias the results of the study. Furthermore, the researcher can be restricted (intentionally and unintentionally) to the access of data; documents, events, sites and people by the research hosts, leading to an incomplete picture of the phenomenon under study.

Lastly, the complexities and limitations of the human mind were identified as the fourth threat to the reliability and validity of a study. The manifestation of this threat was seen as twofold. The first form of this type of threat emanates from participants' “conscious" or "unconscious" misinterpretation of events, environment, and self-portrait in an attempt to mislead those around them. McKinnon clarified that this deception was not intended to mislead the researcher specifically but rather the general public. The second source of this threat was seen as emanating from the natural limitations of the human mind: a participant’s natural forgetfulness, political and philosophical "make-up” 
(which can lead to interpretations of events through a biased lens), etc., which, taken together, hamper the accuracy of accounts.

Drawing on a point developed by Black and Champion (1976), McKinnon (1988) noted that in the social sciences, the phenomena under study is usually composed of abstracted concepts and as such "there are no objective standards against which measurement of these concepts can be compared for verification” (p. 41). Moreover, because each concept usually manifests itself in an infinite number of ways, there exists a universe of indicators for each concept to sample. As a result, McKinnon noted that "researchers in the social sciences can never attain perfect validity and can speak only of degrees of validity” (ibid.). However, to improve the degree of validity, McKinnon suggests utilizing multiple methods "such as observation, interviewing and document analysis, in order to gain access to those multiple indicators” (p. 42). Moreover, drawing from Kidder (1982), McKinnon notes to check for validity—-the variables chosen "should have high correlations with other measures of itself, even though the methods of measurement are maximally different (Kidder, 1981, p. 245)” (ibid.).

On the other hand, to check for the reliability of a study, McKinnon (1988) suggested checking for the "consistency of observations [...] by taking repeated measures of the same trait, or variable, with similar or identical methods" (ibid.). However, McKinnon noted that despite the researcher measuring the same trait various times, because "the researcher and the phenomena of interest exist and occur in real time and context, $[\ldots]$ the researcher nor the event can be represented as identical” (ibid). Thus, the concept of attaining reliability in a study must also be described in terms of degree. 
It is important to note that the steps taken to improve the reliability of the study can affect the validity of the study, and vice-versa. In other words, often times, the soundness and dependability of the study can be addressed simultaneously with one step. For example, as mentioned by McKinnon;

"observation of repeated instances of a phenomenon [... can be] an approach to reliability because it serves to rule out accidental or chance circumstances [however,] it is also [...] an approach to validity because, to the extent that the repeated observations are different manifestations of the phenomenon, the researcher is able to verify the existence of the phenomenon and to delineate its boundaries more comprehensively" (p.43).

As a result, this study takes the posture of McKinnon (1988) and I will not distinguish issues of validity and reliability too strictly. However, the steps taken to mitigate and protect against the four main threats to qualitative studies, as discussed by McKinnon, will be discussed thoroughly.

To protect against the complexities and limitations of the human mind and improve internal validity and reliability, specifically the accuracy of observations, interviews were audio recorded. Participants interviewed during the study were asked to verify their responses to questions and when needed, clarify their position or perspective a topic question. The verification and clarification step was done to check the consistency of an individual's responses and avoid “accidental circumstances of the respondent's lack of concern or care which [could] prejudice the credibility of those responses” (McKinnon 1988, p. 36). Moreover, copious filed notes were taken between interviews and coded utilizing the schema developed by Schatzman and Strauss (1973) and discussed by 
McKinnon (1988). In other words, notes were coded as either Observational Notes (ONs) Theoretical Notes (TNs) or Methodological Notes (MNs). The use of ONs was limited to literal and precise record keeping of what was seen and heard in the field. Ideas emerging on theory development or the relevance of hypothesis set forth in the preliminary stages of the research were coded as TNs. The use of MNs was restricted to the description of steps taken during the collection and analysis of data as well as forthcoming plans concerning the manipulation of data. The coding restriction was done in an effort to separately record and maintain any opinions and inferences made as a researcher from the facts obtained from the data, thus limiting the potential for observer bias.

Verbatim accounts recorded during interviews were transcribed shortly after the interviews occurred to ensure that a substantial amount of detail and information was available. Another technique used to enhance credibility was triangulation-the comparison of results obtained from different sources and different data collection methods. Triangulation was used to offset some of the threats to validity and reliability because of its ability to integrate repeated instances of phenomena from different data collection methods, including interviews, participant observation, and document analysis. These data collection methods were seen as "capable of capturing indicators and manifestations of phenomena from more of the indicator types, as identified by Black and Champion (1976, p 224), than typically available through other research methods” (McKinnon 1988, p. 43). Interviews from citizen committee members, municipal authorities, and members of the community were triangulated to guarantee that we are getting an accurate picture of the process taken by the different citizen committees and the required process regulating citizen committee involvement in the municipal decision- 
making process. Moreover, triangulation of data was also able to provide a more accurate picture of the effectiveness in which the SIF projects were carried out. If interviews, observation, and document analyses did not lead to a similar conclusion, a red flag was placed and a re-analysis of data occurred to identify the differences, document clearly where they appeared, and then identify possible reasons for a divergence in conclusion.

During this process, caution was taken not to lose sight of the context in which each account was taken. As McKinnon [1988, p. 44 drawing on the potential dangers of utilizing multiple methods or observations in field research identified by Silverman (1985) and Garfinkel (1967)] noted, exactly because multiple observations and methods are utilized to confirm and discard accounts, the importance of each account and the specific context in which it occurred is often lost. However, authors such as Campbell and Fiske (1959) and McKinnon (1988) have recommended multiple methods and multiple observations in field studies to counter threats to validity and reliability in field studies more generally. The recommendation is made because by "testing” hypotheses emerging from one source of data against data emerging from another method, "the research is able to detect, and therefore, compensate for his or her own interpretational and perception biases which may have distorted the shape of hypotheses” (McKinnon, 1988 p. 43). Moreover, evaluating "what a subject does against what a subject says is a strong counter to the threats of observer-caused and human mind effects” (ibid.). Lastly, multiple observations and multiple methods, including interviews, observations, and document analyses, allows the researcher to obtain a more complete dataset, thus limiting the threat to reliability and validity caused by data access limitations (McKinnon, 1988). 
As mentioned above, data were collected in the natural setting after prolonged and persistent fieldwork in both Tenango del Aire and Santa Maria Tonantzintla. Because I was a participant in one of the citizen committees of Tonantzintla, there was a possible increased threat of observer bias. As noted by McKinnon, the "choice of type of participant observation (PO) affect degree to overcome validity and reliability” (1988, p. 46). However, "the choice of type of PO is a dynamic process" (ibid. p.49). From 2002 to 2006, I was treasurer for the potable water committee of Tonantzintla, one of the citizen committees included in this study. During this time, my role in the community was not as researcher but as resident. Although it was through that experience that I was able to attain familiarity and acceptance within the community of Tonantzintla, it was not until I began my doctoral studies, two years after the potable water project was completed, that I began to re-examine my experience within the context of the literature available. Moreover, it was not until four years after my experience in that committee that I began to formulate hypotheses for this study. It was not until August 2011 that I arrived to Tonantzintla as a researcher, participating with "limited interaction," trying to obtain data for this study.

As McKinnon (drawing from the work of Gold, 1958, pp. 217-223; Schatzman and Strauss, 1973, pp. 59-63) indicates, there is a PO continuum with the various roles the researcher can assume moving along a continuum that mark the different degrees and threats to validity and reliability for each role. At one extreme of the continuum, there is observing from outside, moving from left to right there is passive presence, followed by limited interaction, active control, observer as participant and at the opposite extreme of the continuum the role of researcher as participant with a hidden identity. While 
observing from outside may have a positive impact in limiting the threats to validity and reliability due to observer caused effects, it has negative implications for observer bias, data access limitations, and threats due to the complexities and limitations of the human mind. Moving along the continuum, the implications for the four threats to validity and reliability are all negative for researchers participating in the field with a passive presence. However, the implications are all positive for researchers participating in the field under the role of limited interactions and active control. On the other hand, while the implications for observer caused effects are positive for both the role of observer as participant and participant with hidden identity, the effects for both roles are negative for observer bias, data access limitations, and complexities and limitations of human mind (McKinnon, 1988).

Although not acting as a researcher while I participated in the committee for potable water in Tonantzintla, had I been, my role would have been closest in kind to that of participant with a hidden identity. That is because although I was known to the "participants" as a member of the committee, I was not known as researcher. Although this role as researcher "offers the advantage of unobtrusiveness $[\ldots]$ the price for zero disturbance is too high in respect to threats of observer bias and data access limitations” (McKinnon, 1988, p. 48). Thus, after five years of participating in the committee, I first returned to the research site as a researcher operating under the role of "limited interaction.” In other words, using McKinnon’s (1988) terminology, I returned “to clarify the meaning of events” that occurred during my time as the committee's treasurer. I then operated as researcher using an "active control" approach guiding conversation through "questions on specific topics as they occurred" in two additional citizen committees in 
which I did not participate. Under the approach to researcher of "limited interaction" I was able to talk to the members of the citizen committee in which I had participated through "casual conversation and questioning," and through the 'active control approach' I was able to obtain information through more formal "interviews."

Despite the threat that my experience as a participant in the potable water committee in Tonantzintla could have biased my observation, because there was a time lag of five years between my roles as participant and researcher, I was able to separate my personal perspectives prior to arrival. Moreover, having spent a long time in the field as a resident allowed me to observe community life on a day-to-day basis without the pressure to "see patterns, uncover meaning, or develop hypotheses and conclusions" (McKinnon 1988, p.40). Thus, I was able to become 'genuinely receptive' to what was occurring around me without the "the temptation to seek interpretation and meaning immediately (or very quickly) after entering the setting [something which] increases the opportunity for observer bias” (ibid). My heightened self-awareness of potential biases forced me to prepare interviews that contained internal checks to minimize the appearance of biased questions reflecting my personal opinion. There were ample discussions with some committee members in which suggestions were made as to how to avoid leading questions that would guide the answer of participants. Thus, a conscious effort was made to avoid observer bias as much as possible.

My prior experience residing in the town allowed for a better understanding of the cultural constraints that I would be faced with as researcher. For example, residents in Santa Maria Tonantzintla have a circular communication style; that is, their answers to questions are not always linear. They might answer a question in a story that ends with 
the beginning of the question. Having experienced this way of communication facilitated the understanding of data gathered from interviews with the members of citizen committees as well as the residents in the area. Moreover, having been exposed to the culture, I was also able to understand that when residents were answering questions, many times they were answering how they would like things to be and not how they were in reality. Realizing the natural aversion to saying things that would be perceived as negative, I had to be prepared to ask them, after they told me how things should work, if that is how they worked in a specific event or occasion. Through follow-up questions I was able to control or divide statements of what they felt things should look like and how things actually occurred during a specific circumstance. I was able to reduce the threat of "the complexities and limitations of the human mind" resulting in residents wanting to only promote a positive image of their community.

Familiarity with the "normal" behavior of the residents also made it possible to reduce the problems associated with observer-caused effects. Understanding the communication style of residents of the study site allowed me to better understand all data, including that which was contrary to my preconceptions and expectations. Thus, utilizing McKinnon's terminology, I was able to minimize the number of "interpretation gaps" and confront "anomalous data": "events and statements that may be contrary to the researcher's preconceptions and expectations” (1988, p. 40). Moreover, having spent a considerable time in the study site improved my access to the data needed for this research.

As noted by McKinnon (1988), there is a "direct link between the length of time spent in the research setting and the reduction of threats to validity and reliability 
imposed by observer bias, observer-caused effects [...] data access limitations [and] it may also be argued human mind effects” (1988, p. 41). Although able to reap the benefits extended length at the study site of Tonantzintla, as a result of prior exposure, this was less of the case in the research site of Tenango del Aire. However, a prior visit to the study site before establishing base allowed for the identification of key informants within the relatively small municipality. Unstructured interviews during that visit allowed me to determine major differences in the inner workings of the municipality as they related to the decision-making processes for allocating SIF and incorporating citizen input to those in the municipality of San Andrés Cholula. A four-month stay in the study site allowed the formal interviewing of all the concerned participants in the study. Moreover, as a researcher with limited interaction and active control, I was able to minimize the threats to validity and reliability established my McKinnon (1988). Moreover, the a-priori trip to the research site allowed me to establish a good rapport and acceptance within the community and more specifically the municipality, which allowed for the acquisition of a complete dataset. The first informal interview conducted was with a woman in charge of a political organization that aims to obtain funds to combat social ills. This woman provided me with the phone number of the municipal president, allowing me to interview him within a few days; the same task required several months of effort in the research site of Tenango del Aire. Moreover, as McKinnon noted, the "Types of PO which on the surface appear most objective and least disturbing of the research setting, in reality provide the greatest threats to validity and reliability” (1988, p. 46).

Unfortunately, as mentioned above, to generalize results from two study sites to the overall rural population in México would be dubious. Moreover, generalizability is 
generally weak in qualitative research. However to improve the external validity of the study, or clarify the translatability and comparability, an effort was made to clarify the location specific traits of the study sites so future researchers can understand the extent to which the results may vary in other settings. Problems encountered in the participatory process were noted and I made an effort to record respondents' recommendations to improve the process. 


\section{CHAPTER 4: LOCAL GOVERNANCE}

\subsection{Introduction}

This chapter focuses on local level governance in México-the municipal decisionmaking process. The ten sections of this chapter provide an in-depth analysis of the factors that affect the decision-making process. The goal is to determine how decisions are made within a municipality, who participates in decision-making, and what factors are taken into account. The next section (4.2) describes the organizational flow charts of the municipalities studied. Section 4.3 provides an overview of the decision-making process from the perspective of the mayors of each municipality. Section 4.4 examines the role of civil service and the level of administrative discretion. Section 4.5 introduces the different kinds of leadership exercised at the local level. Section 4.6 discusses municipal sources of revenue. Section 4.7 provides the auxiliary perspective on the decision-making process. Section 4.8 describes the citizen committees operating in both study sites. On the basis of an examination of municipal treatment of its citizen committees, the next section (4.9) posits a typology of the citizen committees in operation in both areas, which can be expanded in the future by gathering and analyzing additional data from other municipalities. After a discussion of the municipal decisionmaking process, the chapter concludes with Section 4.9.1, which re-examines my a-priori hypothesis on the factors that affect the incorporation of citizen participation in the decision-making process in México. It provides remarks on how the hypothesis compared to the data gathered from both study sites. 


\subsection{Structure of the Decision-Making Process}

The federation of México is composed of thirty-one constituent states and one federal district. States are further divided into municipalities. The municipal structure is headed by the mayor (presidente municipal) who is popularly elected for a nonrenewable three-year term and who oversees a municipal council (cabildo). The municipal council is composed of a group of trustees (regidores) and a syndic (sindico) in charge of municipal laws. Most council members are elected by the mayors' party slate, with a small fraction of members being selected from the highest vote-getting parties that lost the municipal seat during that term's election (Rowland 2001). Prior to the political opening in the country, "the council was basically a group of honorary posts, led by the mayor, used to reward loyal party service” (Rowland 2001: 1378). Today, except for a small portion of the council—composed of individuals from opposition political parties - not much has changed.

"While the council does have the responsibility to approve the municipal budget, plans and other initiatives, this does not in practice translate into effective control of the mayor. Indeed, because electoral rules guarantee the mayor's party a majority in the council, there is usually little need for debate or negation on the mayor's initiatives (Guillen, 1996 cf. Rowland 2001: 1378).”

In the case of Tenango del Aire, for example, six out of the ten trustees are from the mayor's party slate. Because the elected candidate for mayor ran on a coalition 
platform, although the president, syndic and four of the trustees belonged to the Institutional Revolutionary Party (Partido Revolucionario Institucional, PRI), two additional trustees were from the other coalition parties: one from the Ecologist Green Party of México (Partido Verde Ecologista de México) and one from New Alliance (Nueva Alianza). The remaining four trustees were from the opposition: two from the Party of the Democratic Revolution (Partido de la Revolución Democrática, PRD), one from the National Action Party (Partido Acción Nacional, PAN), and one from Convergence (Convergencia).

The municipality of Tenango del Aire is one of the 126 municipalities of the State of México. The surface area of the municipality is approximately $74.15 \mathrm{~km}^{2}$; Tenango del Aire has a population of approximately 10,578 inhabitants (Conteo INEGI 2010). The municipality is composed of several communities. However, because of the small size of the overall municipal territory, these communities do not possess auxiliary juntas. The communities can chose to elect or appoint a delegate to articulate any concerns in the area to the mayor but, according to interviews with the community and government, these volunteers are not active or functioning in the municipality.

The organizational flow chart of the municipal council (Figure 1; provided by Tenango del Aire) depicts the civic commissioners, the mayor, the Syndic of Estates (property taxes) and Public Safety, the General Secretary, and the trustees: $1^{\text {st }}$ Trustee of Public Services; $2^{\text {nd }}$ Trustee of Urban Development and Public Works; $3^{\text {rd }}$ Trustee of Education and Culture; $4^{\text {th }}$ Trustee of Commerce, Street Markets and Tourism; $5^{\text {th }}$ Trustee of Public Health and Social Development; $6^{\text {th }}$ Trustee of Environment, Ecology and Territorial Limits; $7^{\text {th }}$ Trustee of Promotion of Agriculture and Rural Sustainable 
Development; $8^{\text {th }}$ Trustee of Parks, Gardens and Cemeteries; $9^{\text {th }}$ Trustee of Sports and Attention to Youth; and, $10^{\text {th }}$ Trustee of Public Safety and Civil Protection. These individuals work together to resolve problems within the municipality. However, according to the interviews I conducted, power is not shared equality within the municipality; power is centralized in the hands of the mayor, who has ultimate discretion in the decision-making process. The Municipal Secretariat (Secretario del $\mathrm{H}$. Ayuntamiento) coordinates, facilitates, and implements all the activities the mayor proposes to accomplish during the year.

Within the municipality, there are several commissions: the Commission of Municipal Development Planning (Comisión de Planeación para el Desarrollo Municipal), which is in charge of promoting and helping in the formulation and actualization of the Municipal Plan of development; the Municipal Human Rights Commission (Coordinación Municipal de Derechos Humanos), which receives complaints from the citizenry regarding human rights abuses; the Internal Municipal Comptroller (Contraloría Interna Municipal), which supervises the use of financial and human resources in the municipality and the entities involved in the implementation of projects, including the popularly elected citizen committees called Comites Ciudadanos de Control y Vigilancia (COCICOVI) (Citizen Committees of Control and Vigilance, in English); the Commission of Municipal Programs (Coordinación de Programas Municipales), which supervises and expands special municipal programs that are not part of the municipal plan for development; the Finance Commission (Dirección de Finanzas), which organizes, directs, and controls the financial resources of the municipality to prioritize projects and programs with the designated budget; the 
Commission of Urban Development, Public Works and Services (Dirección de Desarrollo Urbano, Obras y Servicios Públicos), which is in charge of public services, maintaining public infrastructure, and coordinating municipal actions in implementing public works projects and formulating municipal plans for urban development; the Directive of Municipal Public Safety (Dirección de Seguridad Pública Municipal) oversees the municipal police force; the Municipal System or Integral Family Development (Sistema Municipal para el Desarrollo Integral de la Familia [DIF]), which develops and implements institutional programs for the State and Federal DIF; the Civil Registrar (Oficialía del Registro Civil); Auxiliary Authorities (Autoridades Auxiliares), which in the case of Tenango, is composed of three delegates who volunteer to facilitate the administration of social services, programs and projects by coordinating with the municipality and their fellow neighbors. 
Figure 1

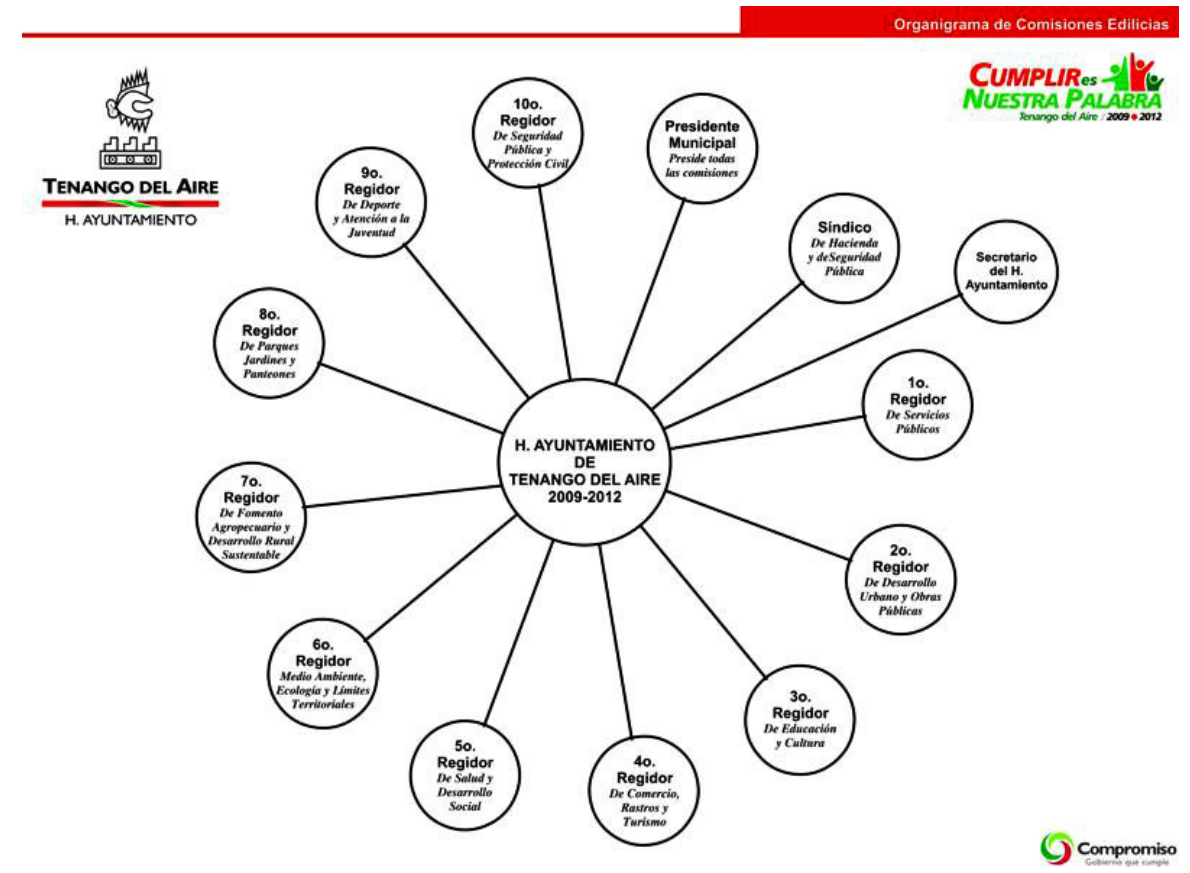

The municipality of San Andrés Cholula, located in the state of Puebla, covers a surface area of $414.69 \mathrm{~km}^{2}$. San Andrés Cholula is composed of six auxiliary juntas. Among the most important and most populated is the cabecera municipal of San Andrés Cholula, where government offices are located. The other five auxiliary juntas are Santa María Tonantzintla, San Francisco Acatepec, San Luis Tehuiloyocan, San Rafael Comac, and San Bernardino Tlaxcalancingo. The governance of San Andrés Cholula, as it relates to the governance of the rural auxiliary junta of Santa María Tonantzintla, is of interest to this study. Unfortunately, the information available in the 2010 census of the population of Santa Maria Tonantzintla was not consistent-population estimates vary between 5,697 and 10,000 inhabitants. Santa Maria Tonantzintla is further divided into three principales (barrios); San Miguel, San Diego de Alcala, and San Pedro. Moreover, it also 
contains two colonias (neighborhoods), San Isidro Buenos Aires, and San Martin Cuachitla and one ejido, Cuachitla.

The flow chart of the municipal government of San Andrés Cholula is the following (Figure 2):

Figure 2.

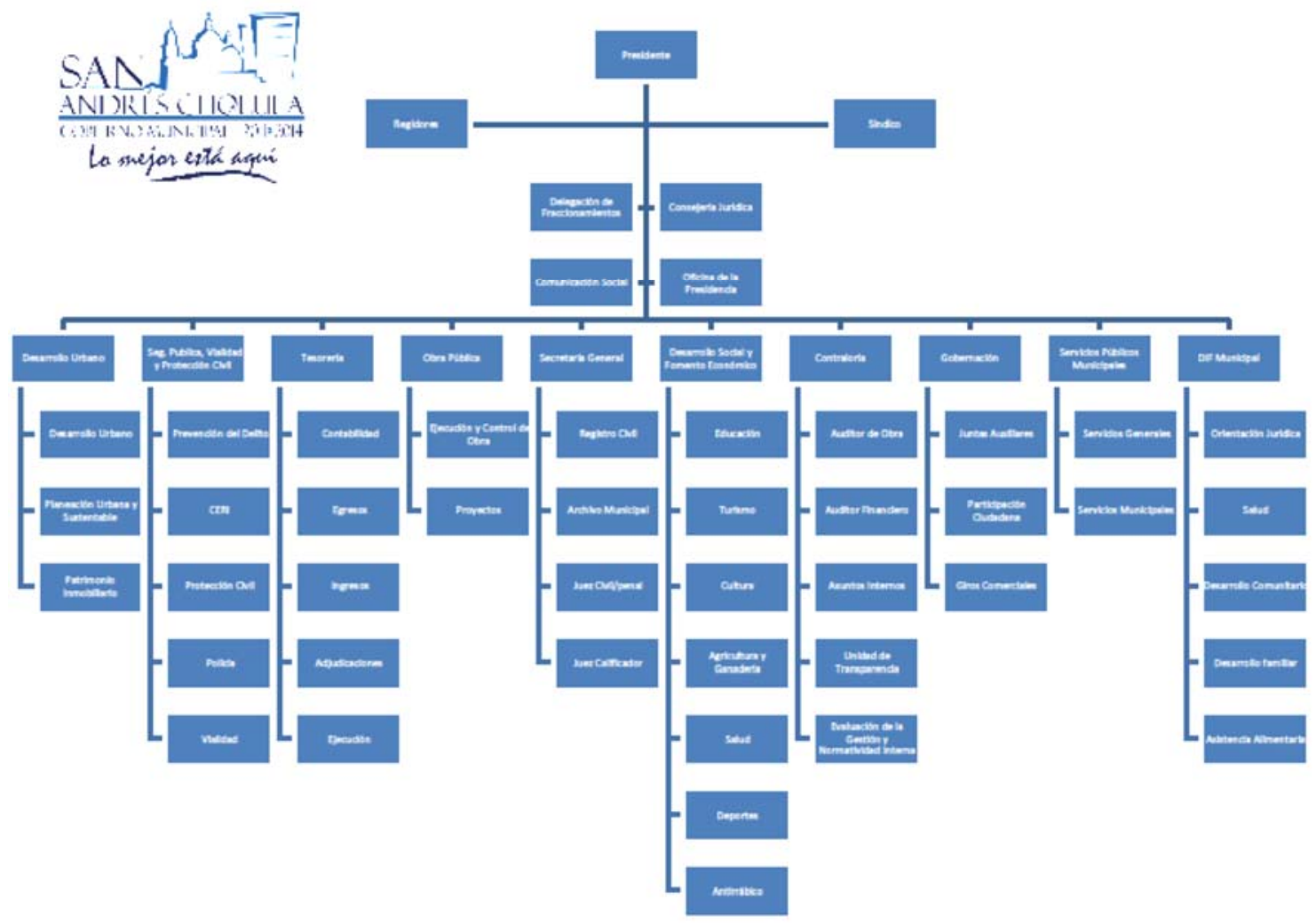

Unlike the structure of Tenango del Aire-where the General Secretary manages the overall administration directly under the supervision of the Mayor-in San Andrés Cholula, the General Secretary manages only specific tasks further down the flow chart. The mayor presides at the top of the flow chart; below him are two different but equal bodies. The first to the left is comprised of the trustees. The trustees, in addition to being 
members of the municipal council-thus, theoretically having the responsibility to approve budgets, plans, and other initiatives in the municipality—oversee their respective secretarias [departments in English], which oversee various directivos [directives in English]. The structure drawn to the right is the Syndic who is in charge of municipal laws. The middle branch flowing directly from the Mayor down further past the first division is divided once again into two divisions; to the left, the Delegation of Real Estate Development and to the right, the Office of Legal Affairs/Legal Advisors.

Continuing down the middle branch of the flow chart, there is another dual division, to the left, the Social Communications Office and to the right, the Office of the Presidency. After these two offices, the power flowing down from the president down the middle of the structure is divided into ten branches, from left to right are the: Department of Urban Development; Public Safety, Transportation and Civil Protection; Treasury; Public Works; General Secretary; Social and Economic Development; Office of the Comptroller; Ministry of Interior; Municipal Public Service; System for Integral Family Development (DIF). Each one of these divisions (Departments) is in charge of several branches/offices (Directives) further down the flow chart. The Department of Urban Development oversees the directive of Urban Development, Sustainable Urban Planning, and Real Estate. The Department of Public Safety Transportation and Civil Protection oversees the directive of Crime Prevention, the Resource Center for International Civil Organizations (CERI), Civil Protection, Police and Transportation. The Treasury oversees, the Office of Accounting, Expenses, Deposits, Awarded Contracts and Bids, and Execution of projects. Public Works Department is in charge of the directive of Execution and Control of the Public Works, and of Projects. The General Secretary 
oversees the County Clerk’s Office, the Municipal Archive, the Civil/Penal Judge, and the Qualifying Judge. The Department of Social and Economic Development oversees the directive of Education, Tourism, Culture, Agriculture and stock farming, Health, Sports, and Anti-rabies directive. The Department of the Comptroller oversees the auditing of public works directive; the finance audits directive; internal affairs; the office of Transparency and Evaluation of Procedures and Internal Legislation. The Ministry of Interior oversees the Auxiliary Juntas, the Directive of Citizen Participation, and the Directive of Private Businesses and Commercial Drafts. The Department of Municipal Public Services oversees the Directive of General Services and the Directive of Municipal Services. The System for Integral Family Development (DIF) provides legal orientation, health, community development, family development and food assistance programs.

In San Andrés Cholula, the Ministry of Interior (which is not linked to the Municipal or State Controllers Secretariat) oversees the Auxiliary Juntas and the directive of Citizen Participation. Notably, unlike the structure of San Andrés Cholula, there is no office/directive of Citizen Participation in the municipality of Tenango del Aire. The Internal Municipal Comptroller (Contraloría Interna Municipal), which supervises the use of financial resources in the municipality, oversees the citizen committees in the area. The Internal Municipal Comptroller reports to the State's Controller's Secretariat, which regulates citizen participation in the entire state.

Pertinent to this study is the governance of Santa Maria Tonantzintla, one of the rural auxiliary juntas of the municipality of San Andrés Cholula. The government body of the auxiliary junta in Tonantzintla is composed of four commissioners-equivalent to 
paid board-members-who manage the junta. One of the commissioners works for the internal ministry of justice within the junta. The other officers within the junta are the commissioner of public works, the commissioner of estates and commerce, and the commissioner of public education. Then there are five reserved deputies or substitutes for each post including a supplement for the head of the cultural house. The money that comes into the auxiliary junta is just for salaries, the municipality handles the money brought in to carry out any project or program in the area directly. The township government is in charge of channeling the demands of its residents to the municipality. There are no prerequisites for running for auxiliary government or being appointed for any of the posts. Moreover, although there are physical government offices in the center of the auxiliary junta, the office does not possess information about its township, the nature of the population (e.g., primarily agricultural or other industry; rates of literacy and poverty; etc.) nor does it possess information on more technical matters such as documentation and records of projects, the cost of projects, petitions made, etc. As noted in Section 5.7, these factors and others attributed to the governing of the auxiliary juntas affect the decision-making process of the municipality and the distribution of funds to these areas.

\subsection{The Mayors’ Description of the Municipal Decision-Making Process}

During the study, the mayor of each municipality was asked open-ended questions, and more specific questions about the factors (continuity, rules set by the state/federal government, the role politics in the availability of federal/state funds, the role of citizen participation, and the level of administrative input) that affect the decision- 
making process. Both mayors stated that social infrastructure projects are, for the most part, established during the election campaign. When asked how he prioritizes infrastructure projects, the mayor of San Andrés Cholula stated:

"That is more of a political matter, you are human and the communities that gave you most support well, you feel obliged to show them your gratification [...] I decide according to the population and also the communities that showed me support, to show them my support.”

Thus, an important consideration when allocating funds was to favor groups or communities based on their allegiance the incumbent mayor. Projects are prioritized largely around the needs of the constituents in areas that promise to garner more votes. In Tenango del Aire, the mayor interviewed for this study ran on a platform of expanding the urban development plan in order to incorporate the outskirts of the municipality into the urban zone. After eight years of not being modified, the population had expanded into the outskirts, and in order to provide them with services—such as water, sewer, and electricity - these areas had to be incorporated into the urban plan of the municipality. The mayor of Tenango del Aire stated that this was the first time that projects outside the city center were being taken under serious consideration-principally due to the significant expansion and growth in these areas.

At the beginning of the term, 'community needs' are established on the basis of promises set during the campaign. After a more technical examination of the cost of the projects and the funds available, projects were prioritized accordingly. Within a few 
months of coming into office, the newly elected mayors have to create a municipal plan for development. After deciding which projects of those promised during the election campaign to implement, the municipality considers other potential projects. Both mayors were asked if the decision-making process is then affected by the need to establish continuity and implement some of the projects that were prioritized, but not carried out, by the previous administration. The surprising answer given in both municipalities was 'no.' Moreover, it was clarified that the municipalities do not maintain a record of projects prioritized or petitioned but not carried out by the previous administration. In the case of San Andrés Cholula the president stated, “We don’t see what was prioritized previously." In Tenango del Aire, the mayor stated that, "There were no projects left by the previous administration. [Well...] they left us only one project that we had to validate, and that was because it was already started and the project needed to be completed. But no, no plans left or anything.” Thus, if a project was petitioned but not initiated by the previous administration, the project must be petitioned again when a new administration enters office.

When asked how rules set by the state and federal government affect the decisionmaking process of what projects to implement, both presidents indicated that the only rules are the ones for the use of funds from Section 33. In regard to the earmarked resources from Section 33, the mayor of San Andrés Cholula stated:

"I am not in agreement with them. Sometimes, the areas where you can use resources fall where there are no people. So, we end up putting sewage or drainage in a street where there is nobody. They determine, according to some formula, which I do not know, what areas are marginalized areas 
and where certain things are needed. Then they say, if we give you funds, you have to use it here. But sometimes it causes problems because people say, 'Why are you doing that project there when there are more people here?' And well, I have nothing to do with that. For example, here in the main square, we have a major problem with flooding. And we would like to use the funds to create a collector of water. But the federal government says that they can only put in or change sidewalks, paint walls, or put lighting in this area. So, even though it is free for our neighbors to provide these services, they get mad because what they want is for us to resolve the flood problem, and we can't. So we end up painting their walls, or taking off the sidewalk and putting another when what they want is drainage, and they get upset, because they don't feel it is as important. We can’t use funds because they are already earmarked.”

The mayor of San Andrés opposed earmarked funds because earmarking limited their potential use for social infrastructure projects in more urbanized zones. These resources were specifically designed for use in marginalized, rural areas. Moreover, the municipality has more self-revenue coming in than any monetary transfer from either the state or federal government, which could be used to resolve infrastructure projects in urbanized areas. In addition, funds from the state government are larger than the funds from Section 33, and, thus, there is no reason why to only use funds from Section 33 for social infrastructure. When asked specifically if self-revenue could be used for social infrastructure, he said, "Yes but here we use it for smaller projects, like painting a school, 
etc. We depend on Section 33 for the major infrastructure projects, like drain and water.” The mayor of Tenango del Aire did not have the same methodology for allocating funds. Both self-revenue and Section 33 funds were used for social infrastructure. However, the mayor from Tenango would prefer greater liberty to use Section 33 funds at will. Moreover, in his interview, he noted that once the municipality uses funds from Section 33 to install drainage, potable water, and pave roads, in a particular area, the federal government does not send funds to maintain the newly created infrastructure. ${ }^{10}$

When asked if party politics at municipal, state, and federal levels of government play a role in the release of funds to municipalities, both mayors indicated that it did not. They said these resources are formula-driven. However, both agreed that politics does affect which 'special projects' will be carried out and funded by state and federal governments. For example, in San Andrés Cholula, the mayor indicated that during elections at the state level, because the governor was running for a second term in office, he (the governor) unexpectedly funded a large project in their area to gain support of his municipality. He funded the widening of a connecting road between the municipality and one of its auxiliary juntas. A similar example occurred in Tenango, where elections at the

${ }^{10}$ It should be noted that SIF from Section 33 is allocated utilizing a formula to account for marginalization of the population in certain areas. Understanding the formula helps to establish the needs of the community. Unfortunately, neither mayor had a clear idea of what that formula is. When asked how level of marginalization affect project selection and fund allocation decisions, the mayor of San Andrés Cholula sated;

"No, what happens is that we don't really involve ourselves or rely on that information. What we base our decision on does however have to do with the number of people, for the cost benefit analysis. Anything else, level of poverty etc. no, we don't deal with that. It could be that the people in charge of vulnerable groups has that information, or the economic development." (Note: the Trustee of Vulnerable groups did not have that information)

A clear understanding of the population and its level of marginalization could inform decisions regarding the allocation of resources. 
federal level influenced the unexpected funding of a large infrastructure project at the local level.

In more open-ended questions, the mayor of San Andrés Cholula explained that for those projects not established during the election campaign, he uses the input of auxiliary presidents. "At the beginning of every year we ask for the participation of every auxiliary president. This is the person who is closest to the people, and we use [his or her] priorities as a base. Here, what we look at is what the auxiliary juntas bring us at the moment, which is how we decide what to do"11. In Tenango del Aire, the municipality is open to solicitations for the expansion of services and project proposals made by citizens and delegates of each neighborhood. However, it was mentioned that in Tenango, the budget is often too small to modify pre-determined plans. Moreover, in the case of Tenango del Aire, delegates are given less authority in the decision-making process than auxiliary presidents because their job posts are honorary, not paid, and, thus, the mayor is in less contact with them than mayors are in contact with the salaried/compensated auxiliary presidents.

When asked how the mayors accounted for citizen participation, the mayor of San Andres indicated that every Thursday morning (Jueves ciudadano), the mayor holds an open meeting with the public to hear the complaints, demands, or comments of the citizenry. However, these meetings occur after the decision-making process and projects have been already prioritized. Moreover, citizen participation was noted by the mayor as only participation in government meetings and through elections but not in terms of citizen committees. When asked about the role citizen participation plays in the decision-

\footnotetext{
${ }^{11}$ As will be noted in Section 5.5, the input process in which auxiliary presidents supply the municipality
} with input is flawed. 
making process, both mayors indicated that there was a lack of participation. In the case of San Andrés Cholula, the mayor commented that:

"We have a severe problem with the lack of citizen participation, I think that [is the case in] the whole country. What we have is a problem with people feeling the need for a paternalistic government. People see government see everything in terms of obligation. You are the government. You have to give me everything, drainage, paving streets, etc."

Thus, citizens petition the municipalities directly to implement particular projects, but these petitions are seen by the municipality as demands and not citizen participation. In addition, the act of petitioning is seen by the municipality as being more common and frequent than the act of citizen participation. This concurs with data gathered by the nationwide LAPOP 2010 survey, which found that $16.4 \%$ of those interviewed solicited help or presented a petition to the local government in contrast with only $9 \%$ who participated in local government meetings, assemblies, and sessions.

In Tenango del Aire, citizen participation was accounted for by participation in local government meetings and also through elections. Participation was noted to be low and was not accounted for through participation in COCICOVIs. When asked about the role of input from trustees and department heads in the decision-making process, both mayors indicated that while the trustees participate in the prioritization process of public 
works, as will be noted in the next section, department and administrative input is not utilized.

\subsection{The Role of Administrative Discretion}

Although the structure of Tenango del Aire suggests equal input or administrative discretion in the decision-making process, this is not the case in either municipality. Interviews conducted with the mayors, trustees, and heads of departments and urban projects in both municipalities confirmed the lack of discretion given to the administrative branches of government; administrative discretion is nonexistent.

In a given municipality, trustees oversee departments, which in turn oversee directives. In the municipality of San Andrés Cholula, four trustees were interviewed: the trustee of Urban Development, Ecology, Environment, Public Works and Services; the trustee of Vulnerable Groups, Youth and Gender Equality; the trustee of Public Education and Cultural, Sporting and Social activities; and the trustee of Economic Development and Tourism. Four heads of departments were interviewed: the director of the Department of Urban and Ecologic Development, the director of the Department of Sustainable Urban Planning, the director of the Department of Potable Water (one of the case studies analyzed dealt with a citizen committee created to obtain potable water), and the director of the Directive of Public Participation. Moreover, various heads of public projects within the Department of Public Works were interviewed. In Tenango del Aire, the mayor, the municipal secretariat, and three trustees, the $1^{\text {st }}$ Trustee of Public Services, the $2^{\text {nd }}$ Trustee of Urban Development and Public Works, and the $6^{\text {th }}$ Trustee of Environment, Ecology and Territorial Limits were interviewed. In addition, four other 
individuals were interviewed, the head of the Commission of Municipal Development Planning, the Internal Municipal Comptroller, the head of the Finance Commission, and the head of the Commission of Urban Development, Public Works and Services. ${ }^{12}$

According to the interviews, the various departments and directives receive petitions from individuals, citizen committees, and delegates (in the case of Tenango del Aire) or auxiliary presidents (in the case of San Andrés Cholula) to implement various projects throughout the year. ${ }^{13}$ Their job is to forward the requests to the trustees who vocalize solicitations to the mayor who prioritizes the projects during one of the monthly meetings with the council. ${ }^{14}$ Trustees, in turn, in addition to receiving petitions from the various department and directive heads, also receive petitions directly from the

12 Number of Municipal Authorities Interviewed

\begin{tabular}{|c|c|c|c|c|c|c|c|c|}
\hline State & 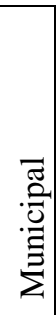 & 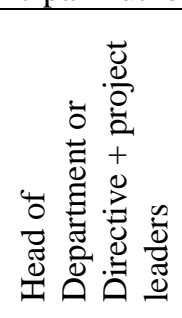 & 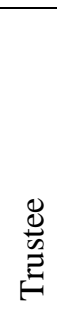 & 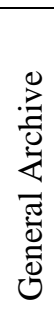 & 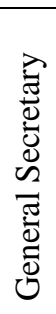 & 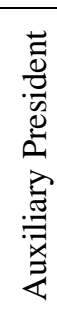 & 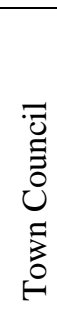 & 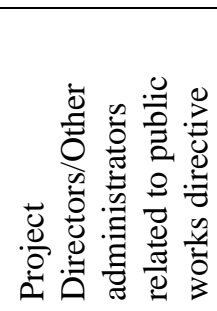 \\
\hline Puebla & 1 & $4+5$ & 4 & 1 & 1 & 4 & 7 & 4 \\
\hline $\begin{array}{l}\text { Estado de } \\
\text { México }\end{array}$ & 1 & $4+3$ & 3 & 1 & 1 & 0 & 0 & 4 \\
\hline Total & 2 & $8+8$ & 7 & 2 & 2 & 4 & 7 & 8 \\
\hline
\end{tabular}

13 Ironically, the only directive who reported not receiving petitions from citizens pressuring the municipality to prioritize a particular project was the directive of Citizen Participation in San Andrés Cholula. This may be due to the lack of citizen awareness of the existence of the directive of Citizen Participation. None of the members of the citizen committees interviewed, nor the residents of Tonantzintla interviewed, knew about the existence of the directive.

${ }^{14}$ As noted by Rowland; "today, there is much debate within municipalities about whether the council members have legislative functions, or simply serve to receive complaints from the citizens and channel them to the mayor" (2001: 1378). As noted in the data collected for this chapter, in both municipalities analyzed in this study, the legislative functions of the council were trumped by the responsibility of channeling citizen demands to the mayor. 
population. During the monthly meetings, if they believe a petition is valid, they present the petition to the mayor. ${ }^{15}$

Officially, in addition to the monthly meetings of the municipal council, the municipality meets for a COPLADEMUN (Comite de Planeasion Municipal, Municipal Planning Committee, in English) to prioritize works. During the COPLADEMUN, civil society, the auxiliary juntas, and some representatives from the state government can participate. Unfortunately, according to the trustees interviewed, this is just a formal meeting, "nothing is decided there” (from an interview with a trustee in San Andrés). In other words, the COPLADEMUN does not occur until after project-selection decisions have been finalized. In the municipality of Tenango del Aire, the general secretariat indicated that the COPLADEMUN was simply used to coordinate and implement projects in the municipality promised by the state or national government during political campaigns. For example, he indicated that during the presidential campaign of Enrique Peña Nieto, the PRI political party promised the State of México and its municipalities that if Peña Nieto won, the PRI would implement certain projects. These projects were noted during a COPLADEMUN, which coordinated their future implementation. In other words, the COPLADEMUN does not operate to prioritize projects or to coordinate the implementation of projects prioritized at the municipal level. This finding supports previous studies indicating that: "the COPLADEMUNs, were either marginalized in the discussions of local matters or simply did not exist” (Rowland 2001: 1381). Thus, they are irrelevant as mechanisms for citizen participation in political matters of the municipality.

\footnotetext{
${ }^{15}$ However, it is important to note that petitions are usually copied to the mayor.
} 
When the heads of departments and directives in both municipalities were asked about their role in the decision-making process, they stated that they do not participate in the decision-making process. Although they receive petitions for services or projects, they forward these requests to the trustees. In other words, "Their role was to translate the decisions made by the mayor into concrete actions" (Interview with department head in San Andrés Cholula). During the interviews, it was made explicit that the trustees do not meet with the heads of the departments and directives to create their own plans for development. Planning the expansion of services or the building of infrastructure, roads, sidewalks, potable water, etc., is not based on projections of growth and predicted demand increases. It is based solely on the demands of the people. The decision-making process is a one-directional top-down process. Decisions are made on a demand basis; promises are made during the campaign. Petitions arrive throughout the year, and based on these demands, decisions are made by the mayor as to what projects to implement. Departments, even that of Urban Development, do not participate in the creation of plans or in the prioritization process of existing demands.

However, the 2012 Municipal Plan for Sustainable Urban Development (El Programa Municipal de Desarrollo Urbano Sustentable), which lists the projects that will be implemented during the coming year, was elaborated by the municipal council of San Andrés Cholula in conjunction with the head of the Department of Urban Development and Ecology and other pertinent administrative departments, along with input from town council representatives and from citizen participants. Moreover, it is said to consider state and national plans for development. None of the interviewed department heads said they had input in prioritizing plans for community development. According to 
the director of the department of Urban Development Ecology and Environment in San Andrés Cholula, his department deals only with granting permits for use of soil, permits for construction, street alignment, and street numbers, etc. It does not contribute to the projection of needed infrastructure plans for the municipality. It has authority to deny a permit over a citizen-petitioned project, but, as far as projects prioritized by the municipality, permits are mostly ceremonial. Moreover, the department maps out the municipality, classifying zones as rural, urban, or ecological preserves, and on the basis of this zoning map, it decides whether or not to implement a particular project. However, although permit-decisions are made on the basis of the abovementioned zoning map, this map does not contain information needed to determine the full impact of any project in a particular zone. The zoning map did not use updated census information to classify each zone. Moreover, when the head of the department was asked about census numbers in Santa Maria Tonantzintla, he answered that it was approximately 160,000 inhabitants. However, according to the latest census, the population was 15,000 and when probed further, he indicated that the department did not have an official census of the area. Moreover, the township offices also did not have a census of the population or any information regarding the levels of poverty, illiteracy rates, percentage of women, children, etc. of the township. In addition, when visiting the rural township, several buildings under current construction were over three stories high. According to the official zoning laws in that particular area, this was not allowed. Local residents reported that they did not go to their municipal authority, or township office, to request building permits. Local authorities in the township government office, when asked, did not have any documents regarding zoning laws or any way of enforcing them. 
All department heads in San Andrés concurred that they do not participate prioritizing projects. The lack of involvement in prioritization was worrisome. When the director of the Department of Potable Water was asked about his role in determining priorities during the fiscal year, he indicated that he does not participate in the prioritization of projects. When probed further, the director indicated his department only manages the existing water system but does not play a role in creating plans to expand service. Thus, when a community requests the expansion of a service, like potable water, the relevant department—in this case the potable water—does not weigh in on the technical matters regarding whether or not to expand the service.

The department heads in the municipality of Tenango Del Aire also indicated that they do not have input in creating or proposing projects to be implemented in their respective municipalities. The technical expertise of department heads is not utilized to program the expansion of services required as a result of population changes in their jurisdiction. In Tenango del Aire for example, the head of the Department of Public Education indicated that his department does not determine whether the construction of more schools is necessary. The department only participates in building schools when petitioned by the mayor. They do not participate in the decision-making process determining whether or not a new school is needed. Municipal departments do not create projections of demand for services. A similar observation was made for all departments in both municipalities.

In the municipality of Tenango del Aire, the Director of Urban Development mentioned that in his municipality, as in San Andrés Cholula, his department is only in charge of granting use of soil permits, and occasionally changing the plan of urban 
development when a project proposed by the mayor extended into an area that is not incorporated in the current urban plan. According to the interviews, growth in Tenango del Aire occurs from the center out. Most lands are subdivided among family members as a family grows. Thus, the municipality does not need to do much to extend service provision as the population grows. However, sometimes residents sell land they own in the outskirts of town and building begins. When this occurs, the municipality must modify the urban plan in order to provide services to these lands, which are not included in the urban zone. However, as indicated by the Director of Social and Economic Development, the Urban Development Plan has not changed since 2004. Changes to the Urban Development Plan can have far-reaching consequences on community growth. Unfortunately, the department does not project growth and propose its own goals for development. In other words, it does not take geographic considerations (for example, regional clusters) into account. They do not indicate where (e.g., residential, commercial, and recreational areas, etc.) growth and projects should be promoted. In other words, it does not produce an "ideal" urban plan that would at least theoretically provide for sustainable, ecological, and economically feasible growth. The Department of Urban Development does not promote and encourage specific kinds of growth; it only responds to requests for services from citizens after growth has occurred.

The Department of Urban Development grants use of soil permits to projects prioritized by the municipality or solicited by citizens ${ }^{16}$. While the granting of permits provides a yes or no vote on an issue, it does not address the broader question of which

\footnotetext{
${ }^{16}$ According to my interviews, it is very common for citizens (in both municipalities) to begin construction projects without requesting official permits and the municipalities rarely become involved in stopping the construction unless officials receive several complaints.
} 
projects the municipality 'should' fund or promote. The technical expertise of each department is not being utilized in planning and proposing a common vision of the future. As the trustees interviewed in both municipalities indicated, they do not have the opportunity to work with the department heads (which they oversee) to suggest projects to the mayor. The trustees and department and directive heads are unable to plan for municipal growth. Urban planning on a technical level does not occur. The establishment of priorities in the municipality does not follow any technical input from experts and department and directive heads. Moreover, every three years, "Every administration is renewed with the incoming president and all offices stop working for a while [... people] are fired and replaced with the people the president brought in. And others are sometimes kept; depending on how many people the mayor had to bring in, [...] this includes hiring new department heads and other office staff, like the secretaries” (Interview with department head in San Andrés Cholula). The policy, therefore, opens the process of hiring technical and administrative staff to a system of spoils or patronage. ${ }^{17}$ The mayor appoints those who helped during his election campaign based on loyalty—not necessarily professional merit. Additional interviews with municipal staff in both municipalities confirmed this custom of changing administrative staff every three years for the incoming mayor, although noted to be less common in Tenango del Aire.

Record keeping in such a system is thus either very difficult or not a priority. For example, when interviewing the trustee of Vulnerable Groups, Youth and Gender Equality in San Andrés Cholula, the trustee indicated that the municipality does not have information regarding census of the population, let alone the nature of the population

\footnotetext{
${ }^{17}$ The mayor can only be elected for a non-renewable three year term. Even if the mayor performed very well while in office, he/she cannot run for a second term.
} 
with regard to the percent of elderly people, young adults, or children, or the income distribution, level of education etc. in the municipality. This begs the question; if the constituents are seemingly unknown, due to the lack of record keeping, how does the trustee of Vulnerable Groups, Youth and Gender Equity determined what projects to implement to 'meet the demands' of her constituency? When interviewing the heads of various departments in the municipality of San Andrés Cholula, I became aware that there was no record in the municipality of the projects that were petitioned for during the previous administration. The same was the case in Tenango del Aire. Specifically, when mayors and trustees were asked if projects prioritized during the previous administration where considered when deciding what projects to implement during the year, everyone answered, "no." A "no" answer was the norm unless the project prioritized by the previous administration had already been initiated and was of a very large scale, such as a stadium construction project. Thus, in a system with no record keeping, petitions made prior to the incoming mayoral administration are often disregarded; petitions are not prioritized based on chronological order of proposal. Moreover, if a community petitions a project or expansion of a service that does not become prioritized in the current administration, when the new mayor enters office, the petitioning process must begin anew because no record of the petition was ever made.

Administrative discretion of the department and directive heads in both municipalities was almost nonexistent; the decision-making process was centralized in the hands of a strong mayor who did not take advantage of the input and the technical expertise of his administration. Moreover, in regard to professionalism, the importance of 
hiring administrative personnel based on skill versus political connection was notably downplayed.

The lack of input of department and directive heads in community planning as well as the lack of professionalism makes both municipalities resemble those of the United States administration during the $19^{\text {th }}$ Century. In the search for a balance "between rational, professional administration and democratic openness and public accountability” (Box 1998: 4), the United States has passed through various reforms, each accentuating the merits of one of the traits mentioned above. In other words:

"The administrative history of our governmental machinery can be construed as a succession of shifts [...], each brought about by a change in emphasis among three values: representativeness, politically neural competence, and executive leadership." [The] "earliest political institutions" [were] reactions to "executive dominance in the colonial era," followed by "extreme reliance" on "representative mechanisms" in the nineteenth century, resulting in a negative reaction to "legislative supremacy" and the spoils system in which many administrative positions were filled on a political basis. This led to the reform efforts of the late nineteenth and early twentieth century, with stronger separation of politics and administration, merit-based personnel systems, and administrative centralization for efficiency (Kaufman 1969, 3-4)” (Box 1998: 12-13). 
Recalling U.S. history, during the seventeenth and eighteenth century, the thencolonies, predecessors of the United States, which were modeled after English institutions, were ruled by elites appointed to local government. American independence brought with it a wave of democratization "an increasing trend toward active policy debate and decision-making by the collected members of the town meeting instead of the familiar deference to the wisdom of the select men chosen as town leaders" (Box 1998:32). The contribution of the United States to the democratic political process during this period cannot be undermined. Unfortunately, the newly founded country "harbored severe doubts about the ability of bureaucratic organizations to address national problems. Indeed, Americans regarded bureaucracies as brute administrative units, not planning or policymaking organizations” (Carpenter, 2001: 40). In not attempting to build the administrative capacity of the country, this era of Jacksonian Democracy, left in its place the "patronage, or spoils, system [...] designed to distribute the offices of slate to party loyalist [, a] system founded on [...] rotation in office” (Carpenter 2001: 41). "At every change in presidential administration, much of the federal bureaucracy would flush itself out through the rotation of party members in and out of executive departments" (ibid.) Moreover, in underestimating the need for technical expertise in managing administrative departments, Jacksonian Democrats created a legacy of "clerical supremacy” within government organizations (Carpenter 2001). In his discussion of the Interior Department in 1909, Carpenter notes that "perhaps the most crippling aspects of clerical supervision for the bureaus lay in the reduction of their authority and discretion within the department $[, \ldots]$ render[ing] the bureaus not "agents of the Secretary" but "foreign organizations." [Moreover] because bureau chiefs could communicate to the 
secretary only through their departmental clerical supervisors, they had little ability to sell programs and administrative innovations to the secretary” (Carpenter 2001: 54). In other words, "nineteenth-century American political culture disabled bureaucracy by casting doubt on governmental careers and bureaucratic effectiveness” (Carpenter 2001: 40).

The pressures of industrialization—rapid urban growth requiring the building of bridges, paving of roads, and the solving of problems requiring technical expertise—on the American administration lead to a new wave of reform, and according to Skowroneck, "It is difficult to imagine how corporate capitalism could have thrived in America without an alteration of the pre-established institutional supports for American democracy" (1882: 17). For Skowroneck, "The modernization of national administrative controls did not entail making the established state more efficient; it entailed building a qualitatively different kind of state” (1982: 4). There was a push toward centralization and the professionalization/incorporation of merit-based personnel systems in government administration. Technical administrative decisions based on proper record keeping and scientific information was now favored over decisions made on political grounds. Thus,

"In relation to the institution of community governance, much of the twentieth century has been spent creating and implementing structural reforms to limit the possibilities of patronage, spoils, and control of government by political machines, reforms such as at-large elections to dilute the political impact of neighborhood (often ethnic) groups, and the 
council-manager plan, which uses the private corporation model of a professional general manager or chief executive officer accountable to a broad of directors (in the public sector, the city council, or county commissioners). Such reforms work well where there [...] are largely physical and technical, such as challenges of infrastructure and finance.

(Box 1998: 34)

After industrialization, the management of two World Wars and the establishment of the prowess of the United States in the world, it has become apparent that, "The twentieth-century rush to professionalism accomplished what was intended, bringing to bear efficiency and economy to solve the largely technical concerns of rapidly growing urban areas” (Box 1998: 34). Having accomplished its goals, all too well, "the reformist zeal [was] generated in reaction to conditions in the nineteenth century” (Box 1998: 35). I would argue that more than a "reaction" to the accomplishments of the era of professionalism, the new generation of reformers shifted their focus from securing the efficiency, economy and competence of government to guaranteeing a more representative and accessible government administration. In either case, in the contemporary United States, and other developed countries:

"The emphasis [of reformers] is shifting the balance from centralized, expertbased systems to decentralized, citizen-centered systems. [However, as mentioned above,] this shift is only possible because of the success of the reform impulse. If the battles for efficiency and effective community government remained to be 
fought, if streets were muddy dirt tracks and water and sewer systems in their crude infancy, if local action was hampered by overly complex governance structure and administration was in the hands of political machines and their patronage employees, the contemporary discussion about citizen selfdetermination would seem trivial and foolish. Instead, we would be worried about solving the basic problems of service delivery, as were the reformers a century ago" (Box 1998: 36).

Unfortunately, the administrations of both rural municipalities analyzed in the present study appeared trapped in the same traditions that governed the era of Jacksonian Democracy in the United States. As mentioned in the previous chapter, in the 1980s, México engaged heavily in decentralization policy and citizen self-determination, reforms that aimed to end rotation in office and patronage, and encourage professionalization. However, municipal department heads and administrative staff (secretaries in charge of bookkeeping, etc.) continue to be appointed on political grounds, not based on their technical expertise. They are subject to the side effects of the spoils system and rotation in office. The municipal administrative staff-which are newly installed with each elected mayor-have difficulty adjusting to new conditions and determining the inner workings of the municipality, and thus they have difficulty smoothly transitioning administrative functions from election to election, being subject to rotation in office themselves. ${ }^{18}$ The rest of the administrative staff, heads of departments

\footnotetext{
${ }^{18}$ Record keeping is just recently becoming a subject of importance. However, each department does not maintain its own records; records are held in a central office and in some cases, the outgoing administration
} 
and directives (e.g., engineers, architects, public education experts) have little ability to use their technical skills to plan and prepare for the future development of their communities. Guaranteeing democratic accountability in service delivery is not just about guaranteeing citizen participation in the allocation of services but also about the responsible allocation of services. Municipal authorities are paid by the citizens through taxes to use their technical expertise to guide the decision-making process.

The input of department and directive heads is not being utilized in decisionmaking. Their technical experience should be the main metric used to hire personnel. Moreover, the municipality should make an effort to improve its record keeping and learn about the nature of the constituents they serve. When the public works office was asked how they conduct a cost-benefit analysis for a particular project, using the paving of a street as an example, they indicated that:

"This includes an analysis of the costs of the work. What we then focus on is trying to give benefit to the largest number of people” (Head of Public Works in San Andrés Cholula).

When probed, it was indicated, “The cost benefit analysis does not include considerations of whether the street has drainage or potable water. It just includes the cost of the paving of the street and if the road is helping to connect two roads, thus giving greater benefit” (ibid.). That is, long-term plans for development and future expenses,

acted consciously 'not leave a good record trail to make the administration of the new mayor [from a different political party than the exiting mayor] more difficult' (Interview in San Andrés Cholula). 
like ripping out a newly paved street to add water in the future and then re-paving, is not considered. ${ }^{19}$ Moreover, they do not have a census of the population, so determining what work will benefit the largest number of people is not clear. Determining who will benefit from the project is determined, for the most part, by the signatures that a particular petition has attached to it, guaranteeing that projects exerting the greatest amount of popular pressure on the mayor are resolved-even if other projects (championed by less mobilized constituents) are of greater benefit and are more urgently needed. ${ }^{20}$ Under such a system of service allocation, the needs of the people are being undercut. Decentralization must be followed by an effort to improve the capabilities of the administrative staff and end patronage, rotation in office, and other elements that hinder good governance. In other words, as noted in the first Inter-American Democracy Conference: Democratic Governance and Effective Policy Development (IPMCS, 2014), a civil service reform movement is needed in the region of Latin America to complement decentralization efforts.

\subsection{The Role of Leadership}

One of the goals of this research is to identify the factors that affect the degree to which municipalities will incorporate citizen participation in the decision-making process. The effect of community leadership on who is heard in the municipality during

\footnotetext{
${ }^{19}$ Interviews with community members of San Andrés Cholula indicated that on several occasions, newly paved roads were ripped out by the subsequent administration to change the material and thus the aesthetic of the street, without considering that the streets were in desperate need of drains in order to avoid flooding.

${ }^{20}$ For example, in the auxiliary junta of Santa Maria Tonantzintla, two out of the three auxiliary presidents indicated that while attempting to supply the township library with potable water (the bathrooms were not functioning because of lack of water), the municipality paved several roads in the outskirts of the town center. According to them, this was mostly because the street neighbors were highly vocal and mobilized and they still had not collected signatures to add to the request for potable water.
} 
the decision-making process cannot be ignored. As was indicated by Box (1998), the kind of leadership exercised at the local level can be determined by analyzing the interest groups attempting to affect land use. "These people include those most immediately connected with land, such as landowners, local businesspeople, investors in locally owned financial institutions, lawyers, realtors and so on” (ibid.:48). While for some (e.g. 'elite theorist'), the decision-making process is seen as being dominated "by a relatively cohesive and closed socioeconomic class, [...others, specifically pluralist theorist view] community governance [as being] characterized by changing and accessible groups of people involved in specific issue areas” (Waste 1986, 13-25, cf. Box 1998: 45).

In either case, as Paul Peterson (1981) put it, "Urban politics [...] is above all the politics of land use, $[\ldots]$ the factor of production over which cities exercise the greatest control” (Box 1998:43). Local governments are, after all, able to exercise control over land by using their financial powers (the use of taxation and investment in infrastructure) and regulatory powers (planning and zoning regulations). By using their financial and regulatory powers, local governments are able to "provide advantages to some people and deny them to others” (Burns 1994, 54-7, cf. ibid).

In the growth machine model advanced by Harvey Molotch in 1976 and elaborated by Molotch and John Logan (1987), land is perceived as having two sets of value driven characteristics: exchange and use. "Exchange values are those of the marketplace, of people whose interest in land is primarily to make money from it. Use values are those of people whose primary interest in land is its use for creating a peaceful and pleasing living environment for themselves and their families” (Box 1998:49). According to Molotch's growth machine model, "The responses to growth could be 
portrayed along a continuum that stretche[s] from growth machine dominance to a weak growth machine” (ibid.: 59). However, community politics in such a model is seen, for the most part, as driven by those promoting the 'growth machine,' those elites who are aiming to enhance lands exchange value. In other words;

"The underlying concept of the growth machine model, that people naturally want to make money from the use of land, it is difficult for citizens to resist the growth machine phenomenon and that it takes sustained effort to do so. For public professionals, the pervasiveness of the growth machine sets clear limits to action, as the "growth machine elite" controls the political power in a community and thus can influence hiring and retaining decision affecting professional careers” (Box 1998:50).

Building on the idea of leadership molded by major interest groups attempting to affect land use, but using a less deterministic and uni-directional approach than that of the growth machine, one can create a typology of communities by examining the decisions residents have made regarding land use and economic growth in their communities. In helping do this, Box (1998) starts by describing and then building on a typology of communities proposed by Oliver Williams and Charles Adrian in their 1963 book, Four Cities: A Case in Comparative Policy Making. The typology of communities identified is fourfold; 
1. Promotion cities: "The primary concern of the government is the promotion of economic growth.” (Box 1998: 51)

2. Amenities communities: "The primary goal of government is to provide and secure life's amenities, the 'home environment rather than the working environment' (Williams and Adrian 1963: 25). In such places, growth is often seen as a threat to the living environment. Amenities communities tend to have relatively homogeneous populations - that is, their residents are sufficiently similar in socioeconomic status and desire for a certain type of community that agreement on community goals can be reached and kept” (Box 1998: 51).

3. Caretaker city: In this community type, "Maintenance of traditional services is the primary goal of government. Residents of this caretaker city wish to keep taxes low, minimize land-use planning and other restrictions on the use of private property, depend on the 'freedom and self-reliance of the individual' (Williams and Adrian 1963:27), and provide only basic and essential services through the local government” (Box 1998: 51).

4. Heterogeneous communities: "The fourth type of community is very diverse, with many interest groups competing for political advantage. The function of local government in this community type is to serve as arbiter between the competing groups. In this hyper-pluralistic environment the highest value is placed on political responsiveness” (Box 1998: 52). 
Box (1998) then draws on the similarities between Williams and Adrian's typology of community orientations to that of the work of Clarence Stone (1993). Stone's typology of community orientations and leadership is also fourfold:

1. Maintenance regime: “(similar to Williams and Adrian's caretaker community) that preserves the status quo and introduces few changes” (Box 1998:52).

2. Development regime: (similar to Williams and Adrian's promotion community) and "“concerned primarily with changing land use in order to promote growth or counter decline’ (Stone (1993: 18)” (ibid.).

3. The middle-class progressive regime: (similar to Williams and Adrian's amenities community) "focuses on 'such measures as environmental protection, historic preservation, affordable housing, the quality of design, affirmative action, linkage funds for various social purposes' (Stone 1993:19)” (ibid.).

4. The regime of lower-class opportunity expansion: "It is different from than Williams and Adrian's arbiter community, in which there are many competing interests, because the arbiter community may or may not emphasize a particular policy orientation, such as expansion of lower-class opportunity” (ibid.) Stone’s fourth regime proposes lower-class opportunity expansion "through programs such as 'enriched education and job training, improved transportation access, and enlarged opportunities for business and home ownership” (Stone 1993:20, cf. ibid.).

In both Williams and Adrian's (and Stone's) typology of communities, the decisions residents make regarding land use and economic growth in their communities 
are diverse, resulting in diverse communities. Community leadership pushes decisions and as Box notes, “There is a continuum of responses to pressures for growth” (1998:57). As mentioned by Box, "Though a particular community is likely to be a mixture rather than a pure example of one of Williams and Adrian's four types of community orientation or one of the four types of community response to the growth machine in the 'expanded' growth machine typology, there are very real differences in local political environments" (1998: 62). The directions that community leadership pushes the allocation of value on land in the municipality of Tenango del Aire and San Andrés Cholula are very different. The allocation of value on land in Tenango del Aire focuses more its use values "creating a peaceful and pleasing living environment for themselves and their families” (Box 1998:49) while in San Andrés Cholula, the allocation of value is focused on exchange or "those of the marketplace, of people whose interest in land is primarily to make money from it” (ibid.).

Tenango del Aire was the first municipality in the country to elect a mayor, in 1985, that was an opposition candidate from the political predecessor of the PRD party. The party ran on the issue of securing free potable water and maintaining low taxes. According to the current political administration, the municipality still has difficulty collecting user fees for services and raising taxes due to the ideology established during the reign of the PRD predecessor. Although a coalition party currently manages the municipality, this municipality leans more toward PRI and PRD support, having never elected a PAN mayor. In any case, the residents' ideology of maintaining low taxes and securing basic services makes the municipality resemble the caretaker city, where "Maintenance of traditional services is the primary goal of government [and] residents 
[...] wish to keep taxes low” (Williams and Adrian 1963:27, cf. Box 1998: 51). The main business in the area is a bakery/coffee shop and restaurant (only open on weekends located above the bakery and owned by the same family) located in the town center. The family that owns the establishment has operated the business for several generations and is very active in the community. The bakery, which has operations in other municipalities in the state, is a main tourist attraction for outside visitors and is the main social meeting place for locals in town. The current owner has formed her own civic organization dedicated at providing aid to the poor. Moreover, she is very well connected with the local government and, 'regardless of political affiliation,' has always had a connection with the government. There are other active (yet smaller) business owners in town, and after conducting interviews, I noted they are primarily concerned with keeping the traditional feel to the town. Growth has been promoted over the years from the town center outward with priority given to the projects in the center of town. It was not until the current administration that attention was given to incorporating the new outgrowths of the municipal center into the urban plan. However, élites who own local business in town still prioritize the preservation of the center. For the most part, the municipality recognized that as in the middle class progressive regime the community focuses on such measures as historic preservation. ${ }^{21}$

As in Williams and Adrian's amenities community, with the exemption of a few families, Tenango del Aire has a "relatively homogeneous population—that is, its residents are sufficiently similar in socioeconomic status and desire for a certain type of community that agreement on community goals can be reached and kept” (Box 1998:

${ }^{21}$ In analyzing the municipal plan for development, a trend emerges: prioritization of development from the inner municipality center outward (GACETA, 2014). 
51). However, the decision-making process is influenced by what Waste (1986), would call "a relatively cohesive and closed socioeconomic class" (cf. Box 1998: 45). A small portion of the population, the business class, is fairly active and has close ties with the government. ${ }^{22}$ During and after elections, this group of the population interacts with government on a regular basis for the functioning of its non-profits, social programs, etc. Thus, for this group of individuals, there are inlets for communication with the municipality, albeit non-official ones. If a citizen is not part of the 'in-group' of the socially active business class in the community, there is limited un-official contact with the municipality. ${ }^{23}$ Membership of the active business class is rather difficult to penetrate because social mobility is a slow process, resulting in relatively stable elite groups. These groups interact with government in a casual manner and indirectly affect the decisionmaking process. The municipal authorities interviewed for this study indicated that other than promoting social works and projects (historical preservation, etc.) through nonprofits, these groups limit their participation to activities that occur during election cycles. The municipality did not recognize petition for services or projects as citizen participation. Moreover, municipal authorities indicated that more often than not, there are not enough funds to modify priorities established during the election campaign. Thus, the decision-making process - the governance process—is closed. Thus, the community of Tenango del Aire shares some characteristics with the Amenities community and

\footnotetext{
${ }^{22}$ Interviews with the community members and government officials.

${ }^{23}$ Having access to one of the prominent families in town guaranteed me immediate access to the government. I had requested interviews through official means, but was unsuccessful. A casual conversation with one of the notable families in town resulted in a call to the municipality (a conversation with a family acquaintance) and an immediate scheduled meeting with the mayor and access to all the staff. Without this contact, the interview process would have taken several months. Being acquainted with a member of the in-group in the community granted me access to the local government and communication allows for the sharing of ideas about what priorities are and how growth should be shaped, etc.
} 
Caretaker city described by Williams and Adrian (1963) and the Maintenance regime and the middle class progressive regime presented by Stone (1993). Moreover, community leadership can be described utilizing the lenses of the 'elite theorist.'

The Municipality of San Andrés Cholula has a stronger affiliation with the PAN political party. As mentioned in previous chapters, some of the party's doctrine and themes utilized for the mobilization of local elites has been anti-satetism translated as a "critique of centralization, [paternalisms] and the defense of private property" (Mainwaring \& Scully 2003: 225). Moreover, the PAN has “a close rapport with business groups, notably the Confederación Patronal de la Republica Mexicana (Confederation of Mexican Business, Coparmex) and other parapolitical ultraconservative associations, such as the Desarrollo Humano Integral AC (Human Development Association), for whom the state was the worst enemy” (Mainwaring \& Scully 2003:230). In other words, the party's main focus was on pro-business policy that supports the urban middle and upper class. The affiliation with the PAN political party in the municipality of San Andrés Cholula makes it more disposed to hearing the interests of the business elites. The municipality is much larger than Tenango del Aire, and its population is fairly heterogeneous. Thus, it resembles Williams and Adrian's (1963) heterogeneous communities: "The fourth type of community [which] is very diverse, with many interest groups competing for political advantage” (Box 1998: 52). As noted by Box, "in this hyper pluralistic environment the highest value is [usually] placed on political responsiveness” (ibid.). Moreover, the decision-making process is usually "characterized by changing and accessible groups of people involved in specific issue areas" (Waste 1986, 13-25, cf. Box 1998: 45). According to interviews, this municipality does receive 
and respond to petitions/demands made after the election process. However, although one can adopt the pluralist view of community leadership, ties of the municipality with the PAN political party makes the primary concern of the government the promotion of economic growth, as in the promotion cities. Or, as in the development regime proposed by Stone, the municipality is "concerned primarily with changing land use in order to promote growth (Stone 1993: 18)” (ibid.).

In San Andrés Cholula, the pluralist lens offers the best view of community leadership, highlighting the ever-present pressure felt by the municipality from diverse groups trying to affect the decision-making process. Municipal authorities in San Andrés Cholula received petitions throughout the year for various infrastructure projects. They recognized that in many cases, private funding to match government investment influenced the prioritization of projects. The municipality acknowledged giving preference to proposals which could be partly funded by the private sector. Thus, the municipality can be viewed as Accessible and as having an Open Governance system, especially if the interests pushing for influence are in alignment with the growth machine, the pushing for a vision of community as a marketplace.

San Andrés Cholula is composed of six townships; the township of Santa Maria Tonantzintla is a rural township competing for resources with more urban and wealthy townships in the municipality. For example, the Angelopolis zone is one of the most urban and wealthy zones in the metropolitan region of the municipality and the home of a shopping mall, Centro Comercial Angelopolis (which contains a movie theater, and several high end retail shops like Lacoste, Hugo Boss, Mango, Tous, Omega, Prada, etc.), and various wealthy home residency enclosures, such as La Vista Country Club and 
Lomas de Angelopolis, as well as several sky scrapers. An astrophysics institute is located within Santa Maria Tonantzintla, which attracts students and professors from around the world; however, this sector of the population, has, with an exception of a short period of period of time in the $1980 \mathrm{~s}^{24}$, remained fairly insulated and not involved in local politics. Hence, community representation and leadership is exercised from agricultural constituents. According to the literature, "There are tensions between the relatively urbanized "capitals" of municipalities (cabeceras) and their rural hinterlands, which also fall under the jurisdiction of local authorities. The traditional complaint [... being] that the areas outside the administrative center of the municipality are neglected even by the local government (for México, see Fox \& Aranda, 1996)” (Rowland 2001:1381). Interviews with the auxiliary presidents of Santa Maria Tonantzintla indicated that their township was neglected by the municipality not because it was outside of the 'capital' but because its constituents represented an agricultural base instead of a pro-growth business class.

\subsection{Sources of Revenue}

The self-governing status of the states and municipalities is constitutionally entrenched in national level legislation. However, the nature of intergovernmental relations has for the most part implied that states, as well as the central government, play an important role in municipal affairs (Rowland 2001). As Rowland has pointed out, "until national constitutional reforms in 1999, municipalities in México were technically an administrative branch of each state, and loyalties within the PRI (ruling party)

\footnotetext{
${ }^{24}$ Interview with community activists indicate that during the 1980s, the institute's faculty actively promoted community development.
} 
traditionally meant the subordination of municipal government to the wishes of the state governor (Fagen \& Tuohy 1972; Graham, 1968)” (Rowland 2001: 1378). Prior to the constitutional reforms of 1999, states had the authority to take over local tasks, such as the management of municipal public services, without the consent of the municipalities. The reforms of the 1990s, as well as the election of mayors and state governors from opposition parties, have altered municipal-state relationships; however, states still hold some power over municipal affairs (Rowland 2001). For example, municipal budgets and other development plans still require approval from state legislatures (ibid.).

Overall, however, the allocation of responsibilities and sources of revenue to states and municipalities follows the guidelines for decentralized government (Rowland 2001). Municipal governments have exclusive authority over property taxes and charges for local public services; however, for most local governments, the main source of income continues to be monetary transfers from the central government (ibid.). Transfers from the central government are twofold. The system of federal revenue-sharing (participaciones) transfers funds from the central government (20\% of the national income from taxes) to the states (according to a formula that accounts for tax effort, population, and poverty levels), and then states allocate funds (approximately $4 \%$ of the total national fund) to their local jurisdictions (ibid). As of 1998, municipalities also have access to formula driven direct/targeted funds from the central government (aportaciones) that bypass the state government (ibid.). Section 33, which transfers direct grants from the central government to states and to municipalities, is divided into eight funds that are distributed according to a formula that accounts for municipal population, poverty, and the isolation of the jurisdiction. The eight funds comprising Section 33 are: 
Funds for Basic Education (FAEB); Funds for Public Health Services (FASSA); Funds for Social Infrastructure (FAIS) which includes (a) Funds for State Social Infrastructure (FISE) destined for public infrastructure projects of general benefit/intra-municipal and (b) Funds for Social Municipal Infrastructure (FISM) destined for public infrastructure projects in municipalities; Funds for the Federal District (FORTAMUN-DF), Funds for Multiple Use (FAM) such as (a) Social Assistance used for alleviating extreme poverty and (b) Funds for Educational Infrastructure for basic and higher public education such as construction, equipment and rehabilitation of physical infrastructure; Funds for Adult \& Technical Education (FAETA) including (a) Information Technology Programs and (b) Adult Education; Funds for Public Safety (FASP); and Funds for the Strengthening Federal Entities (FAFEF) (ORIFIS 2013).

Three sources of revenue—-self-revenue (which is money collected from granting building permits, licenses, etc.), federal revenue-sharing funds, and direct grantscompose the total municipal funds available. In the case of San Andrés Cholula, selfrevenue comprised $51.33 \%$ of the funds available to the municipality in 2012, and was the largest source of revenue, followed by funds distributed by the state, which comprised 21.94\% of the municipality's resources, and federal 'earmarked' funds, or Section 33, which comprised $20.66 \%$ of the funds available (from financial records provided by the mayor). In contrast, self-revenue was the smallest fund available to the municipality of Tenango del Aire. According to interviews with the Secretary of the Municipality of Tenango del Aire, his municipality has access to approximately one million pesos yearly from self-revenue, approximately ten-to-thirteen million pesos yearly from Section 33, and approximately one-to-two million pesos from the state government. In general, 
municipal funds are used for recurrent expenditures rather than investments (Rowland 2001). Mayors from both municipalities indicated that funds given to them for social infrastructure by the federal government are formula driven. In my interview with Juan Marcos Gutierrez Gonzalez ${ }^{25}$, he acknowledged that-a result of constitutional changepolitics are no longer a factor in the release of funds. Prior to the constitutional change, 'aportaciones' were distributed at the discretion of the national government. Sometimes they would be withheld depending on political issues. Now, funding through Section 33 follows a particular procedure and municipalities know exactly how much and when funds will arrive-and this is not subject to last minute changes (ibid.).

In both municipalities, mayors were asked about the discretion granted to them in decisions regarding the allocation of social infrastructure funds and any restrictions associated to specific funds. This was done in order to determine how autonomy or lack thereof affected the municipal decision-making processes. Mayors in both municipalities concurred that they had full discretion in determining where to allocate resources obtained from self-revenue. They also had full discretion over the allocation of resources obtained from participaciones. However, for projects requiring funds from Section 33, both mayors were aware of the restrictions imposed and the resulting limitations to their discretion when using them.

\footnotetext{
${ }^{25}$ Juan Marcos Gutierrez Gonzalez was a principal actor in reforming the Fiscal Coordination Law in México; this reform assured the release of funds, through federal transfers, to states and cities and assured transparency of the shares in 1999.
} 


\subsection{Auxiliary Perspective}

In San Andrés Cholula, auxiliary presidents were noted by the mayor to play an important role in the decision-making process. Thus, three successive auxiliary presidents from Santa Maria Tonantzintla were interviewed. ${ }^{26}$ Auxiliary presidents are elected every three years. The township of Tonantzintla is composed of three boroughs, San Miguel, San Diego de Alcala, and San Pedro. According to interviews with the residents of the township, representatives from each borough take turns running for office and running the administration. Thus, the auxiliary president in office from the latest term included in this study (May 2011-May2014), was from San Miguel, the president before him was from San Diego, and the one before him represented the residents from San Pedro. The election process of auxiliary presidents, based on rotation in office according to borough, is un-legislated, but was confirmed by all three auxiliary presidents. According to an auxiliary president, this rotation of representation takes place "It is not a tradition. It was a decision [...]. It happened because people from only two barrios, San Miguel and San Diego, were being elected. So now, yes, we have a rotation” (auxiliary president May 2008-May 2011 term). The system of rotation was adopted from the religious practice of rotating representation of each chapel, and its parish, in the administration of main church in Santa Maria Tonantzintla (ibid.).

${ }^{26}$ The term limits and respective boroughs of the interviewed auxiliary presidents were the following: President C. Samuel Tecuatl Toxqui (May 2011-May2014) from San Miguel, Lic. Guillermo Ramos Cuautle (May 2008-May 2011) from San Diego, C. Salomon Huepa (May 2005-May 2008) from San Pedro. 
Each one of the boroughs in the township of Santa Maria Tonantzintla has a chapel that is run by individuals referred to as "principales"27. According to interviews with community members and the auxiliary presidents, the "principales" from each chapel take turns being "mayordomos" 28 for the town church of Santa Maria Tonantzintla. The practice of rotating representation by borough, in the administration of the main church, was adapted 'unofficially' by the civil sector to guarantee the equal representation of boroughs in administration of the auxiliary junta of Santa Maria Tonantzintla ${ }^{29}$. As noted by a resident speaking of the township politics, "The church

27 The term "principales" appears in the literature on the evolution of $16^{\text {th }}$ century status groups in México and the cargo system (also known as the civil-religious hierarchy, fiesta or mayordomía system). According to Chance's (1985) discussion on $18^{\text {th }}$ century status groups, there were "the caciques (those who claimed descent from pre-Hispanic ruling families), principales (second-echelon nobles), and macehuales (commoners). [...] only the rank of cacique was determined strictly by inheritance. The statuses of principal and macehual were determined by a contradictory mix of both ascription and achievement (via cargo service). It was often said that there were two kinds of principales de-nacimiento (by birth), and de oficio (by office). [...]Since these were small communities, this ladder of achievement was open to all. [...] The civil cargo system thus had a well-defined internal structure and set of motivations that were responsible for its perpetuation. Caciques and principales by birth sought political office as a means to legitimate their high rank in the absence of wealth or other tangible indicators. Macehuales sought the same offices in order to escape their com-moner status and enter the ranks of the lower nobility. The rewards that the system offered its participants were not all internally derived, however. The [...] hierarchy was a creature of colonialism in the fullest sense" (Chance 1985:16). Today, indigenous men, after passing through a series of ranked offices, "cargos," both civil and religious, which make up the cargo system, and entail "taking on civic duties one year, sponsoring important religious fiestas celebrated in the community the next, and so on. [...] as old men, they attain the status of elders, or "principales," and have considerable authority in local decision-making)” (Friedlander 1981:132).

28 "The mayordomo is a secular figure responsible for organizing major fiestas in small communities throughout México and is generally in charge, or financially responsible for, the local saints. These individuals often represent the parishioners [of their chapel] before the parish priest” (Camp 1997: 26). In Tonantzintla, in addition to the mayordomos' duty planning parties, they maintain the inside of the church, they serve as a Sacristan. The principales from each borough in Tonantzintla take turns serving as mayordomo in the town church.

${ }^{29}$ The specific date when the adoption of this system of rotation was adopted by the local government was not clearly indicated in the interviews. However, upon further inquiry, it was noted that what was being observed was an adaptation of the cargo system (also known as the civil-religious hierarchy, fiesta or mayordomía system) in the civil/political life of the township. Specifically, the essential features of the cargo system (civil-religious hierarchy) identified by Dewalt (1975) are the following:

"1) it involves voluntary service without remuneration (although in most communities there are strong social and/or physical pressures upon individuals to participate in the system); 2) holders of civil or religious offices (cargos) perform most or all of the 
functions necessary for the running of the local government and/or the church; and 3) tenure in these offices is rotated, usually annually, to other members of the community. [...] Traditionally, passage through the complete system of hierarchically based offices has been the most important means of acquiring prestige in the community" (ibid.: 90).

The series of ranked offices 'cargos, in Spanish' was established during the colonial era when "villages came under the control of the religious orders" (Friedlander 1981:69). Because the indigenous members of society were not allowed to become priests, the Spanish missionaries established an elaborate substructure of religious posts to accommodate them and to facilitate their religious conversion and instruction (ibid.). Moreover, they combined secular and religious duties. "In keeping with the traditions of the peninsular Church, [were] encouraged [...] to organize elaborate processions with crosses, saints, incense, flowers and music [... which] ensured a generally high spiritual level in a village as their members could be counted on to monitor others in the pueblo" (Friedlander 1981:69). In Santa Maria Tonantzintla there are several processions and fiestas (parties in English) to honor particular saints. Each chapel in the township, for example, has a patron saint that is celebrated. These parties include free food (usually mole) for the participants, music and dance as well as firecrackers and fireworks displays - the cost of which add up to a substantial amount. In addition to the fiestas celebrating saints, the main church of Santa Maria Tonantzintla has its own parties celebrating the Virgin Mary and Christmas. The 'principales' and 'mayordomos' are obligated to incur the cost of feasting or to gather the funds from the community. "Ethnographers characterize the 'traditional' or 'classic' form of the system as a hierarchy of ranked offices that together comprise a community's public civil and religious administration [...] All local men are expected to ascend this ladder of achievement during their lifetimes, alternating back and forth between civil and religious posts. Each elective office, or cargo, is held for one year and there are numerous 'rest periods' along the way. The higher the cargo served, the greater the prestige enjoyed by the carguero and his family. Such rewards do not come without a price, however, for many cargos, especially the higher ones, require substantial financial outlays. Those who have the resources and longevity to make it to the top of the hierarchy retire from the system and join a select group of town elders. These elders, or principales, are men who have proven their moral worth and often exert considerable influence in local affairs. Overtly Spanish in structure, but with some indigenous underpinnings, this classic form of the system includes the offices of municipal government on the civil side, and positions in sodalities (cofradias or mayordomias) honoring the Catholic saints on the religious side. The expenses and associated prestige are connected with individual sponsorship of fiestas and other ritual occasions held for the local saints.” (Chance 1985:14)

As the cargo system evolved, "details varied from village to village, but all hierarchies were similar in that they encompassed the formal political offices introduced by the Spanish, as well as a few more lowly posts that probably had a pre-Hispanic basis" (Chance 1985:14). Moreover, as noted by Eric Wolf (1982) "The civil-religious hierarchies thus installed a system of elite domination within the communities, while at the same time allowing that elite to represent the community as a whole before external power holders and authorities" (ibid.: 148). Under this system, indigenous residents assumed the responsibility of organizing fiestas and managing local administrative affairs (Friedlander 1981). The system was so successful that "it [was] adopted by the defiantly anti- Catholic post-revolutionary government. [...M] any twentieth-century secular ideologues, like their religious predecessors of colonial times, have been providing the spiritual justification for a socioeconomic policy that maintains an identifiable indigenous population. To transmit the modern version of the old message, the government uses the structure of the traditional fiesta system, encouraging local political leaders, who represent the PRI platform, to take an active role in sponsoring the celebration of México's major national heroes and events" (ibid.: 139). More recently, programs like PRONASOL have utilized traditional indigenous practices to induce civil participation (Beneria \& Breny 1995). Moreover, although "today the civil offices and the mayordomo positions do not have an explicit relationship to one another [...] it is not unusual for a villager seeking a political career in the pueblo to volunteer regularly to serve either as a mayor-domo in a religious fiesta or as a presidente de fiestas patrias in the secular cycle" (Friedlander 1981: 140). Interviews with residents of Santa Maria Tonantzintla 
plays a big part. We say it doesn't, that the church is very different and independent from Cesar, but as they say, customs become laws [...] sometimes there is a conflict with the church officials, someone will be running for president with support, but the church says it is not their turn, and then he doesn't win. So that is how politics works."

One of the questions sought after was if, as a result of this system of rotation, the auxiliary presidents felt obligated to prioritize projects from their borough over projects of general benefit. The simple answer was yes. As stated by one of the auxiliary presidents, "The rotation is illegal. [And] it is not a tradition; it was a decision by not-sowise people. [...I]nstead of projects being carried out that benefit the whole community, we have to meet the needs of the people who we promised we would help. We get pressure to get these projects done first” (auxiliary president from the May 2008-May 2011 term). Thus, after meeting the demands set during the election campaign, the auxiliary presidents create plans for development, including large-scale general benefit projects. Unfortunately, the auxiliary presidents interviewed indicated that they believed the municipality does not like to, or does not have the funds to, implement these projects. Thus, the desire of the municipality to fund several small-scale projects instead of fewer large-scale projects reinforces the prioritization of the projects promised during the campaign, which for the most part, only represent the needs of a specific borough. As noted by another auxiliary president; “They [the municipality] obtain property taxes, fees from permits for businesses, federal funds, but [we are] not allowed to collect money to implement any projects. As money came in, we carried out projects; unfortunately every

indicated that this ladder of ascension into political life is often used in the community. While further investigation as to the inner functioning of the cargo system in Santa Maria Tonantzintla would provide insight into the nature of leadership in the community, for this particular section what was of interest was understanding how this rotation in office affected the decision making process of local auxiliary presidents. 
year the municipality decreases the funding of projects” (Auxiliary president May 2005May 2008 term). Because of the lack of money, and "because we already committed ourselves to specific, smaller projects promised during the campaigns, the funds get used up quickly in small things from one borough" (ibid.). Moreover, it was noted that in general, the municipalities prefer to implement smaller, less expensive projects. ${ }^{30}$ As a result, “[...] people say they want a road, not drainage because it looks better. And because it is cheaper at the moment, the government says nothing, it is political. [T]he road gets built, not the drainage and everyone loses in the long run” (ibid.). Likewise, as stated by one of the auxiliary presidents regarding a large infrastructure project of general benefit he considered during his administration, it “... cost too much, the municipality preferred to have 3 smaller impact side roads paved because these cost less" (auxiliary president from the May 2008-May 2011 term). The neglect of projects of general benefit in the township center is coupled with the problems resulting from a lack of proper record keeping.

When an incoming auxiliary president enters office, he/she aims to address obligations and actions pledged during the campaign; there are no regulations for record keeping and continuity to economic development policy, so projects that were under consideration by the previous administration are not initiated. When asked if past projects—prioritized by previous administrations but not implemented—influenced the selection of potential projects, all three auxiliary presidents indicated that previous administrations did not maintain a list of suggested projects. However, when the

${ }^{30}$ The consensus was that in general, large projects of general benefit are rarely implemented and when they are, they are mostly taken up by the municipality without direct consultation with auxiliary presidents and for most projects proposed by the auxiliary junta; only small projects seem to be prioritized by the municipality. 
presidents were asked if they left a list of suggested projects for the incoming president to consider, one of the three auxiliary presidents indicated that yes—-he had left a list. All the projects on his 'list' were of general benefit:

1. The creation of a craft/artisanal center to create local jobs and help the economy;

2. The expansion of the local cemetery, which is currently filled beyond capacity;

3. Expansion of the auxiliary junta;

4. The purchase of a field for recreational purposes (e.g., Soccer, etc.) (Auxiliary president from the May 2005-May 2008 term).

The auxiliary president emphasized that none of the presidents who had taken office after his departure in 2008 have given priority to any of those works. He felt that they are important and should be considered. When probed further, the president who came after him indicated that "Yes, presidents can leave a list of projects that they feel should be carried out, prioritized by the next president. However, it is up to the next president whether or not to prioritize them, or carry them out. However, typically no projects are left undone and thus are not resumed by the incoming president” (Auxiliary president from the May 2008-May 2011 term).

When asked about rules set by the municipal/state/federal government regarding the use of funds, all presidents indicated that there were none. As noted by the auxiliary president from the term between May 2011 and May 2014, “We don’t have any rules as 
to how to use funds. We depend on monthly allotments from the municipality. This covers salaries. We don't get funds from the state or the federal government. If we do get money, it goes to the municipality and this is then distributed to the juntas auxiliaries [...] but overall, we have autonomy from the municipality to allocate it where we want it.” Notably, two auxiliary presidents ${ }^{31}$ indicated that relationship quality (i.e., good standing/bad standing) between the municipal, state, and federal governments - in terms of political party-affiliation at each level-is a factor in implementing projects. As one president indicated, "It has a big role; it is important that the political party at the municipal level is the same as that in power of the state and federal level. It has a big role in terms of carrying out more public works. Lots of times when the municipality is of one color [political party], and the state is of another, there are difficulties when the municipality tries to obtain funds” (Auxiliary president from the May 2008-May 2011 term). However, the other auxiliary president indicated that if the political parties in power at the auxiliary and municipal levels differ, the auxiliary office can directly petition the state for funds (if the same political party is in power at the auxiliary and state levels). As indicated by one of the auxiliary presidents, "Sometimes a municipality has one party, and the state is another, you can jump to the state” (Auxiliary president from the May 2005-May 2008 term). For example, this interviewee continued, “To fund the potable water project, the auxiliary government wanted to carry out the project but the municipality was putting it off, so we approached the state government for help in getting the project prioritized” (ibid.). He cited an example of a secondary school that needed

\footnotetext{
${ }^{31}$ Only the current president (C. Samuel Tecuatl Toxqui) (May 2011-May 2014) of San Miguel indicated that it did not play a factor.
} 
new classrooms, and he obtained funds from CAPCE (comité administrador del programa federal de Construcción de Escuelas), and jumped the municipality level (ibid.).

All auxiliary presidents interviewed indicated that there was no set amount of money they were told they would receive during their administration for public works. They indicated that there was no formula-driven allocation of resources and no transparency in the allocation of funds from the municipality to their respective auxiliary juntas. Moreover, two of the auxiliary presidents indicated that funding decreased with time. ${ }^{32}$ Every year, less money was received from the municipality to implement projects. According to one source, "There is a political part to this funding allotment. If you don't do this, they don't give you the money. They try to put back projects and not get them done. [...] And you never know what fund of money they are using [...] if it is Section 33 or what” (Auxiliary president from the May 2008-May 2011 term). Thus, although the fiscal decentralization reforms helped municipalities by making the distribution of federal resources formula-driven, such that municipalities could plan for expenditures given their expected allotment, auxiliary juntas do not know what they will receive from year to year, and, thus, financial planning is not possible. In other words, "The municipality handles the money. The money is federal, goes to the state and then to the municipality. [...Auxiliary juntas] are not the ones who have money, [...they] just push for projects and they [the municipality] say whether or not they have the money" (Auxiliary president from the May 2005-May 2008 term).

Projects are prioritized during the election campaign of the auxiliary presidents; these projects, for the most part, represent the needs of only a subset of residents from a

32 The most recent auxiliary president had just entered office and thus had no experience with receiving funds. 
specific borough within the auxiliary junta. However, auxiliary presidents indicated that they submit petitions to the municipality throughout the year for projects they aim to implement. The projects are sent to the municipality—some are funded and others rejected. It is the auxiliary presidents who channel the demands of the citizen committees under study. The citizens who organize themselves into committees for a particular social infrastructure project can petition the municipality directly, but as noted through interviews $^{33}$, the support of the auxiliary junta in which they reside is very important. "If an auxiliary president doesn't act, the project doesn't get carried out. Lots of times the presidents don’t pressure and nothing gets done. We can solicit 20 works to be carried out but only three-to-four will be carried out” (Auxiliary president 2005- 2008 term).

\subsection{Citizen Committees}

As mentioned above, Section 33 of the Fiscal Coordination Law (LCF) transfers resources from the federal government to the municipalities. These resources are earmarked for projects that meet the basic needs of municipal residents. In other words, they are earmarked for the creation of infrastructure for potable water, sewage systems, drainage and latrines, urbanization, electrification of rural and poor neighborhoods, and basic health infrastructure, infrastructure for primary education, improvement of local housing, rural roads, or infrastructure for the promotion of productive rural areas (FUNDAR February 2006).

According to the laws regulating Section 33, municipalities, in order to receive resources from FISM and FORTAMUN-DF, have to prove that there was citizen

\footnotetext{
${ }^{33}$ Interviews with citizens and citizen committees
} 
participation in the processes of planning, prioritizing, monitoring, controlling and evaluating the projects to be implemented with these funds (ORIFIS 2013). Thus, in the planning and controlling of the public works utilizing FISM resources, the municipal authorities must identify the form of citizen participation utilized. A study conducted by the FUNDAR Center of Analysis and Investigation in México found that there were several instances of citizen participation named by municipalities when discussing FISM resources in México. At the community level, the level of interest for the present study, FUNDAR (2006) noted the mention of "Comités de obra pública” (Public Works Committees, in English) which operated at the neighborhood level and were comprised of individuals who benefited from the public work being carried out. At the municipal level, the instances of citizen participation noted were, "Consejos de Desarrollo Social Municipal," and "Consejos de Participacion Ciudadana." Moreover, in the State of México, FUNDAR also noted the mention of "Comites Ciudadanos de Control y Vigilancia (COCICOVI)" (Citizen Committees of Control and Vigilance, in English) by municipal authorities in relation to the inclusion of citizen participation in the use of FISM resources (ibid.). COCICOVIs were also said to operate at the neighborhood level, as were the "Public Works Committees." In any case, all the "instances" of citizen participation working at the neighborhood level are the descendants of Solidarity Committees and what this study designates as citizen committees.

The predecessor of Section 33, PRONASOL hoped to increase transparency and accountability in the use of funds for social development projects through the use of Solidarity Committees, the descendants of the current-day citizen committees or “instances of public participation at the neighborhood level.” PONASOL introduced, for 
the first time, the intervention of the beneficiaries of public works as vigilantes, monitoring the use of funds and the quality with which public works were implemented in their communities. These mechanisms of citizen participation (solidarity committees) developed under the structure of PRONASOL (specifically under the Ministry of Programing and Budget, Secretaria de Programacion y Presupuesto) and subsequently placed under the supervision of the Ministry of Social Development (Secretaria de Desarrollo Social, SEDESOL). At a general level however, it was the Ministry of the Controllers (Secretaria de la Contraloria General de al Federacion, Secogef), today's Ministry of Public Administration (Secretaria de la Funccion Publica, SFP), which, through the predecessor of the current Integral System of Social Accountability (Sistema Integral de Contraloría Social, SICS), was placed in charge of sanctioning the public functionaries when and if they were not following the new regulations for promoting transparency in the use of funds (Fernandez Mejia 2012:15).

In the study sites utilized for the present investigation, citizen participation operating at the neighborhood level differed in each municipality. In Tenango del Aire, participation occurred through COCICOVIs whereas Public Works Committees (Comites de Obra) operated in San Andrés Cholula. Notably, compared to San Andrés Cholula, which has a Directive of Citizen Participation, in Tenango del Aire the Internal Municipal Comptroller (Contraloría Interna Municipal) supervises financial and human resources in the municipality and oversees the COCIVOVIs. The Internal Municipal Comptroller, in turn reports to the State's Controller's Secretariat (which regulates citizen participation in state municipalities), which in turn reports to the federal Ministry of Public 
Administration. This organizational feature resembles that which was originally stipulated by PRONASOL.

As mentioned above, the predecessor of the Ministry of Public Administration, an agency of the Federal Executive, through SICS, was the umbrella organization that monitored adherence to the law and penalized those administrations that were not complying with the regulations of PRONASOL. The Integral System of Social Accountability was designed to promote participation from direct beneficiaries of public policies, and the general citizenry, in the care and vigilance of social programs with two main goals: (1) to prevent corruption and (2) to promote active participation and responsibility of all sectors in society to fight against corruption and to promote a culture of transparency regarding the law (SICS: 2004). Tenango del Aire is one of the twentyfour municipalities on the eastern part of the State of México. Thus, the Internal Municipal Comptroller of Tenango del Aire responds to the Easter Zone Delegation of the State Controller, whose office is in the municipality of Chalco.

This structural feature-positioning COCICOVIs under the supervision of the Internal Municipal Controller-contrasts with that of San Andrés Cholula. In the municipality of San Andrés Cholula, citizen committees in San Andrés are placed under the supervision of the Directive of Citizen Participation, which falls under the direction of the Ministry of Interior, which also oversees the Auxiliary Juntas but is not linked to the Municipal Controller's or the State Controller's Secretariat. The Municipality's Comptroller is a separate branch within the municipality that oversees the Auditing of Public Works, Finance Audits, Internal Affairs, the Office of Transparency and Evaluation of Procedures and Internal Legislation. According to my interview with Juan 
Marcos Gutierrez Gonzalez, ${ }^{34}$ the placement of citizen committees within the organizational chart of the municipality varies from municipality to municipality as a result of the liberty granted to them to specify and regulate the citizen participation needed to solicit funding from Section 33.

The inclusion of citizen committees as a requirement for the assignment of FISM from Section 33 of the Fiscal Coordination Law (LCF, Spanish acronym) has had a far reaching effect on the allocation of all resources for social infrastructure. When mayors in the study sites were asked if the state or federal governments regulate allocation of funds by the municipality, both answered that the only rules for the allocation of SIF are for the allocation of resources from Section 33 of the LCF. However, the head of a project in San Andrés Cholula indicated that although for "the money we collect from licenses, permits, etc., there are no rules because we are a 'free' municipality, we try to utilize the same rules [for Section 33] because that guarantees us that there is more clarity in the way we use the funds.” The use of the same rules from Section 33 in the allocation of all funds was clarified to mean, that among other things, that the municipality tries $^{35}$ to use citizen committees when investing in social infrastructure with a municipality's own revenue, not just when using revenue from FISM. In the municipality of Tenango del Aire, the use of COCICOVIs is mandatory, regardless of the origin of funds, according to state law. Both Public Works Committees and COCICOVIs are instances of citizen

34 Juan Marcos Gutierrez Gonzalez was a principal actor in reforming the Fiscal Coordination Law in México; this reform assured the release of funds, through federal transfers, to states and cities and assured transparency of the shares in 1999.México

${ }^{35}$ As will be noted later, 'public works committees' are not always used. 
participation that can be considered citizen committees and their differences will be noted later in the text.

\subsection{Function and Treatment of Citizen Committees in Each Municipality: A Preliminary Typology of Citizen Committees}

As discussed above, in the Municipality of Tenango del Aire, COCICOVIs are supervised by the Internal Municipal Controller, as their predecessors, the Solidarity Committees under PRONASOL also fell under the supervision of a financial accountability controller's office, albeit at the federal level. Moreover, as indicated by the head of the Internal Municipal Controller's department, "The function of the COCICOVIs is to monitor the responsible execution public works," much as the Solidarity Committees were to provide care and vigilance over the execution of social programs provided by PRONASOL.

The Internal Municipal Controller's department is comprised of three employees who maintain constant contact with the Public Works Department (who informs them of the project that will be implemented during the year) and the State Controller's office in Chalco who "gives them the paperwork to form COCICOVIs" (ibid.). As stated by the head of the department:

"When the Municipal Plan of Development and the priorities have been established, we go to the neighborhoods where the projects are to take place and inform the public by calling a meeting. At least a minimum of twenty people go to these meetings. The day of the meeting we go, along 
with the state [controller's] office and ask the public to form a group [COCICOVI ...]. We don't place them, they vote for themselves who they want to have as representatives. They are given the paperwork of the project: the physical plan of the project, the estimated costs of materials, labor, etc. and a timeline. They are to monitor that the project takes place accordingly.”

Consequently, the Internal Municipal Controller's office is charged with informing and involving the public once the priorities in the municipality have been established. According to my interviews, when the municipality has prioritized a public work, the office of the state Controller in Chalco sends a delegate to observe the formation of the committee: the COCICOVI. The citizens are given the physical plan of the project that is to be implemented, including budget and timeline. Paperwork on the group members is maintained not just in the municipality but in the state's controller's office. Thus, the state office plays a central role in overseeing groups and monitoring and abating (indirectly) use of funds by the municipality.

Because private companies are contracted in Tenango del Aire to implement public works, COCICOVIs monitor use of public funds by private entities. Citizen participation through citizen committees in Tenango del Aire is a mechanism of control, supervision, and vigilance over contracted public works companies as well as a mechanism for maintaining fiscal transparency. All the public functionaries interviewed indicated that a COCIVOVI needs to be formed to implement all public work in the community. As mentioned above, citizen participation is a requirement to receive federal 
funds from Section 33. However, the municipality sees themselves using COCICOVIs to implement all projects. Thus, COCICOVIs are not just mechanisms of financial control and vigilance of FISM resources from Section 33, but all resources in the municipality used for public works. The COCIVOVIs function to monitor that projects are implemented as specified, but also to promote transparency regarding use of funds and the cost of projects. Their lifespan is limited to the period after the project has been selected until project completion. There are no other forms of citizen participation recognized by the municipality that resemble citizen committees. Moreover, other than citizen participation in elections, the data gathered from municipal interviews points to a lack of participation in the decision-making process. As stated by the mayor of Tenango del Aire, “The municipality is very apathetic. They don't participate outside of elections"36.

As noted above, positioning COCICOVIs under the supervision of the Internal Municipal Controller, instead of under the directive of Citizen Participation-like the Public Works Committees are in San Andrés Cholula—is one of the many differences between the citizen committees in each municipality. The directive of Citizen Participation in San Andrés Cholula, which "is in charge of citizen participation in the whole municipality” (interview with head of directive), is comprised of five people. Because they are not tied to the Internal Municipal Controller, their official "function is not to secure the proper use of funds by the municipality" (ibid.). According to the interview with its director, "the official task of the directive is to try to get people to participate” (ibid.). Unfortunately, according to them, “people don’t know what citizen

\footnotetext{
${ }^{36}$ The citizen participation inlets open to NGOs, and the business community, allows for un-official networks to develop that do allow for a sharing of ideas regarding priorities in the municipality.
} 
participation is, so people go directly to the auxiliary junta but not to the office of citizen participation" (ibid.). As a result, "the office does not get consulted by citizens soliciting public works, services or representation” (ibid.). Thus, as stated by the Director of Citizen Participation "[Their] job is to work as part of the municipal authority trying to facilitate the carrying out of specific projects prioritized by the government.. ${ }^{37}$ And although they "have no authority in the decision-making process or in determining the allocation of funds from Section 33, [...they] do serve to overlook the formation and actions of the 'Comités de obra pública’ (Public Works Committees, in English)” (ibid.). According to my interview with the head of Citizen Participation, their relationship with citizen committees is direct, starts with the formation of the citizen committee, and is mostly one directional. When asked if citizens or group members come to the office soliciting a public work, or needing help or backing to promote a particular project, the director stated;

"No, we go to them. Once a particular project has been prioritized, we go to the specific auxiliary junta; we call a meeting to make sure everyone is aware that a certain project is going to take place. We go door to door and make sure they are informed of what is going on. And then we record the members of the newly formed group. We try to make sure that the right individuals are chosen, the ones most affected, and we also try to make sure they pick people who will be successful, who will not obstruct the

\footnotetext{
${ }^{37}$ Every Thursday morning (Jueves ciudadano, in Spanish) the mayor holds an open meeting with the public to hear the complaints, demands, or comments of the citizenry. However, it is the mayor himself who is in charge of carrying out these events. The current mayor decided to open up the government to the people, and not the directive itself.
} 
public work. They are going to be the ones of facilitating the work; we don't want the work stopped, and we want a smooth process to take place.”

Moreover, the group essentially dissolves once a public work is completed. "The lifespan of the group is the lifespan of the project. Once the project is done, the members of the group have to sign off stating that the work is done, that they are content with the work" (ibid.). In this aspect, they were similar to the citizen committees used in Tenango (i.e., the COCICOVIs). When asked if citizen committees always formed when the municipality initiates a project (e.g., construction, service expansion), the answer was no. However, the director indicated that for the most part, the municipality tries to form committees for all public works. In his words, "Well, up until this point this has been the most efficient way to get consent for a project and get a project done. So, yes, we count on them." Exceptions to the norm of having Public Works Committees formed to support public infrastructure works were noted, for example, regarding schools; the interviewee indicated that he does not deal with construction of schools or school-related projects;

"No, we don't deal with the construction of schools; that is public education. It is separate. They have committees themselves, unique to them. It is not part of us. The trustee of public education is in charge of them. He [the trustee of public education] deals with those committees to carry out those projects. So, I don't know of projects with schools. We only deal with drainage, water, paving of streets. Hospitals are also 
different so yeah, they must deal with someone else, also building of stadiums or large-scale projects."

The other funds from Section 33, such as that for public education ${ }^{38}$ and health, do not require proof of citizen participation and thus the municipality does not utilize the input of the directive of citizen participation to form citizen committees to partake in implementing those projects. In any case, the director of citizen participation indicated that he maintains a record of all the citizen committees formed ${ }^{39}$;

"Yes, we have a document for each public works taking place in the municipality. The public works office also has a file of the documents with the cost of the projects, etc. We just have information of the committees. We help with the social part of the project, making sure that the committee keeps on working with the people of their community to make sure the project takes place.”

Unlike the municipality of Tenango del Aire, the state government does not maintain records of public works committees. Moreover, the directive of citizen participation does not maintain a financial record of projects as the Internal Municipal Controller does for

\footnotetext{
${ }^{38}$ However, to understand what committees were formed to support public education infrastructure, the trustee of Public Education was also interviewed and he signaled the use of parent committees to oversee the projects implemented in their area.

${ }^{39}$ However, he did not have a file of the works implemented during the previous administrations. Moreover, as mentioned above, because there is rotation in office, most departments and directives clear out their offices when a new president comes in.
} 
projects in which COCICOVIs participate in Tenango Del Aire. This is an important difference. The function of the Public Works Committees in San Andrés Cholula is not to oversee the spending of FISM funds by the municipality. Public servants view Public Works Committees in their municipality as a mere necessity to meet the requirements for using SIF from Section 33's FISM. Moreover, they see them as a tool to help the municipality gain community support for its projects. They do not view them as a tool that can serve to provide community controls over the assignment or use of resources. In general, there is a lack of transparency over the financial information provided by the municipality regarding projects carried out utilizing Public Works Committees. The Department of Public Works manages financial information as if it were confidential; project budgets are not presented to the Public Works Committees who oversee projects. After projects are approved, they are implemented and the committees serve as proof of citizen participation. There is no oversight by the state government over the directive of Citizen Participation and its management and treatment of citizen committees.

In any case, according to the LCF, beneficiaries of FISM projects operating in the municipality may contribute material resources, free labor, or money to projects. Nevertheless, such contributions should not serve to impede the implementation of projects in marginalized communities. Moreover, the municipalities accepting donations should maintain a detailed list of contributions made by beneficiaries (ORIFIS 2013). However, as mentioned by the FUNDAR study, states vary in regard to citizen participation "instances" named, and, I would add, vary as to whether or not the municipality accepted contributions from project beneficiaries. While the internal municipal controller of Tenango Del Aire stated that no monetary contributions are ever 
collected by the COCICOVIs or expected to be made on their behalf or the behalf of other of project beneficiaries, ${ }^{40}$ the Director of Citizen Participation in San Andrés Cholula stated that "According to the law, they [citizen committees] have to put $20 \%$ of the money for the public work to get done"41. To put the comment in context, he went on to say:

“Sometimes we get a street paved, and in the process, somebody's wall has to be taken down. We make sure they are OK and that they get reimbursed by the rest of the beneficiaries. That money is does not come from Ramo 33 but from the community members. That is why we need the public works committee, to make sure that things run smoothly and that they resolve those kinds of problems. We also answer any questions they have, worries etc. We visit them periodically. But the committee has to convince the community to get things done. According to the law, they have to put twenty percent of the money for the public work to get done, and that is to resolve these kinds of problem, like a light post being left in the middle of the street. The community has to, once the street is paved, put the money in to move the post. That money does that function." ${ }^{22}$

\footnotetext{
${ }^{40}$ Interviews with COCICOVIs and community members confirmed the lack of monetary contribution.

${ }^{41}$ Section 33 does not require any amount of money to be contributed by beneficiaries.

${ }^{42}$ As mentioned by the director of citizen participation, public works for public education are not treated as equal to other public works, and the citizen committees do not pass through his office but rather through the department of public education; thus, interviews were conducted with schools and the trustee of public education on the topic of citizen committees formed to support public infrastructure in schools. The trustee indicated that yes, parent groups function as the citizen committees to request public infrastructure for schools. Moreover, when asked about the monetary contributions of citizen committees, a surprising and
} 
The municipal authorities interviewed, under the guise of avoiding paternalism, justified the contribution of funds expected from citizen committees. Moreover, a perceived contribution from a citizen committee, to implement an infrastructure project (be it through money, materials, and/or labor), was seen as reducing the cost of the project and thus an incentive to prioritize that particular project. Thus, during the election of public works committee members, individuals seen as potential patrons of the project were encouraged by the municipality and the community to fill positions in the citizen committees to ensure project completion. In such a manner, citizen committees' monitoring role is replaced with a role facilitating the creation of public works. The lack of financial contribution from the residents and members of the citizen committees in Tenango del Aire ${ }^{43}$ contrasts with that in San Andrés Cholula.

troublesome response was given by the trustee of Public Education in the municipality of San Andrés Cholula.

"Well, it is important for me to support a culture of participation. We used to have a program where the state government contributed to half of the cost of projects and the affected community would have to put the other half of the money. This program is no longer in existence, but in order to maintain this culture of participation, and do away with paternalism, we only support projects where there is collaboration" (trustee of public education in San Andrés Cholula).

School principals and teachers involved with parent groups were asked about aid received from the municipality for infrastructure projects. All confirmed that they needed to form a committee in order to promote the implementation of a particular project and to collect funds in order to receive aid. A school principal in a middle school visited in Tonantzintla indicated that;

“[they] don't have wealthy parents, and they don't have water in the bathrooms, the kids have to carry water in with a bucket to flush, and because they haven't been able to collect money, the municipality refuses to help" (interview from Telesecundaria).

When asked how long they have been petitioning for aid, they indicated a timeframe of approximately 10 years. Moreover, they had been requesting potable water for the community and paving for the main road for well over fifteen years and "the parents had even put money for the committee to petition the work” (ibid.) but nothing got done until recently, and we don't know why they finally decided to put water and then pave "probably an election promise" (ibid.). In any case, parent groups and Public Work Committees are often made up of the same individuals and solicit the works from both the public works office and the trustee of public education.

${ }^{43}$ However, interviews with both municipal officials and community members of Tenango del Aire indicated that prior to the existence of COCIVOVIs (approximately fifteen to twenty years ago), the community was expected to contribute-financially or physically - to the implementation of public infrastructure projects. Groups were formed with representatives of the community to gather resources and 
On the basis of the similarities and differences in function and treatment of citizen committees by both municipalities, an approximation of a typology of committees in both areas can be made. Albeit the explicit appointment of citizen committee members by the government in Riedel's typology of citizen committees, versus the appointment, selfappointment of members, or election of citizen committees members by the communities they serve in México, Riedel's typology gives us a model that can be altered to describe the treatment and function of citizen committees studied in the present study in México. Riedel's typology of advisory committees is quite extensive; it includes four categories, each possessing several sub-categories. Under this classification, the main differences between categories have to do with the "implicit [political] motives of the appointing body” (p. 22). The categories and the subcategories of Riedel's typology are the following:

The advisory category has four sub-categories but in general, "advisory" committees guide the appointing committee in the decision-making process. The first sub-category, "Advisory I," is intended to provide direction on how to implement a decision. "Advisory II" is intended to provide the public with alternative courses of action in order for the appointing agency of gauge public response. "Advisory III” is designed to identify possible problems and provide alternative solutions. Lastly, "Advisory IV" or "open-ended committees" are created when a decision has been reached by the appointed office, but the office is open to suggestions to modify its decision in the face of possible resistance.

materials and manage the contribution of physical labor of fellow community members. This use of what they called FAENAS changed with the creation of COCICOVIS. 
The supportive committee category has three sub-categories. However, in general, these committees are formed to legitimize decisions of the appointing office. In other words, "experts" might be called upon to form a committee to provide added weight to a decision that might otherwise face opposition that is precisely the motive behind creating a "Supportive I" committee. "Supportive II" committees are formed to direct the wants of the public in a particular direction and are the main tool is designing a "neutral" committee that will present the public with "all" acceptable alternatives. "Supportive III" or "visiting committees" are appointed to evaluate a particular program. The evaluation is kept public or private depending on the results of the evaluation. Decisions that add legitimacy to the original decision of the appointed agency are made public; all others are held private.

Put-off committees, as the name implies, are created to "put off" a decision. "Putoff I" committees are created when the appointed agency is under pressure to act and is unwilling or unable to do so. As a result, the appointed agency consciously selects members of a committee who will never agree on an action, putting-off the decision to act. The appointing agency can also chose members to create "Put-off II" committees as a tool to "put-off" a decision or action accordingly. Members with a "narrow-spectrum" perspective are selected so that the rest of the community puts off the decision they reach. "Put-off III” committees are created by selecting 'experts' or members who will delay the decision-making process, lagging until pressure is diverted and hopefully dissipated with the passing of time. Lastly, "Put-off IV" committees are formed when the agency does not want to take an action because of strong pulls from two opposing political sides. As such, the appointing agency selects representatives for the committee from both sides of 
the issue. Once a decision has been made, the committee then becomes an advisory or supportive committee.

Sub-categories for "Put-on" committees vary more than the sub-categories of Riedel's other committees. "Put-on I” committees are created when an agency makes a highly partisan decision. To mitigate potential outcry from the community, a seemingly “unbiased” group of individuals is chosen to reach the same decision as the appointing agency. "Put-on II” committees are composed of citizens demanding "broad” government action. In order to confuse and diffuse the group enthusiasm, the appointing agency feeds the committee complicated material in the hope that the group will reach the conclusion that the action is too complicated to be implemented while making the "appointing agency look responsive” (p. 27). Lastly, when an appointing agency is aware that a problem is out of their control, "Put-on III” committees are sometimes assembled to help reach the decision that "intergovernmental cooperation is the only or best hope" (ibid.) With this framework in mind, commonalities begin to emerge between specific characteristics of categories and subcategories of Riedel's typology and the function and treatment of the citizen committees (COCICOVIs and Public Works Committees) in each municipality - these parallels advance our discussion, and enhance our classification of these groups towards a typology of citizen committees in both municipalities.

Unfortunately, no municipal authorities in either study site viewed COCICOVIs or Public Works Committees as a method to guide the decision-making process. When mayors were asked how they accounted for citizen participation in the decision-making process, "participation in meeting, elections, completion of surveys asking their needs, citizen committees, etc.," both mayors stated that needs were established at the beginning 
of their election campaigns. Moreover, both presidents indicated that there was a lack of citizen participation. In Tenango del Aire, the mayor stated that "Municipality is very apathetic, they don't participate, in election yes but otherwise no.” In the case of the mayor of San Andrés Cholula, the mayor commented that:

"We have a severe problem with the lack of citizen participation, I think that the whole country... What we have is a problem with people feeling the need for a paternalistic government. People see government see everything in terms of obligation. You are the government. You have to give me everything, drainage, paving streets, etc.”

Thus, when running for office, candidates make their promises and if elected, account for citizen participation by keeping the promises made to the constituents who participated in getting them elected ${ }^{44}$. Notably, in my interviews, citizen participation was discussed as an abstract concept and not in terms of citizen committees. In other words, as noted by the FUNDAR study, mayors see the role of citizen committees only as one that supports (2006) a previously prioritized municipal project—not one that enables community control over the assignment of resources. However, while the advisory category of Riedel's typology can be dropped in the context of Tenango del Aire, it cannot be altogether dropped from the discussion of San Andrés Cholula, as will be noted later.

In Tenango del Aire, the role of the COCICOVIs was more straightforward, and the implicit motives were made explicit and vice versa. As in Riedel's supportive committee category, COCICOVIs are formed to legitimize a municipality's previously

\footnotetext{
${ }^{44}$ As noted previously, in the case of the municipal mayor of San Andres, the mayor indicated that every
} Thursday he holds a meeting in a different neighborhood to hear complaints, but not establish priorities. 
decided matter. They share similarities with Riedel's "Supportive III" committees or "visiting committees," which are appointed to evaluate a particular program. They are assembled to monitor that a project is implemented according to specifications. The COCICOVIs oversee a project, ensuring that the standards of the plan are being followed, and COCICOVIs provide final approval of the work at project completion. The evaluation is kept in the office of the municipal and the state controller's office. By "guaranteeing" that a project was carried out successfully in budget and quality, the original decision is given added legitimacy. COCICOVIs provide an added transparency to funds utilized for municipal public works. The main difference is that the members of the COCICOVIs are not appointed by the municipality; they are elected by community members.

Although the COCICOVIs are not formed to promote any particular project during the decision-making process, they do oversee the process of implementing the project. During the electoral process, public needs are identified and priorities are set. The Internal Municipal Controller utilizes meetings called to form COCICOVIs to inform the public about particular projects that will be implemented. They might resemble Riedel's "Supportive I" committees, which are created by the appointed agency when contentious decisions are made. It may be that not all municipal residents are content with a decision to implement a project. The municipality forms a COCICOVI with beneficiaries of the project, and then the project is implemented. In other words, the COCICOVI is formed and gives added weight to a decision that might otherwise face opposition. The COCICOVI is formed to support the carrying out of the project. Moreover, the COCICOVI gives legitimacy to the means with which the projects are 
carried out. The COCICOVIs are seen as passive recipients of information. Thus, although they could be used as Advisory III committees, "designed to define possible problems and provide alternative solutions,” the flow of information is one-directionalthere are no feedback loops available for participants to provide input to improve implementation of a project. The Internal Municipal Controller's office is charged with informing and involving the public once the priorities in the municipality have been set. In other words, as stated by the controller during his interview, “They [the public] don’t come to petition to this office. So, here we form the group and keep records of these groups. The Internal Controller offers help and explanations as to why a project isn't carried out to specification.” Moreover:

“COCICOVIs only come here after they are formed if there is a problem, for example, if the project doesn't start during a set time. Complaints are received here, and here, we give them an explanation why the problem might be occurring. So, for example, sometimes it rains, and we can’t start a project within the set dates. So we explain why the construction didn’t start on set date. The state brings paperwork to start a COCICOVI and collects all the papers once they have signed off on the project. This office facilitates the process” (ibid.).

Thus, the Internal Controller's office sees the Citizen Committees as supportive and as a means to ensure a project is implemented effectively and efficiently. ${ }^{45}$

${ }^{45}$ As noted in the next chapter, interviews with the community and citizen committee members indicate that COCICOVIs do not always have the knowledge base needed to assess the quality with which the projects are being carried out or that the Internal Controller's office is helping to resolve the problems 
In Cholula, the implicit motives of the municipality in its treatment of citizen committees (i.e., the Public Works Committees) were not always made explicit and vice versa. However, as with Riedel's supportive committee category, these committees are officially formed to legitimize the previously decided matter by the appointing office. Officially, as Supportive III committees, they are also formed to evaluate a particular program, giving their signature to not only serve as proof of citizen participation in the utilization of FISM funds from Section 33, but also as a way to guarantee citizen contentment with the project. However, as stated by the head of the Citizen Participation directive, members are not always "elected" but rather "selected" to facilitate the process of signing off on a project. Thus, the role of Public works committees, as "neutral evaluators," is placed at risk and can be contentious in some cases ${ }^{46}$ Thus, the motives behind the appointment of Public works committees can also resemble Riedel's "Put on I" committees. In the case of the Public Works Committees, the directive of Citizen Participation in San Andrés Cholula can select members that will facilitate project implementation, no matter how contentious a project may be.

Although COCICOVIs in Tenango del Aire are not formed to promote any particular project during the decision-making process, this is not the case in San Andrés Cholula. The head of the directive of Citizen Participation in the municipality indicated that Public Works Committees are formed only after a project is prioritized and selected for implementation, and indicated that they do not receive calls from non-official groups

brought to their attention by the COCICOVI and is rather just serving the committees with explanations of why the problem is occurring.

${ }^{46}$ The evaluation is just a signature given, or not given, once the project is completed-accepting the overall quality of the completed project. It is not based on an evaluation of the costs or time spent completing the project. 
petitioning the municipality for a particular project and asking for their support in the process. However, interviews with the Public Works Department, the auxiliary junta, various trustees and the mayor in the municipality indicated that they do receive petitions throughout the year from "unofficial" committees soliciting projects. Moreover, members of two of the citizen committees (Public Works Committees) interviewed indicated that they formed their committees before their projects were prioritized, and they petitioned/solicited the project to the municipality until it was eventually prioritized. ${ }^{47}$ Because these groups are shifting government decisions in their favor, defining community problems and providing solutions, the term Advisory committee can be used loosely to define them. Once the project is prioritized, and the public works department sends information to the directive of Citizen Participation, the committee is officially "formed" and recognized as a public works committee. With the "help" of the directive of Citizen Participation, the citizen committee continues working with the people of their community and the Public Works Department to make sure the project is implemented, because, as stated by the directive head of the Citizen Participation Directive, "If it doesn’t take place during a set period of time, they have to start over.” In other words, if the project does not begin within the allotted time period, it is dropped from the list of priorities and must go through the petitioning process all over again in order to be reprioritized.

\footnotetext{
${ }^{47}$ Some members of citizen committees indicated that in order for the municipality to take their requests under consideration, they had to be notarized as an official group prior to consulting the municipality about a particular project they wished to have carried out. According to the interview with the directive of citizen participation, however, when asked if the groups have to be notarized to submit a request, he indicated that "this is not necessary because the forms they need to fill out are official.
} 
As mentioned above, in San Andrés Cholula, the auxiliary presidents also play a role in channeling the demands of the citizenry to the municipality. They prioritize projects during their election campaigns and receive petitions for projects throughout the year, some of which they channel up to the municipality for consideration. The citizens who organize themselves into committees for a particular SIF project can petition the municipality directly, but as noted in the interview transcripts above, the support of the auxiliary junta in which they reside is very important. Moreover, as stated by one of the auxiliary presidents of Tonantizntla:

"Even when people mobilize to form groups, and ask for funding, 'comités de obra' only become a legal entity when they are lucky, and their project is prioritized by the municipality. Then, a meeting is called and a group is 'formed.' If a group forms before that, and begins petitioning, then they are pinpointed out and labeled as subversive, problematic. [...] So then that group gives up. Or, an interesting thing happens. The authority of the municipality tells these groups that the work is not being done because the auxiliary president didn't turn in their forms. But then, if they do get formed because the work gets prioritized, if the group doesn't keep on pressuring, then the municipality says that the work did not get done because of the lack of action of the group. There are lots of projects that have been prioritized and thus far, this year, only one road is getting paved, because of this situation. Moreover, [... sometimes the] government will not make a move until people pa[y]. [...] Those with 
money get their work done, those without, get left out” (auxiliary

president from the May 2008-May 2011 term).

Thus, Public works committees in San Andrés Cholula can also resemble Riedel’s "Put-on II" committees. "Put-on II" committees are created when the agency is under pressure to act and is unwilling or unable to do. In order to confuse and diffuse the group enthusiasm, the appointing agency feeds the committee complicated material in the hope that the group will reach the conclusion that the action is too complicated to be carried out while simultaneously making the "appointing agency look responsive.” As in "Put-on II” committees, the municipality of San Andrés Cholula can prioritize a project, have the directive of Citizen Participation legally form a Public Works Committee, and then put traps or requirements (for example, demand monetary contributions from the committee ${ }^{48}$ or complicated paperwork ${ }^{49}$ ) in the process creating a delay in the process, lagging until pressure to act is averted and dissipated with the passing of time. The municipality also receives petitions from unofficial committees not yet legally recognized by the directive of citizen participation. These citizen committees, which are formed after the municipality has decided its priorities, can become "Put-on II" committees simply by

\footnotetext{
48 According to interviews; "citizen committees must be formed in order to obtain funds" (Auxiliary president of May 2005-May 2008 term). Moreover, "they [the municipality] always talk[s] about having the community pay their share" (Auxiliary president from the May 2008-May 2011 term). In other words; there is an expected monetary contribution that residents must make to ensure that their projects are carried out. Specifically, once the municipality has gotten back to the auxiliary junta, indicating what projects it will implement, citizen committees become officially recognized and in addition to working to oversee the project, they must match $20 \%$ of the project costs. When probed further, the auxiliary junta indicated that the $20 \%$ is variable: sometimes less, sometimes more. However, all auxiliary presidents indicated that a contribution is expected.

${ }^{49}$ As will be noted in Chapter 5, several of the citizen committees in Tonantzintla felt that the steps and paperwork required from them, including obtaining environmental impact studies, were very complicated and one of the reasons previous groups had failed to gain initiation and completion of their projects.
} 
remaining unofficial and by not being made aware of and directed to the Citizen Participation directive, which can legally recognize them as public works committees simply by having them fill out paperwork. That said, the unofficial citizen committees might also be able to spur the municipality to act (especially if they have funding to supplement the investment made by the municipality, making it more economical for the municipality to implement the project) in the process becoming an Advisory III or Supportive III committee.

In light of the data gathered from the citizen committees in both municipalities, the Put-off category of citizen committees from Riedel's typology is not present in either site. Moreover, several of the subcategories of Advisory, Supportive and Put-on committees must also be dropped in the discussion of these two municipalities. The citizen committees present in each municipality vary considerably. In Tenango del Aire, COCICOVIs resemble Supportive III committees; they are utilized to evaluate a project and gain legitimacy by making sure it is implemented in accordance with specifications. Hypothetically however, they can also be used as Supportive I committees in that their presence is used to legitimize to a project that is not necessarily supported by the community. In San Andrés Cholula, the term Advisory Committee can be used loosely to describe unofficial citizen committees who might potentially affect the decision-making process by signaling the importance of a project and thus gaining its prioritization. However, once legalized by the municipality, registered by the directive of citizen participation, public works committees could become Supportive I, III and Put-on II committees. 


\subsection{Conclusions}

The primary goal of this research is to identify the factors that affect the degree to which municipalities incorporate citizen participation in the decision-making process. In the last chapter, it was noted that one of the theories posited in the literature was that in municipalities "where social movements operate in an oppositional, revindicative mode (or 'expressive-disruptive' rather than 'integrative-corporatist') and are strongly allied with the party in local government, participation will be more difficult to institutionalize” (Goldfrank 1998: 11-12). These two different strategies for contesting power, "cogovernment and opposition [...] the former [which] involves contributing to the workings of the institutional arrangements of which it is part [and] the latter [which] involves blocking the functions of government [...] with a view to achieving power," were observed in PAN and PRD strategies designed to deal with perceived electoral fraud (Mainwaring \& Scully 2003: 201). Moreover, following this train of thought, it was hypothesized that PAN's ability to compromise with PRI and adopt a co-government position promoting decentralization policies; it would be more likely that it would incorporate participatory mechanisms in the municipalities it controls. On the other hand, PRD's adoption of an opposition strategy in dealing with the PRI administration in the $20^{\text {th }}$ century, and PAN after the 2000 year election, would indicate that the municipalities governed by PRI and PRD would be less likely to incorporate participatory mechanisms.

As noted in the previous section, the use of citizen committees in Tenango del Aire is more restricted and more uniform in treatment and function than in San Andrés Cholula. Section 33 of the LCF allowed great flexibility to the municipalities in determining how to incorporate participatory mechanisms. Having a legacy utilizing 
Solidarity Committees, most municipalities simply adopted and adapted this model of citizen committees to meet their own unique needs. The state government of Tenango del Aire, the State of México, is involved in monitoring COCICOVIs while the state of Puebla is not involved in monitoring the use of "public works committees" in its municipalities. One of the hypotheses set forth at the initial stages of this research that party affiliation would affect municipal willingness to incorporate participatory mechanisms.

Tenango del Aire is currently run under a coalition party, and this municipality leans more to PRI and PRD support, having never elected a PAN mayor in the municipality and having been the first municipality to elect a candidate from the political party that preceded PRD. The municipality belongs to a state that is a traditional PRI stronghold. Cholula's current and past mayors, since 1995, come from the PAN political party. The state of Puebla has a current governor, Rafael Moreno Valle Rosas (20112017) who belongs to the PAN party. Nonetheless, all previous governors belonged to PRI. Functioning citizen committees were present in both municipalities. State involvement in COCICOVIs - and the absence of state involvement in citizen committees in San Andrés Cholula—could be a result of the centralization tendencies of PRI and an effort to manipulate and regulate its municipalities. In other words, the function of the COCICOVIs in the State of México may be seen as an effort to monitor municipal use of resources by the state rather than promote citizen participation in the decision-making process. The willingness of Tenango del Aire to allow state involvement in its use of COCICOVIs could be due to the lack of decentralization doctrine followed by the political parties in charge of the local administration. On the other hand, the lack 
of state involvement in the functioning of the "public works committees" in San Andrés Cholula could signal that their function is not to aid state government in monitoring municipal action, but rather truly enable citizen participation in the decision-making process. Because San Andrés Cholula was run under PAN leadership, known for advocating decentralization doctrine and promoting municipal autonomy, it might have been more open to accept the authority granted to regulate its own citizen committees without state oversight. Interviews with state-level government officials are needed to understand why this difference appears. Moreover, in order to draw such conclusions at a more aggregate level, a quantitative study is needed to analyze the relationship between state involvement in the oversight of citizen committees, and political party affiliation at the local and state level.

As per the a priori hypothesis, data gathered from interviews in both municipalities indicated that neither municipality viewed citizen committees as playing an important role in the decision-making process or as an essential element in their efforts to increase citizen participation. That said, the more diversified typology of citizen committees observed in San Andrés Cholula, and specifically the appearance of seemingly Advisory committees, could be interpreted as an increased municipal willingness to accept citizen input in its decision-making process. However, it could also be a result of more funds available in the municipality and thus more willingness to make changes to pre-determined plans in response to the pressures made by well-organized citizens. Moreover, once recognized by the municipality, or legalized by the directive of citizen participation, Advisory "public works" committees could become Supportive I or Put-on II committees, in the process, making the decision-making process closed to 
citizen input. Moreover, although the citizen committees observed in Tenango del Aire merely resembled Supportive committees, they did provide for more citizen participation in assuring government accountability and transparency in the use of funds than those observed in San Andres. Thus, although efforts to gauge if one municipality is more willing to incorporate citizen participation did support the apriority hypothesis, a cautionary note is needed indicating that more case studies are needed to make any generalizations. Moreover, the present study found that local context (traditions of residents) and the leadership exercised in communities affected whose voices are heard in the decision-making process. As stated in Section 5.5, leadership, a government's response to growth, and whether "community" is seen as a marketplace or "community" is seen as a living space, determines if a municipality will be accessible and open or exclusionary and closed, affecting who will participate and whose interests will be taken into consideration in the decision-making process. 


\section{CHAPTER 5: CITIZEN COMMITTEES: Formation and Involvement; an Evaluation of the Participatory Mechanism}

\subsection{Introduction}

This chapter presents and discusses the data gathered on citizen committees in the two research sites in México (the municipality of San Andrés Cholula and the municipality of Tenango del Aire). Citizen committees were treated as nested cases from which information could be gathered on the factors that affect committees' formation and involvement in rural Mexican administrative decisions. In total, nine citizen committees were chosen from both municipalities. I aimed to highlight the factors that affected formation of these groups, the factors identified by group members as aiding them in their participation, and documenting the perceived treatment these groups received from government officials and the perceived impact of these groups on the quality of government services rendered. Three citizen committees were chosen from the rural auxiliary junta of Santa Maria Tonantzintla in the municipality of San Andrés Cholula and three citizen committees were chosen from the overall rural municipality of Tenango del Aire. In addition, in Santa Maria Tonantzintla, the staff of three public schools was interviewed to understand the role, if any, that citizen committees play in public schools. ${ }^{50}$ Several community members were interviewed from both study sites to corroborate the role and the impact of these committees on the provision of government services. The chapter is divided into seven sections. Section 5.2 provides the narrative and the data gathered from the 'public works committees' in the township of Santa Maria

\footnotetext{
${ }^{50}$ When possible, citizen committees were treated as focus groups-all members being interviewed at the same time. Questions were posed to the group and individuals were asked to clarify and expand on statements made by others.
} 
Tonantzintla. Section 5.3 provides the narrative and the data gathered from the local schools in the area. Section 5.4 provides an overview of the factors identified as affecting the formation of citizen committees in San Andrés Cholula. Section 5.5 provides the data gathered from COCICOVIs in the municipality of Tenango del Aire. Section 5.6 discusses the factors that affect the formation of COCICOVIs in Tenango del Aire. This chapter concludes with Section 5.7, which focuses on how these group members—as well as their communities-feel their participation in the groups: affected government performance; promoted accountability; improved governance, ethics, economy, efficiency, effectiveness, and responsiveness; and established cost recovery mechanisms. and provided an evaluation of the participatory process utilizing the criteria specified by Rowe and Frewer (2000).

\subsection{Santa María Tonantzintla 'comités de obra'51}

Community meetings have historically been called by ringing the local chapel's bell. These meetings concern church related affairs, parties celebrating saints, and holidays, etc., and the formation of fundraising committees and designation of sponsorship of events. However, these meetings are also used to deliberate the general, secular needs of the community. For example, discussions are held on the need to create a new school, pave a road, or petition for a service. It is in these meetings that the community decides which needs are a priority for the community. Once needs are established, if a particular project cannot be carried out through private sponsorship, fundraising occurs and if need be, the government is solicited for aid. Church

${ }^{51}$ In English 'public works committees' 
participation is important to maintain abreast of community affairs. ${ }^{52}$ Once needs are determined and prioritized, the chapel leadership holds meetings to inform the public of any progress made on the matter.

\section{Potable Water Committee:}

In the 1990s, Latin American countries began implementing new water resource management and water-related public service reforms that shared the commonality of broadening and strengthening decentralization processes. Most countries, for example, applied the suggestions made by the World Bank and adopted institutional arrangements that allowed greater stakeholder and private sector participation. Moreover, countries began adopting the view that water is a natural resource as well an economic good with social and environmental dimensions (Wilder and Lankao 2006, Trejos et al. 2008). These policies altered the dynamic and role of stakeholders involved in both the demand and supply side of the water sector. In México, the implementation of the 1992 National Water Law (Ley de Aguas Nacionales) transferred water management responsibilities from the federal government to municipalities (Wilder 2005). Coupled with the adoption of PRONASOL, which altered the funding mechanisms for infrastructure projects in municipalities, the reforms allowed for the creation of democratized spaces for participatory water management.

After the chapel meeting held in Santa Maria Tonantzintla on June 5, 2002, members of a newly formed citizen committee walked to their township government, and in the presence of the auxiliary president, asked the secretary to create a document legally

\footnotetext{
${ }^{52}$ In interviews with members of the community who were not originally from the area, few knew that the ringing of the chapel bell represented a call for a general community meeting discussing secular matters.
} 
recognizing the committee and their demands for potable water. ${ }^{53}$ The auxiliary president was in his last year in office and no record was found that he ever informed the municipality of the request for potable water made in his township. The potable water citizen committee did not become officially recognized by the municipality of San Andrés Cholula until May 20, 2005, when the project was finally prioritized by the municipality. The committee dissolved in 2008 when the project was completed. Water resource management plays an important role in both poverty reduction and sustainable development and in recognition of the significance that obtaining potable water in a community is, this case study is highlighted in this chapter.

Factors that affected the formation of the Potable Water committee:

\begin{tabular}{|l|l|l|l|l|l|l|}
\hline $\begin{array}{l}\text { Citizen } \\
\text { Committee }\end{array}$ & $\begin{array}{l}\text { Year } \\
\text { Formation }\end{array}$ & $\begin{array}{l}\text { Year } \\
\text { Recognized }\end{array}$ & $\begin{array}{l}\text { \# of } \\
\text { Members }\end{array}$ & $\begin{array}{l}\# \\
\text { Elected }\end{array}$ & $\begin{array}{l}\text { Age: } \\
\text { above } \\
30\end{array}$ & $\begin{array}{l}\text { Year Project } \\
\text { Completed }\end{array}$ \\
\hline $\begin{array}{l}\text { Potable } \\
\text { Water }\end{array}$ & 2002 & 2005 & 6 & 4 & 5 & 2008 \\
\hline
\end{tabular}

${ }^{53}$ According to interviews with community members and members of the citizen committee, efforts to obtain potable water date back to the early 1980s. Because, in their majority, community activists depended on unofficial meetings with local government officials to gain prioritization for their projects and because their methods did not leave a paper trail, only verbal accounts of such efforts remain. These accounts include claims of corruption and false promises resulting in delayed action by government to provide potable water. One such claim, reported by several interviewees from the community, was that a past auxiliary president had already collected money from the community to build a well. However, it is said he kept the money, built a well on his land, and then began his own business selling water via water trucks at a very high cost. This action reportedly demoralized the community such that the collective action to reprioritize and petition the installation of infrastructure for potable water was delayed for several years. As described by a member of the water committee when relaying the story; "The majority of the people here don't know their rights and they just feel these injustices happen but nothing can be done. That is why it was so hard to motivate them to start working on the project again.” In the meeting in 2002, there was a heated debate between those who wanted to prioritize the paving of the main road and those who wanted to first create the infrastructure for potable water and then, in the future, petition to pave the main road in the neighborhood. This was the first effort to obtain potable water that left a traceable paper trail. Two of the members of the citizen committee had retained a copy of the legal document recognizing the group in their personal files. However, a copy of these documents were not found in either the municipal or auxiliary government offices. 
When speaking to a member of the water committee, the interviewee stated:

"If government came and did the work, without a committee, then we would not find the need to meet and form a group. But, the way things work is that if we don't ask, it doesn't get done. And as far as working government is concerned, you can’t just come with 200 people and ask that something get done, the government wants to know who they are dealing with and ask we form a group. You have to a call to the community to get together. Then you pick a president, treasurer, etc. to represent the community and go to register the group. Because the potable water project was big enough to need collective sponsorship as well as government aid to be carried out, a committee needed to be formed.”

Lack of government community planning and action was seen by residents and committee members as a reason why secular community needs were discussed in church meetings and why they felt the need to form citizen committees. They felt that if they did not incite the government to act on specific issues, the government would not, and nothing would get done in their community.

This particular committee was composed of six members: president, treasurer, secretary, and three individuals charged with disseminating information. Four of the members were nominated and elected by the community (males) and two were selfnominated (females) filling positions that were left empty by a nominated (male) member of their family who could not take responsibility at that time. Members of the committee were asked open ended questions about the nomination process as well as some yes and 
no questions of potential factors-identified in the literature- that could have affected the election of citizen committee members.

When asked specifically about the role that gender, participation in the church, personal economy, and political aspirations played in the nomination/self-nomination and election of citizen committee members, the results were as follows:

\begin{tabular}{|c|c|c|c|c|}
\hline $\begin{array}{l}\text { Citizen } \\
\text { Committee } \\
\text { Member }\end{array}$ & Gender & $\begin{array}{l}\text { Participation in } \\
\text { the Church }\end{array}$ & $\begin{array}{l}\text { Personal } \\
\text { Economy }\end{array}$ & $\begin{array}{l}\text { Political } \\
\text { Aspirations }\end{array}$ \\
\hline President & Some & Some & Some & None \\
\hline Secretary & $\begin{array}{l}\text { "Definitely, they } \\
\text { wanted my } \\
\text { husband [...] but } \\
\text { when he couldn't, } \\
\text { they accepted me } \\
\text { reluctantly to } \\
\text { represent him.” }\end{array}$ & $\begin{array}{l}\text { Some: } \\
\text { "In my case no } \\
{[\ldots] \text { but you see }} \\
\text { our president was } \\
\text { mayordomo" }\end{array}$ & $\begin{array}{l}\text { Some: "We have } \\
\text { to run around for } \\
\text { copies and pay } \\
\text { those processes } \\
\text { that might not be } \\
\text { much for us, but } \\
\text { do add up." }\end{array}$ & None \\
\hline Treasurer & Yes & ---------- & Yes & None \\
\hline 1.Vocal Rep. & $\begin{array}{l}\text { "Yes, just recently } \\
\text { a woman ran for } \\
\text { auxiliary office and } \\
\text { she didn't win } \\
\text { because she was a } \\
\text { woman. And it is } \\
\text { the same for the } \\
\text { nomination of } \\
\text { women in public } \\
\text { work's } \\
\text { committees." } \\
\text { "Unfortunately, } \\
\text { women are still not } \\
\text { given the } \\
\text { opportunity as they } \\
\text { should be." } \\
\text { "Things } \\
\text { changing are } \\
\text { unfortunately here } \\
\text { the tradition is that } \\
\text { women still don’t } \\
\text { act without their } \\
\text { husbands. } \\
\text { Sometimes you go } \\
\text { ask for their }\end{array}$ & $\begin{array}{l}\text { "Well, it all has to } \\
\text { do. [...]Any } \\
\text { participation in the } \\
\text { community is } \\
\text { welcome." } \\
\text { "I was a } \\
\text { "Mayordomo" of } \\
\text { the capilla of San } \\
\text { Isidro in my } \\
\text { community. } \\
\text { Through this, } \\
\text { people saw what } \\
\text { kind of person I } \\
\text { was, honest." }\end{array}$ & $\begin{array}{l}\text { "It is also } \\
\text { important that the } \\
\text { community feel } \\
\text { that you will be } \\
\text { able to be solvent } \\
\text { and maintain } \\
\text { yourself as } \\
\text { member of the } \\
\text { group. This is } \\
\text { because it cost } \\
\text { money to get } \\
\text { official petitions } \\
\text { into the } \\
\text { presidency and it } \\
\text { cost money to } \\
\text { transport yourself } \\
\text { to the offices they } \\
\text { ask you to go to, it } \\
\text { cost money to take } \\
\text { time off of work. } \\
\text { So, if you don't } \\
\text { count with the } \\
\text { money to sustain } \\
\text { yourself through } \\
\text { the process, the } \\
\text { community will }\end{array}$ & $\begin{array}{l}\text { "As far as the } \\
\text { water, I was going } \\
\text { to run for the } \\
\text { position of } \\
\text { auxiliary president } \\
\text { that year [...] I } \\
\text { was selected as } \\
\text { pre-candidate for } \\
\text { 2005. Because I } \\
\text { had all my } \\
\text { experience paving } \\
\text { of Rafael Ramirez, } \\
\text { participating with } \\
\text { schools, and they } \\
\text { approached me, } \\
\text { Miguel Porquillo } \\
\text { and others and } \\
\text { said, you will get } \\
\text { your water but it } \\
\text { isn't your turn to } \\
\text { be president, and if } \\
\text { I gave up my } \\
\text { position, they } \\
\text { would do the water } \\
\text { and the road, and } \\
\text { as you can see, }\end{array}$ \\
\hline
\end{tabular}




\begin{tabular}{|c|c|c|c|c|}
\hline & 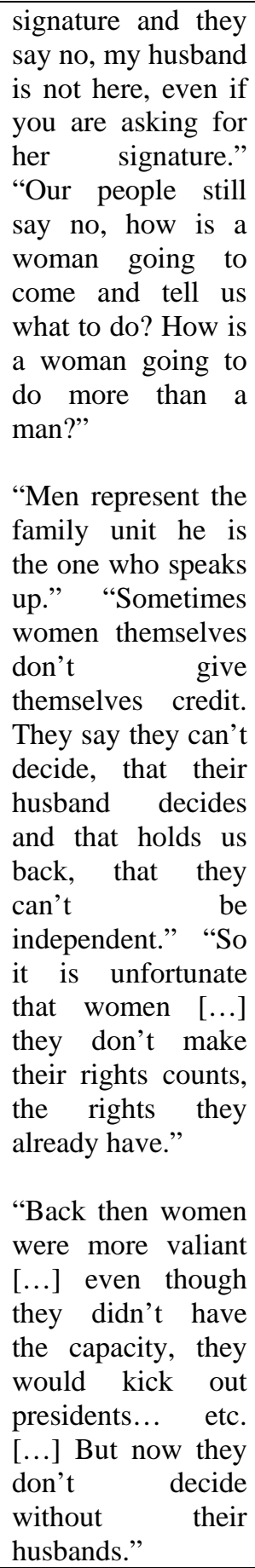 & & $\begin{array}{l}\text { probably not } \\
\text { select you to be a } \\
\text { part of the group. } \\
\text { If you don't have } \\
\text { personal money } \\
\text { then sometimes } \\
\text { nothing gets done, } \\
\text { you might want to } \\
\text { but you can't } \\
\text { afford the process. } \\
\text { So, some people } \\
\text { who would like to } \\
\text { participate say, no, } \\
\text { I don't have the } \\
\text { money to miss a } \\
\text { day of work, etc. } \\
\text { Personal economy } \\
\text { is important. } \\
\text { Moreover, they } \\
\text { don't want you to } \\
\text { take off with the } \\
\text { money collected } \\
\text { from the group. In } \\
\text { order for lots of } \\
\text { projects to take } \\
\text { place, you have to } \\
\text { show the } \\
\text { government that } \\
\text { you are, as a } \\
\text { community to thect } \\
\text { willing to take on } \\
\text { some of the cost, } \\
\text { so, you collect } \\
\text { money and they } \\
\text { don't want you to } \\
\text { steal it and they } \\
\text { don't } \\
\text { you."54 }\end{array}$ & $\begin{array}{l}\text { they did it. It was } \\
\text { Salomon's turn. } \\
\text { They told me, if } \\
\text { you want to wait, } \\
\text { wait } 9 \text { years and } \\
\text { you will get what } \\
\text { you want but you } \\
\text { won't get water or } \\
\text { the road, better } \\
\text { sign with us. }\end{array}$ \\
\hline 2. Vocal Rep. & $\begin{array}{l}\text { "Well, I am going } \\
\text { to be frank, yes." }\end{array}$ & $\begin{array}{l}\text { "In this community } \\
\text { people are very } \\
\text { religious and this }\end{array}$ & $\begin{array}{l}\text { "Yes, you have to } \\
\text { have the money to } \\
\text { do all the }\end{array}$ & No \\
\hline
\end{tabular}

${ }^{54}$ Follow up question: Do people really steal the money? Answer; "Yes, on several occasions, so then people don't want to give money for a project even though the government requires a contribution from the population. [...] So there is an apathy resulting in the community. Because a few rotten apples, things don't get done, or it takes longer than it should to motivate people.” 


\begin{tabular}{|l|c|c|l|c|}
\hline & & plays a major role.” & $\begin{array}{l}\text { paperwork they } \\
\text { require of you.” }\end{array}$ & \\
\hline 3.Vocal Rep. & Some & Yes & $\begin{array}{l}\text { Yes “I am a } \\
\text { business man and } \\
\text { people see how I } \\
\text { do business.” }\end{array}$ & No \\
\hline
\end{tabular}

In this case, gender played a role in the selection of community representatives. Four out of six members answered yes, gender plays a role in the election process. The women in the group felt they had been elected by default when the husband of one, and the father of the other, had been nominated but could not serve. Men have traditionally been the ones trusted to represent their families outside the home and in official matters. Although, as noted in one of the interviews, women are active in the community in unofficial matters, and in school parent groups, women are not preferred as representatives in public works committees. That said, change is occurring slowly and as noted by a member of the committee for potable water, in a later community meeting prioritizing the paving of a street in the same neighborhood, a woman volunteered to serve on that public work committee. At first, a participant of the meeting said "there should be no women but, in recognition of the work done by the women in the potable water committee, and using them as an example, other participants defended the woman volunteering and she got the post.”

According to interviews with community members, ${ }^{55}$ participation in the church, as an extension of the variable trust, helps people feel secure that they are selecting someone who has either been trusted by the church to administer money and/or has high moral character. Notably, according to the LAPOP 2010 study, citizen participation in

\footnotetext{
5530 members interviewed.
} 
México occurs mostly within religious organizations. Thus, it could be that those who participate in the church are active members of the community and thus also active in community affairs. In either case, for this particular case study, participation in the church was viewed as a positive trait in elected community representatives in the potable water committee.

Personal economy was also seen as an important factor when selecting representatives to form part of this public works committee. Level of income served two functions. First, it helped ensure that people who participate could support themselves economically through the demanding process of petitioning the government for project prioritization. It also served as a way of ensuring trust in the administration and collection of funds from township residents. According to interviews with community members and members of citizen committees, because people who serve in public works committees sometimes stealing the money they collect from the community, selecting people based on their personal economy (i.e., level of individual wealth) makes community members feel more secure that theft will not occur due to personal need. Moreover, people with higher incomes were seen as capable of matching the funds needed to complete the project out of pocket, if need be.

Lastly, regarding political aspirations - the last factor queried in the yes or no questions with citizen committee members—only one out of six answered that he had political aspirations. The literature had suggested that participation in citizen committees helps people become more engaged in local government and more likely to become leaders. Thus, participants in the citizen committees were asked if they held a position or 
agreed to serve the term because of political motivations. In general, service in citizen committees was not seen as a channel to pursue higher political posts.

During open ended questions with citizen committee members and community members regarding election/self-nomination criteria, trust emerged—as suggested by the literature-as an overriding factor in the selection of committee members. The members of the committee concurred that being a long standing member of the community was very important in the nomination process. As stated by a community interviewee, "more than anything, what is important in this community, is that the person is well known, from the community." "The people in a town already know each other and they know who works well, so they themselves choose, nominate people to be part of a committee and then vote" (vocal representative 1). Being a member of the community for an extended period of time increases a candidate's chances of being elected to a public works committee.

In any case, four members of the committee indicated that they had participated actively in past community affairs. Five members indicated they had been members of parent committees at their children's schools, two had served in a religious volunteer post for the chapel, and one had been a previous auxiliary president from 1993-1996. Only one member had never participated in a community post prior to becoming a member of this committee.

Factors identified by committee members that helped them attain their goals

When committee members were asked during a group interview what characteristics made their committee successful, four factors stood out: following official 
channels/establishing a paper trail, having a certain level of literacy, jumping government tiers, and money.

1. Following official channels:

All members agreed that obeying official government procedures, and thus leaving a paper trail of efforts, was important. As described by some of the interviewees:

"Sometimes people think that by meeting with someone [in government] their project will get done, but the paperwork is important, the experience to know it matters made a difference. They [the government] can say they are going to do something but if they don’t sign then ‘they forget' and they don’t do anything” (committee president).

"Sometimes people don't know what all that paperwork is for, $[\ldots]$ sometimes they don't know they have to do it” (Vocal representative 1).

"People who have been in committees are people well respected and who usually have a connection to the people in government, it used to help pull strings to have them in committees. Then they might think they are taking a shortcut by just meeting and talking with a local politician or government official, they don't realize that it is better to follow procedure and take the long road to get there” (committee president).

“So, [keeping record is important because] even though the municipality doesn't want to spend the money and they 'lose' the paperwork, [in our case] we had a copy of the petition and the prioritization by the SOAP and the state and the federal government [...] they had to pay attention, and thank goodness we knew we had to go and keep track of these things" (Vocal representative 1). 
All these statements make it clear that understanding the importance of following official channels and leaving a paper trail are important to gain prioritization for a project. Members of the committee concluded by indicating what differentiated their committee from prior committees-and what was a major factor in helping their committee attain its goals—-was being persistent and keeping track of their progress and requests through the maintenance of a paper trail.

\section{Literacy}

Related to the points above, on the importance of following official channels for putting in requests to the local government, it was noted by committee and members of the community, that these channels demand a certain level of literacy. In other words, knowing how to read and write is vital. One interviewee described personal committee experiences and other, unsuccessful committees, which did not attain their goals due to a lack of literacy. The interviewee used agriculture as an example: campesinos (farmers) were attempting to protect their lands while ejidos (the commons, communal lands) were being dissolved due to legislation undermining their legal protection. He stated:

"Look with agriculture, the ejidos are almost gone [...] but anyhow, the only people who can get organized to petition for help when there are agricultural problems are the people who controlled the ejidos, who might not even use the land but they know how to read and write and petition for help. But the poor campesino who doesn't know how the system works? Well, he doesn't even know how to petition for help when he needs it because he can't read or write, it is the same with these works" (Vocal representative 3). 
The committee president added:

“Most groups don’t know what the government is asking from them; like they asked us for an environmental impact study [...] I was lucky I knew the paperwork had to get done” (committee president).

Interviews conducted with community members concurred in indicating that some of the previous 'active members' of the community, especially the elderly population, did not know how to read or write. However, in prior years members of this now elderly population were primary contributors of physical labor to construct the community's chapel and schools and organize town parties for the church. However, at present, these members of the community are no longer effective participants and thus are no longer asked to participate 'officially' because they are illiterate. ${ }^{56}$

\section{Jumping government tiers}

Members of the potable water committee identified that asking for government help from different levels of government was a major factor contributing to the prioritization of their potable water project. As noted by an interviewee when speaking about why prior committees failed in their efforts to obtain potable water:

“Well, maybe [they failed] because they didn’t know how to work the system [...] how to go to the state government or the federal government to ask them for help. That is important. That is why we got the water project done. Because there are laws that prioritize the water. So, even though the municipality doesn't want to spend the money

\footnotetext{
${ }^{56}$ An elderly woman credited by the potable water citizen committee for being in charge of 'unofficially' facilitating the collection of funds from the community as well as disseminating information on the progress of the potable water committee was also interviewed for this study. She confirmed that she would have preferred to participate as an official member of the committee, but she was embarrassed because she could not read or write and she was a woman — and women like her are not typically elected to represent the community.
} 
and they lose the paperwork, we had a copy of the petition and the prioritization by the SOAP and the state and the federal government [...] they had to pay attention” (committee president).

Another committee member noted:

"Yes, we wrote a letter to the governor, he responded and then the municipal president had to say yes, we will consider the project, we threatened we would write another letter until he acted” (Committee secretary).

\section{Money}

All committee members confirmed that a considerable amount of money is necessary to complete the paperwork required from them by the municipality. Some of the interviewees described this issue;

"You need personal money to get copies, to drive or take a bus to different government offices to get documents stamped, to take time from work to turn documents in, to ask for signatures, etc.” (Secretary).

As stated by another member of the committee: "having the funds to follow through is important, every step has a cost, we paid for the land where they built the well, the legal work to get it legally transferred in our group name, and then the legal work to transfer it to the government and then they [the government] paid for the well” (Committee president). The project "was done in parts, buy the land, get the water well built, get the tubes installed etc.” Thus, “it [the process] requires personal funds and then money from the community for the large costs” (ibid.). 
"We were lucky, my girl who just graduated from primary school, they [the students] spent 5 years waiting for a ramp for disabled students to use in emergencies to be built in the school. They [the government] were asking too much money [from the families of the children represented by the parent committee] for it to get it done. In this case, we had the money” (Vocal representative 2).

In other words, having the money to be persistent and follow through with all the government requests was seen as very important and one of the leading factors that contributed to the successful completion of the potable water project.

\section{On the Typology: Treatment received from the Municipality}

The typology of citizen committees used in the present study is based on an adaptation of Riedel's (1972) model, which utilizes municipal treatment of citizen committees to establish a typology. For the present study, in an attempt to classify citizen committees according to a typology, not only is the verbal account of the perceived function of these groups by municipality important but also the perceived treatment received by the citizen committees. Thus, all citizen committees were asked about the treatment they received from local government when attempting to attain their goals. The potable water committee, in response to questions on the treatment they received from the municipality during a group interview, answered as follows:

"Polite yes but how many times did they lose our petitions? I can't even count them anymore" (committee secretary).

“What happens is that government doesn't give the people what they need if one doesn't ask. And yes, citizens have to do their part, but then the bureaucracy sais ok, 
well, come back in one day, in two, in three, in a week, in a month, and time passes” (Vocal Representative 1).

"I have the impression, they try to have you give up, they make you run around, they ask you for millions of copies of the signatures you have collected, for an environmental impact study [which cost the committee money], or to go write a petition to take to another department, to get permits or whatever and then they tell you are too late for that fiscal year" (Secretary).

"Well, you see, in our case, they had decided that they were not going to do our project so, they said that the auxiliary president never turned in the forms [...] and then they lost the ones we turned in and they gave us more paperwork to take care of, they made us get a geological study carried out, when they are the ones who are supposed to do it, and we paid for that [...] all this to make sure we didn't' get our way, because they knew they had to prioritize us but really had no intention to do so" (Vocal rep. 3).

Another committee member stated "they made us waste time. Then the state government prioritized us but the auxiliary president and the municipal administration term was over, and a new one began so, we had to start petitioning from scratch. And then it was done in parts, buy the land, get the water well built, and get the tubes installed etc. all this took time and money, and did they help us with getting money from the community to buy the land? No. Or did they help with the complicated paperwork? No. They were not helpful” (Vocal Representative 1).

Based on the group interview conducted regarding perceived treatment of the potable water committee from the municipality, members felt they were a 'put off' 
committee — designed as a façade of citizen participation, but in reality intended to put off the action of prioritizing and implementing the potable water project in their community.

\section{Outcome: Perceived impact of participation}

It was a goal of the present study to analyze the impact that these groups have on government accountability, transparency, efficiency, and improvement of overall government performance. In an attempt to clarify the role of the potable water citizen committee in the process for establishing potable water in the community, an interview was conducted with the director of the Operation of Potable Water in the Department of Urban and Ecologic Development.

According to this interview, a citizen committee must be present to implement public works related to potable water. In this particular case, funds came from Section 33 and "the company who carried the work out was chosen from a group from the private sector who presented their proposals, the most economical and most efficient and effective one was selected to carry out the project.” The department does not maintain contact with citizen committees after project completion because after the infrastructure is created, the municipality becomes responsible for providing the service. According to the interview, initially about 214 families were provided with service, and then 43 were added later. The department is charged with chlorinating the product and maintaining a constant supply. The monthly per family average cost is around 78 pesos and this price was based on "the cost of salaries, electricity, maintenance cost, repair, etc. but not the initial sunk cost of the project." "The infrastructure money was provided by the federal government [and] we don't have to pay that money back, even though the Law on water 
and its related treatment in the State of Puebla, indicates that the initial investment is recoverable, and retrievable, through the monthly bills etc., we don't try to regain that money back, in this case the community was really supported.” However, "Only 30\% of the people who receive the service pay for the potable water, 70\% doesn't pay.” When asked if the committee could help inform the community of this service and promote that they pay, the interviewee stated: "The committee is gone at this point, and we inform the people by passing out a flyer stating how much they need to pay. They still wait to pay as long as they can, some haven't paid in two years and then they can't pay and then they want to petition for help so they don't' have to pay, it is complicated.” Thus, even though decentralization reform promoting citizen participation is designed to aid in cost recovery for infrastructure, this did not occur in this particular case study.

When questioning members of the citizen committee and the community about the potable water committee's impact on the project, especially with regard to improved governance, transparency, cost effectiveness, accountability, and overall project quality, the results were as follows. Neither the members of the community nor the citizen committee knew the final, total costs of the potable water project. The citizen committee knew only of their personal expenses and only kept track of the use of the contributions collected from the community. As stated by an interviewee of the committee: "As far as transparency, we were never informed on the cost of the project, they chose their own construction firms and they dealt with their budget in doors” (committee president). Thus, little can be said about the cost effectiveness of the project from the perspective of the 
citizenry. ${ }^{57}$ "In terms of government accountability, there is nothing we can do to make them accountable for the things they do wrong, and well, sometimes there is no accountability even within the committee" (community resident). This comment was made in reference to a misuse of funds by one of the members of the potable water citizen committee, who, after being accused of stealing money, was removed from the group but was not forced to return the funds.

When asked about the quality of the project, a member of the committee answered; “Well, people don’t know what a water project is supposed to look like, and sometimes even if people are not happy, they are pressured into signing when the work is done” (vocal representative 3). When asked if this member felt pressured to sign to accept the project he said, "kind of but look, have you seen the street Benito Juarez, up by the church? [...] when that road was put in, they left it with a light pole right in the middle [and when they complained] the community was told that the municipality put in the road and the neighbors had to put in the money to change the place of the pole, [not them,] so they signed, they didn't have the money” (ibid.). In questions regarding level of satisfaction with the potable water project, the answers from committee members interviewed as a group were mixed. This mixture of feelings was exemplified by one interviewee, who was asked if the project was implemented in a satisfactory manner: "yes and no, I have seen that where the water is collected it overflows and well, they waste water, they turn it off certain days of the week but other than that, yes we are satisfied with the quality of the project” (committee president). Others said they were happy about the water, but worried the supply plumbing pipes were too small and made of material

\footnotetext{
${ }^{57}$ The government officials interviewed indicated that the project costs were $\$ 2,290,736.54$ pesos from FISM
} 
that would deteriorate with time. Two committee members indicated the location of a leak in the pipe system that occurred shortly after project completion and that they have been asking the municipality to fix to no avail, adding to the concerns over the overall quality of the project. The same concerns were expressed by members of the community. There were equal amounts of pro and con comments — and many “yes, but” comments.

\section{Tepoxtla Street Paving Committee:}

Factors that affected the formation of the committee:

According to the interviews with this citizen committee, and residents living on Tepoxtla Street, neighbors began petitioning the local auxiliary government to pave their street approximately six years prior to the public work being prioritized. One day, the Mayor of Cholula "unexpectedly showed up [on our street] with the auxiliary president looking for people to gather and form a group so that we could begin the process of getting the road paved. We [the group that formed] filled out the paperwork in the auxiliary office and they then took it to the municipal offices and we became a committee” (president of the committee).

As narrated by the committee president, the group of neighbors who met upon the arrival of the mayor was small (9 people). The auxiliary president met two people on the street and walked with them to the local store on the respective street. He called the store owner to meet with him at the store, asked him to become the president of the committee and call his 'compadres'58. The newly nominated committee president called his neighbors (friends, male businessmen living on the street) and along with the three other

\footnotetext{
58 'friends in English'
} 
neighbors present in the store (they recall two women and a man), discussed the street paving prospects with the Mayor and the auxiliary president. The remaining citizen committee members (all friends with the store owner) self-nominated themselves to support the efforts. The composition of the groups is as follows:

\begin{tabular}{|l|l|l|l|l|l|l|}
\hline $\begin{array}{l}\text { Citizen } \\
\text { Committee }\end{array}$ & $\begin{array}{l}\text { Year } \\
\text { formation }\end{array}$ & $\begin{array}{l}\text { Year } \\
\text { Recognized }\end{array}$ & $\begin{array}{l}\text { \# of } \\
\text { Members }\end{array}$ & \# Elected & $\begin{array}{l}\text { Age: } \\
\text { above } \\
30\end{array}$ & $\begin{array}{l}\text { Year Project } \\
\text { Completed }\end{array}$ \\
\hline $\begin{array}{l}\text { Tepoxtla } \\
\text { Street }\end{array}$ & 2005 & 2011 & 6 & $\begin{array}{l}5 \text { self- } \\
\text { nominated; } \\
1 \\
\text { approached } \\
\text { by } \\
\text { auxiliary } \\
\text { president }\end{array}$ & & \\
& & & & & & \\
& & & & & \\
\hline
\end{tabular}

All members of the committee indicated that their project was likely prioritized because the mayor was originally from the township of Tonantzintla and he probably wanted to "give back" to the community, even though he had not been elected based on any such promise. In open ended questions, when asked about the factors that affected individual selection/self-nomination of committee members, two factors emerged. One was being well-connected, and the other was being known by the community as trusted and active members of the community. "Everyone who nominated themselves was active" (committee treasurer), and "we all knew each other and everyone knows and trusts us because we are active" (vocal representative one). When asked about specific factors such as gender, participation in the church, personal income and political 
aspirations - and the role these factors play in the formation of these types of committees—-the results were as follows:

\begin{tabular}{|c|c|c|c|c|}
\hline $\begin{array}{l}\text { Citizen } \\
\text { Committee } \\
\text { Member }\end{array}$ & Gender & $\begin{array}{l}\text { Participation in } \\
\text { the Church }\end{array}$ & $\begin{array}{l}\text { Personal } \\
\text { Economy }\end{array}$ & $\begin{array}{l}\text { Political } \\
\text { Aspirations }\end{array}$ \\
\hline President & $\begin{array}{l}\text { "Yes, even in } \\
\text { the other } \\
\text { committees, the } \\
\text { ones for the } \\
\text { drain and the } \\
\text { light, it was } \\
\text { men, because } \\
\text { they have } \\
\text { power." }\end{array}$ & $\begin{array}{l}\text { "I have been } \\
\text { and an active } \\
\text { member of the } \\
\text { community, I } \\
\text { have sponsored } \\
\text { several events, } \\
\text { that is why I } \\
\text { accepted the } \\
\text { nomination." }\end{array}$ & $\begin{array}{l}\text { "Yes, we have } \\
\text { to put the cost } \\
\text { ourselves of the } \\
\text { sidewalks. [... } \\
\text { Moreover] we } \\
\text { need gasoline } \\
\text { to go here or } \\
\text { there to copies, } \\
\text { or have a } \\
\text { meeting and } \\
\text { give a drink } \\
\text { (soda), it all } \\
\text { comes from } \\
\text { us." }\end{array}$ & Some \\
\hline Secretary & Some & Some & Yes & None \\
\hline Treasurer & Some & Some & Yes & $\begin{array}{l}\text { "I don't but } \\
\text { some in the } \\
\text { group do and } \\
\text { this might have } \\
\text { affected their } \\
\text { wanting to be } \\
\text { part of the } \\
\text { group." }\end{array}$ \\
\hline 1.Vocal Rep. & Some & Yes & $\begin{array}{l}\text { "Yes, we have } \\
\text { to pay for the } \\
\text { sidewalk" }\end{array}$ & Some \\
\hline 2.Vocal Rep. & Yes & Some & Yes & None \\
\hline 3.Vocal Rep. & $\begin{array}{l}\text { "Yes, here we } \\
\text { were all men." }\end{array}$ & Some & Yes & None \\
\hline
\end{tabular}


Gender was identified as a factor in participation of public works committees, not just by members of the street paving committee, but also by community members who resided on the street in question. Participation in the church and personal income were also seen as influential in the selection of participants. It appeared that those who are involved in the church and sponsor parties are also more likely to sponsor or contribute financially to public works in the area. Three members of the committee identified that participation in public works committees was a way of attaining political clout and aid in attaining future leadership positions. The remaining committee members and most community members did not indicate this was the case.

Factors identified by committee members that helped them attain their goals

Because the work was in its initial stages, committee members were asked only what factors, thus far, were facilitating work progress. The answer identified by all members was 'being persistent': "We try to go once a week, at least every two weeks" (committee president). Moreover this group also recognized, as the potable water committee recognized, the importance of jumping government tiers-in other words, as noted by a member of the committee: "going to the municipal government directly is the best” (vocal representative 1). This committee consulted directly with the municipality instead of approaching the auxiliary government.

On the Typology: Treatment received from the Municipality

When individual committee members were asked about the treatment they received from the municipality, members indicated that at the beginning, the municipal 
mayor was very helpful: "the mayor this year is from this area so, that helped [but then,] well, they have a lot of work. We almost felt they forgot about us, so we go and put pressure and I think persistence is why they will get it done, they know we will not forget” (committee president). Because the project was not completed, little could be said about the impact of this group on government performance. As far as transparency is concerned, none of the members of the committee knew how much the street would end up costing them or the municipality. ${ }^{59}$ All they knew was that they, the committee, would end up having to collectively cover the cost of the sidewalk. The members of the committee were not sure if that cost would come out of pocket or if they would put a part and collect the rest from their neighbors.

\section{Paving of Revolución Street:}

Factors that affected the formation of the committee:

Discussing the committee's formation, the committee president indicated: "We had been working to get this road done for such a long time, and we were not just waiting but calling every day to see if there was any movement. We are lucky, some neighbors have been waiting for 15 or more years and because they don't get along with the local politicians their streets never get done. Then they give up.” Because of the system of representation and election by borough in the government in Santa Maria Tonantzintla, the committee had to wait for an auxiliary president from their barrio to be elected before their street was prioritized: "This should not play a factor but as you can tell it did. The street in San Pedro got paved but ours didn't' and well, we had to wait for the next

\footnotetext{
${ }^{59}$ According to the municipality, this project will be funded through FORTAMUN (2011) and would cost $\$ 3,339,392.73$ pesos.
} 
president but by then we had already given up and gone directly to the municipality” (committee secretary). To get the committee formed, "we had to go to the auxiliary president to get recognized as a group and make your petitions” (committee president). This group had only one woman member, self-nominated to join the group after the remaining male members were elected.

\begin{tabular}{|l|l|l|l|l|l|l|}
\hline $\begin{array}{l}\text { Citizen } \\
\text { Committee }\end{array}$ & $\begin{array}{l}\text { Year } \\
\text { Formation }\end{array}$ & $\begin{array}{l}\text { Year } \\
\text { Recognized }\end{array}$ & $\begin{array}{l}\text { \# of } \\
\text { Members }\end{array}$ & \# Elected & $\begin{array}{l}\text { Age: } \\
\text { above } \\
30\end{array}$ & $\begin{array}{l}\text { Year Project } \\
\text { Completed }\end{array}$ \\
\hline $\begin{array}{l}\text { Revolución } \\
\text { Street }\end{array}$ & 1999 & 2006 & 5 & $\begin{array}{l}4 \text { elected; } \\
1 \text { self- } \\
\text { nominated }\end{array}$ & 5 & 2007 \\
\hline
\end{tabular}

When asked about the role that specific personal factors played in the election of members to the committee, the results were as follows:

\begin{tabular}{|c|c|c|c|c|}
\hline $\begin{array}{l}\text { Citizen } \\
\text { Committee } \\
\text { Member }\end{array}$ & Gender & $\begin{array}{l}\text { Participation in } \\
\text { the Church }\end{array}$ & $\begin{array}{l}\text { Personal } \\
\text { Economy }\end{array}$ & $\begin{array}{l}\text { Political } \\
\text { Aspirations }\end{array}$ \\
\hline President & Some & None & Some & $\begin{array}{l}\text { "Yes, well, I } \\
\text { love politics } \\
\text { and getting } \\
\text { involved and } \\
\text { no because I } \\
\text { don't run for } \\
\text { office, maybe I } \\
\text { should. But I } \\
\text { won't." }\end{array}$ \\
\hline Secretary & $\begin{array}{l}\text { "Yes, } \\
\text { unfortunately } \\
\text { yes. Men are the } \\
\text { ones elected and } \\
\text { I nominated } \\
\text { myself, I do feel } \\
\text { that it plays a }\end{array}$ & $\begin{array}{l}\text { "No. I am not } \\
\text { an active } \\
\text { participant in } \\
\text { the church and } \\
\text { although that } \\
\text { plays a big } \\
\text { factor for lots of }\end{array}$ & $\begin{array}{l}\text { "Yes, I saw } \\
\text { that that played } \\
\text { a role in who } \\
\text { got selected, } \\
\text { usually people } \\
\text { who have a } \\
\text { store or who }\end{array}$ & Some \\
\hline
\end{tabular}




\begin{tabular}{|c|c|c|c|c|}
\hline & factor.” & $\begin{array}{l}\text { things, my } \\
\text { neighbors were } \\
\text { willing to } \\
\text { overlook that } \\
\text { and they didn't } \\
\text { give me any } \\
\text { pressure for it.” }\end{array}$ & have more.” & \\
\hline Treasurer & None & None & $\begin{array}{l}\text { "Some, we } \\
\text { have to pay for } \\
\text { lots of legal } \\
\text { processes and } \\
\text { most people } \\
\text { can't afford } \\
\text { them." }\end{array}$ & None \\
\hline 1.Vocal Rep. & --------------- & -------------- & ------------- & --------- \\
\hline 2.Vocal Rep. & -- & $\begin{array}{ll} & - \\
-- & \end{array}$ & $\begin{array}{l} \\
--\end{array}$ & --------- \\
\hline
\end{tabular}

Factors identified by committee members that helped them attain their goals

In interviews, committee members indicated that working directly with the municipality, "bypassing the auxiliary junta (the township gov.) was useful because it helped keep track of who was really going to conduct the public work" (committee secretary). "Unfortunately, from the year the committee started requesting the work, there were two municipal elections and the petition process had to start all over again” (committee president). In other words, with each election for mayor, because of the lack of municipal record keeping, the committee had to submit a new petition from the group to the administration to have them re-consider paving the road. Moreover, during that period, the committee lost two of its members, complicating matters for the group. Unfortunately, one of the members never saw the project reach its goal. Committee members indicated that even more than working directly with the municipality, persistence in petitioning the work was important. "Every year the municipality would 
ask [them] to do something new, get a plan made, get more contributions for the sidewalks, re-register when new elections came in, etc.” (committee treasurer). When they had to re-register the group after the elections form mayor with the new administration, they felt that maintaining good relations with the auxiliary government was important because government personnel could create a document recognizing that the committee was indeed long-standing — and not forming for the first time. "Money was also important, we got a lot of money stolen [from politicians promising favors] but regardless, even if some was stolen, we were happy to have it because, without it, we would not have gotten our street paved" (committee president). Each committee process/activity required some amount of money, and it was important to have funds readily available.

On the Typology: Treatment received from the Municipality

When asked about the municipality's treatment of the committee, one member answered:

"In our case, they made things more difficult than they had to be. For starters, it became obvious that the auxiliary president didn't want to get our road paved. So, we still formed a committee and waited while one road, the one he lives in, in San Pedro got paved. [After that one got done,] still, nothing. Then, we jumped right to the municipality, which unfortunately also gave us trouble; they would give us the run around. Sometimes, they would even send us to meet with someone who really was not the person we were asking to meet and they would say it was. I recognize faces, I am not stupid” (committee president). 
Another committee member continued;

“Then, one day, his guy from a political party came and said he would do what he could to get the street paved but that we needed to pay for a study. He convinced our committee to pay him, from our pockets, you know you get frustrated and just pay out of your pocket what you can, 5,000 pesos to get the study in. The study was a line on a paper nothing, nothing. So, we kept it but we got ripped off. The municipality didn’t need it. Then, while the same president was in power, we would go to see when our street was going to get paved. Believe it or not, they would say, we don't' have a record of your petition. How could they not? Good thing we kept our study and our petitions and then started to bug and bug and bug, like every other day we were calling” (committee treasurer).

The other committee members had similar comments on the treatment they received from the municipality, indicating that the municipality was treating them as a put off committee.

Outcome: Perceived impact of participation

Lastly, committee and community members were asked if they were content with the quality of the road. Most said, 'I am happy it is done.' However, committee members indicated that although they were happy with the road, they were not absolutely convinced that the work was completed correctly. They lacked trust in the workmanship because "when they were putting in the road they discovered that the drainage of our street was never connected to the main line. So, that is why there was always moisture in that lot at the end of the street, we had worked to get that drain in years back and well, 
look how that turned out so, who knows who this will end up, thus far fine" (committee president). Neither committee nor community members knew the project's final cost; moreover, they were not aware if the government maintained records of the work.

\section{Section 5.3 SIF and Public Schools; 'padres de familia'60}

In the township of Santa Maria Tonantzintla, personnel from three (out of eight) public schools were interviewed to gain understanding of the role that citizen committees play in implementing public works at these institutions. Interviews were conducted in the middle schools 'Telesecundaria Alejandro García' and 'Secundaria Enrique Erro,' and the high school ‘Bachiller Guillermo Haro.' Interviews were not conducted in elementary schools or kindergartens because the municipality, specifically the trustee of public education, stated that while middle and high schools are overseen by the municipality, it is not directly responsible for elementary schools and kindergartens. Although public works committees/citizen committees operated in the initial stages of the creation of schools, after the schools were operational, parent groups/‘padres de familia’ took charge and citizen committees dissolved and no longer participated in school affairs.

\section{Escuela Secundaria Luis Enrique Erro, C.C.T. 21EEO3172;} Interview with school vice-principle, Miguel Joaquín Quiroz \& two teachers.

In response to a question about the role of citizen committees in implementing public work projects in schools, the vice-principle of the middle school—Luis Enrique Erro-first provided a brief history of the school and explained the critical role that a citizen committee played in its creation:

${ }^{60}$ Parent groups in English 
"In 2002, a citizen committee who had been petitioning for several years to get a school built, and had already bought the land where the school they wanted would be built, they got the go ahead from the municipality to start running a school and I was hired as a vice-principal. When I came in we did not have classrooms. No space to give classes. We operated from the 'casa de la cultura' (municipal cultural house/space in English) for the first years and then, for I think for one year, we operated from the offices of the auxiliary presidency. The committee continued petitioning for the construction of the school. We could not believe that the government would open a school without actually having a school. We, the school principal and the parents, and the original committee, petitioned and petitioned for the project. It wasn't until a couple of years later that they finally prioritized us and got the school built in 2005. They used funding from Ramo 33 to carry out the construction. They built three classrooms and a bathroom within the year; two classrooms and one laboratory. They left the building empty.”

The committee that originated the project, and purchased the land for its construction $^{61}$, continued the petitioning process to initiate construction but dissolved after the school was built. According to the interviewee, there was no transparency or accountability to monitor the cost effectiveness of the project. Nobody knew how much the municipality paid to complete construction. Regarding treatment the committee and school personnel received from the municipality and auxiliary government during the

${ }^{61}$ Utilizing funds they had collected from neighbors. 
process, the interviewee stated: "We were treated well, but it took three years!!! We had to pressure to get this work prioritized [...] the auxiliary president had already prioritized other works.” When asked if he felt the work would have occurred if the committee had not participated in petitioning, he answered; "Definitely not, there was no plan for our school to get built.” All interviewees indicated that citizen participation, channeled through this citizen committee, initiated creation of the school. There was early involvement and persistence throughout the entire process, without which the needs of the community would not have been met.

Once the school was built, and the citizen committee dissolved, a comité de padre de familia (a parent group, in English) was formed. It was a parent group that motivated the parents of the school to contribute money to equip the laboratory and the classrooms. The parent committee received matching funding from the "programa de escuela digna" to purchase the remaining benches and black-boards for the classrooms. According to one teacher, "the release of funding from the program of 'escuela digna' was released because of political reasons, elections were coming up.” Regarding the composition and responsibilities of these groups, the vice principal stated:

“The 'comités de padre de familia' form every year. There is a president, a vice-president, a treasurer, a secretary and 5 vocal members. At the beginning of the year they determine how much each parent has to pay for the maintenance of the school. The money collected goes for basic things like, money for the salary of the maintenance personnel, money for the painting the school, the garden, electricity, water, etc. all the maintenance. They are in charge of those finances and also working with 
us to solicit projects from the auxiliary and municipal presidency. They are a mixture of males and females and they are usually the parents with time in their hands for this kind of thing. There is nothing particular about these individuals besides the fact that they are responsible people.”

As indicated by one teacher, "it was one of these parent groups which took charge of the second phase of the schools construction, the building of two other classrooms and one computer room which took place in 2009.” This parent group and the staff who worked with them began petitioning for the building of the second story about a year after the initial construction was completed. The second stage of construction was implemented with money from the Secretary of Public Education, a state entity that pays teacher salaries. According to the interviews, there was no transparency in the use of funds and no disclosure of the cost of the $2^{\text {nd }}$ stage of construction. When school staff was asked if these projects could be implemented or initiated without the intervention of the parent groups, one teacher answered: "definitely not, [...] we have to push every year for anything we want to get done.” Although parent groups currently petition for public infrastructure projects at this school, the vice principal indicated that at the beginning, it was a citizen committee that served as a catalyst - a citizen committee that later became a parent group.

2. Bachillerato Guillermo Haro, Calle Reforma Sur. Interview with Directora Matilde Zambrano Teutl \& a teacher who facilitates the participation of the parent committees in the school. 
Guillermo Haro is a state school that was built ten years prior to the interviews carried out in 2011. The interviews conducted at this school, as with the others, aimed to determine the process of implementing infrastructure projects in these institutions and the role of citizen committees, if any, in that process. According to the interview with the school principal, it is only parent groups who participate in petitioning for infrastructure projects—not public work committees. Moreover, according to the school principal, these parent committees:

“are essential in petitioning for any project, they are elected every year. They have to put in half the funding for most projects. For example, today we inaugurated the infrastructure or the equipment for the laboratory, the parents put half the funding, and the municipality put the other half. In addition, the money they collect from the other parents is used for maintenance, painting of the school etc.. The parent groups, together with me [the principal], have to first petition the auxiliary junta and then the petition goes to the municipality and then they decide what funding we get, $[\ldots]$ you can't jump the auxiliary junta and the municipality, it is not convenient to do so. If you do, you can get in problems.”

It is interesting to note that as with the public work citizen committees, these parent groups must also contribute funding in order for their petitioned project to be implemented. Moreover, party politics plays a role in the release of funds for schools. Specifically, when the party in control of the municipality is the same as the party in control of the state government, "things run more smoothly, at least from our experience 
[and] we have been pretty lucky because these last six years a PAN president has been in power and thus the funding has come in quite smoothly” (school principal).

When asked about the factors that affect the formation and composition of parent committees, factors such as gender, income, and participation in church, one teacher indicated that "no, there might be a few more women but that is hardly notable [...] mostly parents nominate themselves and it is not until there really is a lack of volunteers that people start nominating each other. It is usually just based on who has more time available and nothing else, and no, personal income doesn't play a role, the contributions are made by all the parents so personal income does not play a role and neither does participation in the church.” Thus, the factors that affect the formation of the parent group differ from those that affect the public works citizen committees analyzed in the same area.

3. Telesecundaria Alejandro Garcia, Calle Adolfo López Mateos. Interviews with school principal Mariana Lopez Espinoza and members of the staff actively involved with the parent groups.

When interviews with the school staff were conducted, this school was noted to be ten years old and have 52 enrolled students. The staff was asked about public works citizen committees, and if they are used by the school to solicit funding for infrastructure projects. The individuals interviewed indicated that if there is some collaboration with the committees, it is only when they are consulted by a committee because a particular community project will affect their school, such as the paving of a road. However, for internal matters, it is the parent committees who solicit the funds needed for 
infrastructure projects. When asked to elaborate on their collaborations with citizen committees, it was noted that collaboration is rare and has only occurred twice: once when a committee asked the school to collect parent signatures to complement a petition for potable water and second when approached by a committee asking the parents to sign a petition to pave the street leading up to the school.

On the other hand, parent committees are used with regularity. These groups are composed of members who are elected every year. There is a president, vice president, treasurer, secretary and a set of two vocal representatives. Their main job is to collect an annual fee (approximately 70 U.S. dollars) from parents and to use these fees to maintain the school and purchase material that might be needed for a special event. Their secondary role is to annually petition, with the support of the school principal, the municipal and state governments for certain infrastructure projects. According to the interviews, the only project implemented in the past six years was the paving of the school driveway. All the parents contributed around 35 U.S. dollars for the sidewalks. According to the school principle, "that is a lot of money considering how many of the parents have difficulty paying the yearly maintenance free which for most, has to be divided into instalments for them to be able to liquidate.” According to the interviews, the parent groups must collect matching funding to implement all projects in the school. “Thus, first the projects are delayed because of lack of prioritization by the municipality and the auxiliary government, and then projects are delayed because they can't collect the matching funds” (school principal). Government funding mostly comes from a Federal program called 'peso por peso’ ('dollar per dollar'), which according to the principal, 
"means we are supposed to pay for half of any project even while our parents have difficulty paying the yearly quota!”

In the past five years, the school petitioned for funding from both the auxiliary junta and the municipality, and because of the inability to match the requested funds, none of the projects have been implemented. At the top of the list of these projectswhich includes building a fence around the school, building a main office, and building a partial enclosure that will allow kids to play outside when it rains-is upgrading the school restrooms, which currently do not have running water. Currently, the staff and children must transport water from outside to flush the toilets. Government authorities have not responded to these projects and the interviewees at the school felt this was because the government knows the parents cannot contribute to the cost of the project. That said, "Every three years politicians running for mayor come knocking at their door making promises that if elected, their special projects will be carried out, but nothing gets done” (teacher interviewed).

When asked in more detail about the formation of these parent groups and the characteristics its members have in common, school staff noted that although most of the members were females, they were not the overwhelming majority. Moreover, as noted in the other schools, the factors that affect the formation of citizen committees in Tonantzintla, (gender, personal income political aspirations, and religious affiliation) do not seem to be present in parent committees. Schools that lack resources (i.e., the parents have less personal income) receive less funds. Moreover, all school personnel felt that party politics played a role in the release of state funds. 


\section{Section 5.4 Determinants of Citizen Participation in San Andrés Cholula}

In the municipality of San Andrés Cholula, projects are prioritized during the election campaign. After these projects are prioritized, the municipality opens up its doors to requests made by auxiliary presidents and citizen committees. In general however, it is the auxiliary presidents who channel the demands of the citizen committees. Citizens who organize themselves into committees can petition the municipality directly, but as noted in the interviews, support from the auxiliary junta in which they reside can help them gain legal recognition from the corresponding directive in the municipality. Until they are legally recognized by the directive of citizen participation, un-official public works citizen committees loosely resemble 'Advisory Committees'-that is, citizen committees who can potentially affect the decision-making process, signaling the importance of a project and thus potentially gaining its prioritization. However, once recognized by the municipality and legalized by the directive of citizen participation, 'public works' committees, can become Supportive I, III and Put-on II committees ${ }^{62}$.

In all cases, the municipality expects monetary contributions from its citizen committees to match part of the cost of implementing a public work. Moreover, in some cases, committees are required by the municipality to aid the process by obtaining the legal permits, studies, etc., required to implement infrastructure projects—tasks which often require the committees to interact with different offices within the municipality and different levels of government. This process requires a significant time commitment from

\footnotetext{
${ }^{62}$ Public work committees can petition the construction of a new school but once a school is formed, 'parent groups' replace these committees in the solicitation of aid from the municipality.
} 
members of the citizen committees, a certain level of literacy, political savvy, knowledge of the system, good record keeping skills, and a certain level of trustworthinessobtained within the community. The following factors, noted by committee members, affect the ability of citizen committees to gain attention for their demands from the municipality: persistence, jumping government tiers, knowledge of the system (literacy), time, and money.

Moreover, in the township of Santa Maria Tonantzintla, the following factors were identified as affecting the selection of individuals who will form part of citizen committees: participation in the church, gender, and personal income. Analyzing these factors in detail, parallels emerge between citizen committee formation and traditional church-related mechanisms for acquiring leadership roles and administrating community affairs-specifically the cargo system. As noted in Chapter 4.7, there was an adoption of church practices (i.e., rotating representation of each parish and its patron saint in the main church in Santa Maria Tonantzintla) by the civil/political system and specifically the township method of electing auxiliary presidents based on the rotation of representation of each borough in the township government. Upon further inquiry, this study found that a variation of the cargo system (also known as the civil-religious hierarchy, fiesta or mayordomía system), identified by Dewalt (1975), is still present in the religious life of the township, and I posit, in addition to spilling over and affecting the election process of auxiliary presidents, also affects the election of representatives who will form citizen committees.

Under the cargo system, indigenous residents assume the responsibility of organizing fiestas and managing local administrative affairs (Friedlander 1981). In 
alignment with the defining characteristics of the cargo system, as a way of acquiring prestige in the community, men in the township boroughs of Tonantzintla volunteer to hold a cargo (religious office) and implement the functions necessary to run the church and its parishes. As noted in other cases, "traditionally, passage through the complete system of hierarchically based offices has been the most important means of acquiring prestige in the community” (Dewalt 1975: 90). In addition to installing a system of elite domination within the communities, noted by Eric Wolf (1982), the civil-religious hierarchies allow "that elite to represent the community as a whole before external power holders and authorities" (Chance 1985: 148). The participants in this system "are men who have proven their moral worth and often exert considerable influence in local affairs" (ibid.). Moreover, although "today the civil offices and the [... religious] positions do not have an explicit relationship to one another [...] it is not unusual for a villager seeking a political career in the pueblo to volunteer regularly [in church posts]” (Friedlander 1981: 140). Thus, the participants of the system have a certain degree political savvy, especially those who run for office as auxiliary presidents ${ }^{63}$ Furthermore, the network includes those who have connections to a political circle.

As noted by Chance, the cargo system requires substantial financial outlays from its office holders to sponsor religious activities (1985). In Tonantzintla, those cargo holders who cannot afford to privately sponsor a particular party, event, or project collect money from the community and administer it accordingly. Participation in a religious cargo is one way to demonstrate administrative abilities: one's ability to collect funds

\footnotetext{
${ }^{63}$ Interviews with community members as well as auxiliary presidents confirm that active participation in the church helps build political credibility, and thus many auxiliary presidents emerged as politicos after serving office in the church.
} 
from the community and administer them accordingly to support church activities. Ascendance through the cargo system is a way to gain prestige and a certain level of trustworthiness. In parallel, the ability to raise funds to match the funding from the municipality, and administer them accordingly, is needed by citizen committee members to implement an infrastructure project in the current municipal participatory process. Citizen committee members must be trusted not to steal or misuse funds to be successful in their collection efforts. As noted by Crow, in general, participation depends on the confidence of individuals to collaborate (e.g. trust is imperative) (2009). Previous experience holding a church cargo is an effective way of proving one is trustworthy in managing community funds; If the petitioners are able to prove they have sufficient accumulated funds to sponsor the project (either individually or collectively), there is increased likelihood that the petition will be considered. In addition, those who have held a cargo are also likely to have a network of political connections and clout to aid when soliciting a project to be prioritized on behalf of the community. Thus, holding a post in the church is a valued trait in citizen committee members.

Notably, gender played a significant role in electing an individual to a citizen committee. If community members are trying to emulate the traits of cargo holders in the citizen committees, it explains why men are sought after and not women (cargo holders are all males). In any case, as discussed in Chapter 4, community meetings to prioritize public works are initiated and held in the boroughs' parishes. Thus, in general, participation in these church meetings facilitates being informed of community affairs. Notably, the 2010 LAPOP study found that most citizen participation in México occurred within religious organizations. In any case, in the township of Santa Maria Tonantzintla 
in San Andrés Cholula, the process of participation available to citizen committees reinforces the selection of members according to old traditions.

\section{Section 5.5 Tenango del Aire's 'COCICOVIs'}

\section{COCICOVI Aula Telsecundaria San Mateo Tepopula}

Factors that affected the formation of the COCICOVI committee:

This COCICOVI was composed of three women who were self-nominated to be part of the group monitoring the infrastructure project that was prioritized by the municipality in 2009.

\begin{tabular}{|l|l|l|l|l|l|l|}
\hline COCICOVI & $\begin{array}{l}\text { Year } \\
\text { formation }\end{array}$ & $\begin{array}{l}\text { Year } \\
\text { Recognized }\end{array}$ & $\begin{array}{l}\text { \# of } \\
\text { Members }\end{array}$ & \# Elected & $\begin{array}{l}\text { Age: } \\
\text { above } \\
30\end{array}$ & $\begin{array}{l}\text { Year Project } \\
\text { Completed }\end{array}$ \\
\hline $\begin{array}{l}\text { Aula } \\
\text { Telsecundaria } \\
\text { San Mateo } \\
\text { Tepopula }\end{array}$ & 2009 & 2009 & 3 & 3 & 3 & 2009 \\
\hline
\end{tabular}

As indicated in the table below, none of the factors that affected the formation of the citizen committees in Tonantzintla affected the formation of this group.

\begin{tabular}{|l|r|r|r|r|}
\hline $\begin{array}{l}\text { Citizen } \\
\text { Committee } \\
\text { Member }\end{array}$ & Gender & $\begin{array}{l}\text { Participation in } \\
\text { the Church }\end{array}$ & $\begin{array}{l}\text { Personal } \\
\text { Economy }\end{array}$ & $\begin{array}{l}\text { Political } \\
\text { Aspirations }\end{array}$ \\
\hline $\begin{array}{l}\text { Contralor } \\
\text { Social 'A' }\end{array}$ & NONE & NONE & NONE & NONE \\
\hline $\begin{array}{l}\text { Contralor } \\
\text { Social 'B' }\end{array}$ & NONE & NONE & NONE & NONE \\
\hline $\begin{array}{l}\text { Contralor } \\
\text { Social 'C' }\end{array}$ & NONE & NONE & NONE & NONE \\
\hline
\end{tabular}


However, committee members were all parents of students in the school where the classroom was built and had participated in the 'parent groups' within the school prior to this work being prioritized. According to Contralor Social A, "we all are active in the school and we all knew each other so when the principal called a meeting after school and told us [parents] that the classroom was going to be built and that he just needed to form a COCICOVI, we all volunteered.” When asked what the difference is between COCICOVIs and parent committees, the principal indicated that "that while parent groups work on the maintenance of the school and planning of special events, COCICOVIs are formed for infrastructure projects.” According to the LAPOP (2010) study, most individuals participating in parent groups are women. Thus, it could be that this particular COCICOVI functions more as an extension of a parent group than a COCICOVI, because the meeting calling for its formation occurred within the schoolnot outside, among the general public.

According to the women in the COCICOVI, although they had been presented with a study indicating the cost of construction and the timeline in which the project would be carried out, they did not feel they had the competency to understand the construction plans and ensure that the plans were being implemented in a cost effective and adequate manner. The women felt they had access to state and municipal officials in charge of the COSIVOVIs when they had questions; however, they felt the project was carried out smoothly and thus never consulted them. As the Contralora Social C indicated, "I think everyone is happy with the outcome." All COCICOVI women interviewed concurred with the statement. 


\section{DIF Municipal}

Factors that affected the formation of the COCICOVI:

The current municipal president was elected based on a platform that, in addition to including the expansion of services to areas not included in the current urban zone, he would also prioritize the creation of a municipal Center for Integral Family Development (DIF acronym in Spanish). The prioritization of this project was led by the wife of the municipal president, who called for a meeting in the area of affected residents and helped the state COCICOVI representatives form a group to oversee construction. The women in the group were very excited to be part of this committee but were not completely satisfied with the process.

\begin{tabular}{|l|l|l|l|l|l|l|}
\hline COCICOVI & $\begin{array}{l}\text { Year } \\
\text { Formation }\end{array}$ & $\begin{array}{l}\text { Year } \\
\text { Recognized }\end{array}$ & $\begin{array}{l}\text { \# of } \\
\text { Members }\end{array}$ & $\begin{array}{l}\# \\
\text { Elected }\end{array}$ & $\begin{array}{l}\text { Age: } \\
\text { above } \\
30\end{array}$ & $\begin{array}{l}\text { Year Project } \\
\text { Completed }\end{array}$ \\
\hline $\begin{array}{l}\text { DIF } \\
\text { Municipal }\end{array}$ & 2011 & 2011 & 3 & 3 & 3 & 2011 \\
\hline
\end{tabular}

None of the women were involved in the municipal president's political campaign, which called for construction of the DIF. Moreover, none of the women indicated that any of the factors bellow had a role in their selection to be part of the COCICOVI. Although none of the women had participated before in a COCICOVI, and they had all nominated themselves, they had participated in a parent committee and felt sufficiently competent to participate.

\begin{tabular}{|c|c|l|l|l|}
\hline $\begin{array}{c}\text { Citizen } \\
\text { Committee }\end{array}$ & Gender & $\begin{array}{l}\text { Participation in } \\
\text { the Church }\end{array}$ & $\begin{array}{l}\text { Personal } \\
\text { Economy }\end{array}$ & $\begin{array}{l}\text { Political } \\
\text { Aspirations }\end{array}$ \\
\hline
\end{tabular}




\begin{tabular}{|l|c|c|c|c|}
\hline Member & NONE & NONE & NONE & NONE \\
\hline $\begin{array}{l}\text { Contralor } \\
\text { Social 'A' }\end{array}$ & NONE & NONE & NONE & NONE \\
\hline $\begin{array}{l}\text { Contralor } \\
\text { Social 'B' }\end{array}$ & NONE & NONE & NONE & NONE \\
\hline $\begin{array}{l}\text { Contralor } \\
\text { Social 'C' }\end{array}$ & & & \\
\hline
\end{tabular}

On the Typology: Treatment received from the Municipality

According to a group interview, the DIF took one year to build. However, the community had repeatedly asked the government to create a center for 12 years—-with no response. Once the women became part of the COCICOVI, they indicated that they were disappointed that no meetings occurred after the initial meeting to provide them with information on the progress of the project; they were also disappointed when members of the community asked for updates on the project, but no information was available. Moreover, the project's final costs exceeded projections, and they felt too much money was spent. They felt they did not know enough about construction to assess if the work was in compliance with building codes. When community members consulted them with doubts about the construction or complaints, the women indicated that it was not easy to contact state COCICOVI representatives and the process was not facilitated by the municipality. Thus, in addition to complaints about elevated costs, the COCICOVI members complained that they were not regularly updated by the municipality or the state; in other words, the government was not resolving doubts about the construction of the center. 


\section{COCICOVI Pavimento Hidráulico San Juan}

Factors that affected the formation of the COCICOVI committee:

This COCICOVI was composed of two women and one male. One of the women nominated herself and the other two other members were asked by the municipality to join the group because nobody else attended the meeting. The project took one year to complete (the project stayed within the timeframe allotted) and the committee was content with the process of paving the road, especially because they were able to verify that the project stayed within budget.

\begin{tabular}{|l|l|l|l|l|l|l|}
\hline COCICOVI & $\begin{array}{l}\text { Year } \\
\text { formation }\end{array}$ & $\begin{array}{l}\text { Year } \\
\text { Recognized }\end{array}$ & $\begin{array}{l}\text { \# of } \\
\text { Members }\end{array}$ & $\begin{array}{l}\text { \# } \\
\text { Elected }\end{array}$ & $\begin{array}{l}\text { Age: } \\
\text { above } \\
\text { 30 }\end{array}$ & $\begin{array}{l}\text { Year Project } \\
\text { Completed }\end{array}$ \\
\hline $\begin{array}{l}\text { Pavimento } \\
\text { Hidraulico } \\
\text { San Juan }\end{array}$ & 2006 & 2006 & 3 & 3 & 3 & 2006 \\
\hline
\end{tabular}

The members of the committee were asked why they decided to participate and all agreed that it was not so much of a choice but a sense of obligation because they were the only ones at the meeting. They had attended the meeting out of curiosity and did not engage the municipality to ask questions or be updated. They only attended the first and last meeting, which is where they were able to compare the resulting budget and time frame with what actually occurred. None of the members had previous experience with COCICOVIs and only one member had participated in a parent group. They all agreed that if an election had occurred to elect representatives for the COCICOVI, that none of the factors bellow would have affected the nomination process. 


\begin{tabular}{|l|c|c|c|c|}
\hline $\begin{array}{l}\text { Citizen } \\
\text { Committee } \\
\text { Member }\end{array}$ & Gender & $\begin{array}{l}\text { Participation in } \\
\text { the Church }\end{array}$ & $\begin{array}{l}\text { Personal } \\
\text { Economy }\end{array}$ & $\begin{array}{l}\text { Political } \\
\text { Aspirations }\end{array}$ \\
\hline $\begin{array}{l}\text { Contralor } \\
\text { Social 'A' }\end{array}$ & NONE & NONE & NONE & NONE \\
\hline $\begin{array}{l}\text { Contralor } \\
\text { Social 'B' }\end{array}$ & NONE & NONE & NONE & NONE \\
\hline $\begin{array}{l}\text { Contralor } \\
\text { Social 'C' }\end{array}$ & NONE & NONE & NONE & NONE \\
\hline
\end{tabular}

They were all happy with the treatment they received from the municipality and felt that they would participate again if needed. They were especially happy about being informed of the project costs and ensuring the project was implemented as promised. When asked about the quality with which the project was carried out they said they liked the new street but when asked about having it built up to code they all showed ambivalence in answering and concluded that, as nicely put by one of the members, "they did not have enough construction knowledge to know about the specifications met” (Contralor Social 'B”).

\section{COCICOVI Prolongacion Hidalgo Potable water and Drainage}

Factors that affected the formation of the COCICOVI committee:

This COCICOVI was the only case studied in Tenango del Aire that was composed entirely of men. Two of the men nominated themselves, one because he had knowledge of construction and the other because he was curious about the process of participating in a COCICOVI. The other member was nominated to the committee.

\begin{tabular}{|l|l|l|l|l|l|l|}
\hline COCICOVI & $\begin{array}{l}\text { Year } \\
\text { formation }\end{array}$ & $\begin{array}{l}\text { Year } \\
\text { Recognized }\end{array}$ & $\begin{array}{l}\text { \# of } \\
\text { Members }\end{array}$ & $\begin{array}{l}\text { E } \\
\text { Elected }\end{array}$ & $\begin{array}{l}\text { Age: } \\
\text { above } \\
30\end{array}$ & $\begin{array}{l}\text { Year Project } \\
\text { Completed }\end{array}$ \\
\hline $\begin{array}{l}\text { Prolongacion } \\
\text { Hidalgo }\end{array}$ & 2010 & 2010 & 3 & 3 & 2 & 2011 \\
\hline
\end{tabular}




\begin{tabular}{|l|l|l|l|l|l|l|}
\hline $\begin{array}{l}\text { Potable } \\
\text { water and } \\
\text { drainage }\end{array}$ & & & & & & \\
\hline
\end{tabular}

The youngest member of the COCICOVI volunteered because he had political aspirations and thought this would be a good way to find out how things were done. No other committee members had political interests and none felt the other factors listed below had a role in their election or self-nomination into the COCICOVI. None of the members had prior experience working with COCICOVIs.

\begin{tabular}{|l|c|c|c|c|}
\hline \multicolumn{1}{|c|}{$\begin{array}{c}\text { Citizen } \\
\text { Committee } \\
\text { Member }\end{array}$} & Gender & $\begin{array}{l}\text { Participation in } \\
\text { the Church }\end{array}$ & $\begin{array}{l}\text { Personal } \\
\text { Economy }\end{array}$ & $\begin{array}{l}\text { Political } \\
\text { Aspirations }\end{array}$ \\
\hline $\begin{array}{l}\text { Contralor } \\
\text { Social 'A' }\end{array}$ & NONE & NONE & NONE & NONE \\
\hline $\begin{array}{l}\text { Contralor } \\
\text { Social 'B' }\end{array}$ & NONE & NONE & NONE & NONE \\
\hline $\begin{array}{l}\text { Contralor } \\
\text { Social 'C' }\end{array}$ & NONE & NONE & NONE & SOME \\
\hline
\end{tabular}

The project took a little over a year to complete. Members were content with the project and their treatment from the municipality. The member involved in construction indicated that he was more actively involved than the other members in monitoring the cost and quality with which the project was carried out. He felt that short cuts-in terms of quality-were balanced with needs to keep within the budget. The member who had political aspirations indicated that although he felt "disappointed because he did not get to know more about the general process of how government operates, [he] did enjoy keeping members informed when delays occurred and why they occurred, etc." (Contralor Social 'C'). The Contralor Social 'B,' who was nominated and elected, was 
content but indicated that he only participated in the first meeting and the last meeting when the closure of the project occurred—he was not aware of any other meetings. The members of this committee did not remember anybody petitioning for the project and all were informed that the project would be implemented when the meeting to create the COCICOVI occurred. As a result, they were not asked about the process of prioritizing the public work.

\section{Section 5.6 Determinants of citizen participation in Tenango del Aire}

In Tenango del Aire, the factors affecting the formation of public works committees in Santa Maria Tonantzintla did not seem to affect the formation of COCICOVIs. In Tenango del Aire, COCICOVIs were more uniform in function and treatment. In Tenango del Aire, COCICOVIs resembled Supportive III committees—-they were utilized to evaluate a project and gain legitimacy by making sure it is implemented to specification. ${ }^{64}$ They were not required to make monetary contributions for their project, and the municipality was more transparent in providing information regarding the participatory process available to them. According to interviews in municipality, when a public work has been prioritized by the municipality, the office of the state controller in Chalco sends a delegate to call a meeting in the area where the public work will occur and form a committee with affected representatives: a COCICOVI.

A COCICOVI is to be comprised of only three people who should be elected and who are not expected to make any monetary contribution on behalf of the group or the

\footnotetext{
${ }^{64}$ Hypothetically, however, they can also be used as Supportive I committees in that they are used to legitimze a project that is not necessarily supported by the community.
} 
community $^{65}$. This was confirmed by everyone interviewed, including the municipality’s controller's office and most importantly the members of the COCICOVI ${ }^{66}$ COCICOVIs are not formed 'unofficially' prior to the work being prioritized by the municipality to promote the project, as occurs in some cases in San Andrés Cholula. The work of the COCICOVI is to ensure that a given project is implemented within the time period allotted, the budget and within the quality standards predetermined in a study provided to the COCICOVI. Although members of the COCICOVIs complained that in some instances they did not have the technical skills needed to determine if a project was within compliance of building codes, the overall process of participation was seen as being clear and easy to follow. The tasks involved with being a member of a COCICOVI were not perceived as being complicated.

Interviews with COCICOVI members indicated that they did not feel anything in particular affected their selection or self-nomination ${ }^{67}$. Interviews with the staff from the municipality's controller's office, the office in the municipality that oversees the COCICOVIs in the area, indicated that they, as the data indicated, found that most members were older women who participated in parent groups within the public schools. This resembles results found in the nationwide Latin American Public Opinion Poll

\footnotetext{
${ }^{65}$ According to interviews with community members and government officials, as late as the $1990 \mathrm{~s}$, contributions from the community were required for projects to be implemented.

${ }^{66}$ These same interviewees indicated that decades in the past, community projects were implemented by the municipality with expected, monetary, or physical labor contributions on behalf of affected citizens. In other words, the municipality had a history of using Faenas, the indigenous practice of having community members contribute with manual labor in carrying out public works.

${ }^{67}$ The exception was one COCICOVI member who nominated himself because he wished to become more involved in community government.
} 
(LAPOP 2010) survey, which found that most participants in 'committees for community improvement’ (citizen committees) in México are older women.

\section{Section 5.7 Evaluation of the Participatory Process: Conclusions}

As noted in the previous sections, the factors that affected the formation of citizen committees differed in each study site. In San Andrés Cholula, the following factors affected the selection of individual committee members: gender, participation in the church, and personal income. Moreover, the following factors affected citizen committees' ability gain recognition from the municipality: persistence, jumping government tiers, knowledge of the system (literacy), time, and money. The factors that affected the formation of public works committees in San Andrés Cholula did not seem to affect the formation of COCICOVIs in Tenango del Aire. Moreover, in the township of San Andrés Cholula, most citizen committee members were men above age 30 whereas in Tenango del Aire, the members were mostly women. These factors seemed to vary according to the nature of the participatory process, the present typology of municipal treatment, and the determinants that facilitated committee efforts to capture local resources.

In the township of Santa Maria Tonantzintla in San Andrés Cholula, the public works committees were more diverse in their formation (i.e., some were formed before the projects were prioritized and others after prioritization). As discussed in Chapter 4, public works committees also varied according to the motive of appointment by the municipality and thus treatment received by local government. The treatment these groups received from the local government-the municipal willingness to collaborate 
with citizen committees-affects the level of involvement of these groups in the local government. In Tenango del Aire, COCICOVIs were more uniform in function and treatment. The COCICOVIs resemble Supportive III committees as they were utilized to evaluate a project and provide legitimacy to the project by ensuring it was implemented according to specifications. The differences between public works committees in Tonantzintla and the COCICOVIs in Tenango del Aire become clearer using criteria specified by Rowe and Frewer (2000) to evaluate the participatory processes accessible to each.

Rowe and Frewer (2000) specify the following major points for evaluating participatory processes: acceptance criteria, which includes the criterion of representativeness (the public participants should comprise a broadly representative sample of the population of the affected public); criterion of independence (the participation process should be conducted in an independent, unbiased way); criterion of early involvement (the public should be involved as early as possible in the process as soon as value judgments become salient); criterion of influence (the output of the procedure should have a genuine impact on policy); and criterion of transparency (the process should be transparent; the public should be able to observe actions and the decision-making process) and process criteria, which includes the criterion of resource accessibility (public participants should have access to the appropriate resources to enable them to successfully fulfill their roles); criterion of task definition (the nature and scope of the participation task should be clearly defined); criterion of structured decisionmaking (the participation exercise should use/provide appropriate mechanisms for structuring and displaying the decision-making process); and criterion of cost- 
effectiveness (the procedure should in some sense be cost-effective) (Rowe \& Frewer 2000).

When examining the acceptance criterion in San Andrés Cholula versus Tenango del Aire, the following was observed with regard to each criterion:

1. Criterion of representativeness: participants should be "representative of the broader public (or the affected subgroups within the population), rather than simply representing some self-selected subset” (Rowe and Frewer 2000: 12). In both study sites, the citizen committees simply represented a subset of the population, specifically a subset comprised of those interested in implementing a particular project. In the Auxiliary Junta of Santa Maria Tonantzintla in San Andrés Cholula, the selection criteria for electing members of public works committees favored certain traits over others, typically: being a male, a business owner, and a participant in the church. These traits were preferred in the hope that—as a result of selecting a narrow subset of representatives - the needs of the group would be more readily heard. Thus, this criterion was not met. However, interviews with COCICOVI members in Tenango del Aire revealed that their selection or self-nomination was not influenced/affected by anything in particular; thus, this criterion came closer $^{68}$ to being met in Tenango del Aire.

\footnotetext{
${ }^{68}$ I state 'closer' to being met because there were not enough case studies to determine if the groups were a representative sample of the population or not.
} 
2. Criterion of independence: (1) project managers and facilitators of the participation process should be independent of each other; (2) public representatives should be independent of the sponsoring body (Rowe and Frewer 2000: 13). In the municipality of San Andrés Cholula, the citizen committees studied were diverse in function and treatment. In some instances, they form prior to the municipality's prioritization of a particular project and in others, they are formed after prioritization; on some occasions, citizen committee members are chosen at the discretion of the municipal authorities - a process that does not allow the public representatives to be truly independent from the sponsoring body. In general, when Funds for Social Municipal Infrastructure (FISM) are utilized from Section 33, project managers call the facilitators of the participation process within the municipality to visit the project's locale to form a public works committee. The interviewees from the directive of citizen participation indicated that they facilitate the plans/actions of project managers instead of helping citizen committee members voice their concerns. As a result, the role of the facilitators of the participatory process is compromised. Thus, this criterion was not met.

In Tenango del Aire, all citizen committees analyzed were uniform in function and treatment and all were formed after the project was prioritized by the municipality. There were institutionalized procedures in place to ensure that management was done by an independent wing of the municipality - the Internal Comptroller—and with state government oversight. Thus, procedures 
allowed for project managers and facilitators of the participation process to be independent of each other. Moreover, public representatives were also found to be independent of any affiliation to the sponsoring body.

3. Criterion of early involvement: public debate should include include deliberation of the underlying assumptions and agenda setting and not just discussion of narrow, predefined problems (Rowe and Frewer 2000: 13-14). The public deliberation process that occurs in the chapels of the township of Santa Maria Tonantzintla allows residents to prioritize projects needed in the community. Once priorities are established, citizen committees are formed to present specific projects to local government authorities. Unfortunately, this does not occur in all cases; in some instances, committees are formed after the local government has decided to implement a project. Moreover, the general public does not decide, once citizen committees are formed, which one of those committees should receive backing and support. Thus, this criterion is only moderately met. In Tenango del Aire, there is no early involvement; all COCICOVIs form after project selection has occurred and thus, this criterion was not met.

4. Criterion of influence: citizen committees should not be used simply to legitimize decisions or to provide the appearance of consultation without any intent of acting on recommendations (Rowe and Frewer 2000: 15). In San Andrés Cholula, this criterion is somewhat met. Citizen committees that exert 
influence can convince the municipality to act on their recommendation of which SIF projects should be prioritized. However, after the municipality receives input from citizen committees on which projects should be considered, citizen committees do not to participate in the process of determining how a project should be implemented. In Tenango del Aire, COCIVOVIs function only to monitor the implementation of a previously prioritized municipal project and are unable to exert community control over the assignment of resources. In other words, as noted by the FUNDAR study, mayors see the role of citizen committees as only instrumental (2006), to support a previously prioritized municipal project. This criterion was not met in Tenango del Aire.

5. Criterion of transparency: The process should be transparent so that the public can see what is occurring and how decisions are being made (Rowe \& Frewer 2000). In both locations, the decisions regarding project selection were made behind closed doors and without explanation to constituents. The citizenry is not allowed into the municipality's decision-making process regarding which projects to implement during the year. Moreover, they are not informed about the decision-making process regarding how projects should be implemented.

In San Andrés Cholula, citizen committee members are not provided any information regarding the committee's specific function and obligations nor are they provided with information to evaluate the process of 
implementing their specific project. When members of citizen committees in San Andres Cholula were asked, 'Do you know how much your project ended up costing?' All group members answered “no.” Participants recived limited or no information on a project's associated costs, materials used, approximate time of planed completion, etc., which impeded citizens from learning how to manage information and apply techniques of control, vigilance and supervision over the execution of public works. Although neither public works committees nor COCICOVI members were allowed insight into the decision-making process, and thus have no real ability to exert community control over the assignment of resources, COCICOVI members are informed about their specific duties and obligations and are able to monitor project execution. The COCICOVIs received project outlines, which included information on project costs, materials used, and a timetable of expected project completion, etc. Moreover, they are given the contact information of project facilitators at the municipal and state levels in case they have any questions. Thus, the process in Tenango del Aire allowed for more transparency during project execution. Although the criterion was not met in San Andres Cholula, it was moderately met in Tenango del Aire.

When examining the process criteria in San Andrés Cholula versus Tenango del Aire, the following was observed with regard to each criterion: 
1. Criterion of resource accessibility: citizen committees should have all necessary resources, which "include (1) information resources (summaries of the pertinent facts), (2) human resources (e.g., access to scientists, witnesses, decision analysts), (3) material resources (e.g., overhead projectors/whiteboards), and (4) time resources (participants should have sufficient time to make decisions)" (Rowe and Frewer 2000: 15). In San Andrés Cholula, this criterion was not met. The participation process required financial outlays and excessive time and specialized knowledge from participants. The municipality did not compensate citizen committee members for the cost incurred or provide them with facilitators to aid and inform participants. In Tenango del Aire, the participation process did not require financial outlays or significant time obligations. Moreover, facilitators of the participatory process helped provide participants with information they felt was needed to help them function as project evaluators. That said, the interviewed COCICOVI members stated that they lacked knowledge that would permit them to monitor and evaluate some of the technical aspects of public works. They felt the information provided was not sufficenitly adequate to truly help them serve as project quality evaluators. Thus, the criterion was moderately met in Tenango del Aire.

2. Criterion of task definition: aspects of the participatory process-the scope of a participation exercise, its expected output, and the mechanisms of the procedure—should be clearly defined at the outset (Rowe and Frewer 2000: 
16). As with the criterion of transparency and resource accessibility, this criterion was not met for the citizen committees in San Andrés Cholula. However, it was met in the cases studied in Tenango del Aire.

3. Criterion of structured decision-making: "The participation exercise should provide participants with appropriate mechanisms for structuring and displaying the decision-making process [enabling] the underlying reasons behind a decision to be examined, as well as the extent to which a conclusion was well supported” (Rowe and Frewer 2000: 16). This criterion was not met in San Andrés Cholula or in Tenango del Aire.

4. Criterion of cost-effectiveness (the procedure should in some sense be costeffective) (ibid.) In San Andrés Cholula, this criterion was not met. The participatory process open to citizen committees required significant financial outlays on behalf of members and time-which inhibited the costeffectiveness of the process. In Tenango del Aire, this criterion was met.

In general, when speaking to citizen committee members (public works committee and COCICOVI participants) and members of the community about the impact these groups had on government performance, the promotion of accountability, improved governance, ethics, economy, efficiency, effectiveness, responsiveness, and establishment of cost recovery mechanisms, the results were as follows. In San Andrés Cholula, for questions regarding level of satisfaction with social infrastructure projects implemented with the help of citizen committees, the answers were mixed. Although 
interviewees were happy that the projects were implemented, commentary on the quality of the project indicated disappointment. Moreover, they felt they were not qualified to assess project quality because they were not engineers. Thus, the overall satisfaction was average. Many interviewees indicated that there was no available information on the cost efficiency of projects, and in regard to ethics, there were accusations that some committee members had stolen funds. The interviewees indicated a lack of trust in the government's ability to hold these groups accountable—or even make their own employees accountable for inflating the cost of projects. There was a general lack of trust in the government to provide services in a fair and honest manner. In addition, some interviewees in Tonantzintla indicated pressure to approve projects and "sign off" in approval-despite questions regarding the implementation of projects. These results indicate that the participation of citizen committees does not result in the promised benefits.

In Tenango del Aire, results indicated a higher level of satisfaction with government performance. There was no indication of misuse of funds or lack of trust in the government. Some dissatisfaction was noted with the municipality's use of contractors to implement infrastructure projects. Interviewees felt that private companies had hired workers from outside the community—despite a perceived high-level of unemployment in the area; hiring local workers could have reduced unemployment levels and lowered project costs. But in general, the role of the office of inspector general in overseeing COCICOVIs helped guarantee a certain level of perceived accountability and pressure to perform and deliver higher quality services and projects than in San Andrés Cholula. 
To place these results (on the level of satisfaction with government services rendered in the two municipalities) within the general context of the Mexican population, the LAPOP (2010) study is very useful. In México, one in every two individuals interviewed felt that services rendered in their municipality were satisfactory (i.e., neither good nor bad) in quality (41.3\% of Mexicans) (ibid.). On the other hand, $29.4 \%$ believe that the services are good and $22.4 \%$ believe the services rendered are low quality or bad. The percentages in the extreme categories, very good or very bad, are less than $10 \%$ : $1.4 \%$ and 5.5\% respectively (ibid.). Compared to other countries in the Americas, whose citizens were asked about their level of satisfaction with services rendered by the local governments, México scored worse than half of the other countries in 2010 (LAPOP 2010). Only four out of ten Mexicans who presented a petition to local authorities had their petition resolved (LAPOP 2010:147).

The LAPOP study also found that level of satisfaction with government services determines the degree of citizen participation (2010). Specifically, this study found that dissatisfaction with government services makes citizens vote and engage in institutional participation less often. Moreover, LAPOP researchers found gender to be a determinant of satisfaction in local government services, finding that women are more satisfied than men (ibid.). This could be why more women participated in COCICOVIs. The LAPOP study also found that most citizen participation in México occurred within religious organizations, bringing into question the relationship between participation in the church and in public works committees observed in San Andrés Cholula.

The perception of good government performance is the most important thing in maintaining democratic values in the region (LAPOP 2010). Among the multiple factors 
that affect 'legitimacy,' and thus support for a stable democracy, a major contributor was the government's perceived ability to satisfy the needs and demands of its citizens (LAPOP 2010). The perceived positive performance of government in its service delivery is directly linked to the perceived legitimacy of that government. The hope of decentralization efforts was to increase citizen participation in the decision-making process and in the process improve government services. Democracy is based on the assumption that all citizens should have equal rights and deserve equal representation in the setting of priorities in society. In order to guarantee democratic accountability in service delivery, the representative nature of the political process must be safeguarded and government institutions must be accessible to all citizens, not just citizen committees. 


\section{CHAPTER 6: CONCLUSIONS}

The present study sought to shed light on the decision-making processes of rural municipalities and the rural townships associated with more urbanized municipalities in México. In general, it found that politics played a prominent role in this process. Local politicians were involved in shelving projects from previous administrations, favoring projects of supporters rather than works of general benefit, and-despite constraints imbedded in earmarked funds-allocating money using personal discretion. Politics dominated the decision-making process. In San Andrés Cholula and Tenango del Aire, public works were converted into instruments that the government used to reward certain groups who supported election campaigns. The selection of projects favored political sympathizers. Government authorities did not need to listen to the citizen committees. That demonstrated the lack of working procedures that public participation mechanisms are intended to avoid: clientelism. Once priorities were established, public functionaries in both municipalities went to the communities where the public works would be implemented to register participants comprising 'public works committees' and 'COCIVOVIs.' This was done to meet the requirements for using social infrastructure funds (SIF) from one of the major funding pools, FISM resources, and in the case of Tenango, to meet state requirements.

Neither municipality viewed citizen committees as playing an important role in the prioritization process of public works or as an essential element in their efforts to increase citizen participation. The participatory process open to public works committees in San Andrés Cholula and the COCICOVIs in Tenango del Aire varied in their ultimate purpose and the level of empowerment or shared decision-making authority granted to 
participants. The participatory process open to COCICOVIs fell short of involvement and functioned to only inform and consult in the monitoring of project execution. In certain instances, the public works committees in San Andres collaborated in the prioritization of specific public works, but these committees lacked any authority to dictate how a project should be implemented. Public works committees in the township under study in San Andrés Cholula, which participated in the prioritization of a specific public work, indicated that they formed out of frustration with lack of government initiative and action. Moreover, in San Andrés Cholula, the present study found that municipal authorities used the guise of avoiding paternalism as an excuse to not provide services or infrastructure without the financial contribution of 'citizen committees' and 'parent groups' (in the case of projects carried out in public schools), despite the lack of legal justification for doing so.

Regarding the decision-making process, the present study found threats to fairness, resulting from constraints of the local context, rotation in office, patronage, and a general not merit-based personnel system, which resulted in a lack of administrative capacity. Reforms to the civil service are needed. Thus, the use of citizen committees, specifically public works committees and COCICOVIs, in San Andrés Cholula and Tenango del Aire respectively, fell short of providing the promised benefits of utilizing a participatory planning and management (PPM) strategy. As noted by Garcia-Zamor (1985), PPM can promote the integration of local community interest and the goals set forth in developing projects by providing a space for dialogue with various perspectives. However, the participatory process open to the citizen committees in both municipalities did not allow for a general discussion of at large community goals and prioritization of 
projects. The PPM did not provide a space for open communications, identification and resolution of community needs, and conflictive viewpoints. Citizen committees in both areas represented narrow interests rather than broad community priorities. They functioned as interest groups promoting specific public works. Neither the COCICOVIs nor the Public Works Committees could be said to be politically aligned, nor associated to social movements that could affect the election process in the municipality. The citizen committees were too narrow in scope to hold the administration accountable for a particular unmet promise or drive any organized campaign to drive out an administration based lack of government performance.

By promoting the involvement of beneficiaries, project performance is said to increase because affected members of the community have an intrinsic stake in the functioning of the project and have more of an incentive to accept and meet the performance criteria. However, participants in both municipalities felt they lacked the technical knowledge to assess the quality of the completed work. In the case of San Andrés Cholula, members of citizen committees felt pressure to accept projects despite their concerns over the quality of the project output. According to the literature, by allowing for citizen input, one increases the chance of developing more targeted, useful solutions to problems faced in the community. Moreover, by creating a built-in feedback mechanism, PPM allows for the early identification of problems associated with the project and helps to open the gateway for identifying more effective ways of resolving quality output issues and promoting the longevity of the project. However, neither participatory mechanism studied allowed for true feedback loops or mechanisms for beneficiaries in affected communities to have their voices heard during the prioritization 
of projects or project development. COCICOVIs were provided with information on finalized project outlines but had no input in their development. In San Andrés Cholula, projects were also developed by the municipality and in addition, there was no transparency during the project execution process allowing for citizens to reflect on the process. Moreover, once the projects were completed, the citizen committees in both areas were dissolved, preventing their intervention in monitoring the project longevity.

In San Andrés Cholula, one concern raised about the use of citizen committees in the process of carrying out SIF projects was the identification of flaws within the participatory process, specifically in the way these committees formed, which created a bias toward one group over others. When the municipality was identifying potential project beneficiaries, those who were most articulate in an open forum context were the most likely have their concerns addressed. The participatory process simply reinforced the prestige and wealth of one group over others, over representing the interests of those with power positions in society and essentially giving them the power to prioritize local needs. Moreover, because the participatory process in San Andrés Cholula required financial outlays on behalf of project beneficiaries, this approach did not motivate members of society to participate, specifically those struggling with economic hardship. In general, because the PPM approach does not produce immediate financial rewards, it is difficult to motivate beneficiaries that are at or near the subsistence level. The poorest of local residents often find it the most difficult to take time away from work because the economic impact of doing so is harder felt. Thus, they often feel content to allow wealthier local elites negotiate such projects for their community. Moreover, in San 
Andrés Cholula, beneficiaries lacked sufficient information to define their role in the participatory process.

In Tenango del Aire, the formation of COCICOVIs was less biased and the selection of members was less discriminatory in nature-no funds were required from participants, the process was more transparent, and the definition of roles and expectations from participants was clear. The more diversified typology of citizen committees observed in San Andrés Cholula, and specifically the appearance of seemingly 'Advisory' committees, could be interpreted as an increased municipal willingness to accept citizen input in its decision-making process. However, once recognized by the municipality, or legalized by the directive of citizen participation, Advisory 'public works’ committees could become Supportive I or Put-on II committees. In the process, making the decision-making process closed to citizen input. Moreover, willingness to carry out projects outside those prioritized by the mayor could simply reflect the larger budget at the disposal of San Andrés Cholula--- compared to Tenango del Aire--- allowing it to make changes to pre-determined plans when pressured by well organized groups. In addition, although the citizen committees observed in Tenango del Aire merely resembled Supportive committees, they did provide for more citizen participation in assuring government accountability and transparency in the use of funds than observed in San Andres.

The lack of state involvement in the functioning of the 'public works committees' in San Andrés Cholula signaled that their function is not to aid the state government monitoring of municipal action, but truly allow for citizen participation in the decisionmaking process. State involvement in the monitoring of COCICOVIs in Tenango del 
Aire indicated that the municipality did not accept the authority granted to it in order to regulate the participatory processes without state oversight. The decentralization doctrine promoting municipal autonomy adopted by PAN, and not the PRI or PRD, could explain this difference. Furthermore, because the Internal Municipal Comptroller, who controls the human and financial resources of the municipality, and not a Directive of Citizen Participation (as in San Andrés Cholula), regulated COCICOVIs, the function of COCICOVIs was interpreted to be aiding in monitoring the use of municipal resources, and not promoting citizen participation in administrative decision-making.

The apparent transparency and higher level of accountability in carrying out public works in Tenango del Aire versus San Andrés Cholula is a potential result of the State's authority to monitor the use of COCICOVIs. I suggest accountability and transparency in San Andrés Cholula could improve with the willingness and ability of the state to impose sanctions against those local governments, which do not respect structures for citizen participation. Interviews with state level government officials are needed to understand why variations in the oversight function of states upon their municipalities appear. The present study supports the hypothesis that political party affiliation at the municipal, state, and federal levels of government affected application of participatory mechanisms at the local level. However, to draw conclusions at a more aggregate level, a quantitative study is needed to analyze the relationship between state involvement in the oversight of citizen committees, and political party affiliation at the local and state levels. 


\section{Bibliography}

Abers, Rebecca. (Fall 1996). "From Ideas to Practice: The Partido dos Trabalhadores and Participatory Governance in Brazil," Latin American Perspectives, Issue 91, 23:4.

Abers, Rebecca, and Allan Heskin. (Winter 1995). "Book Review” in Journal of the American Planning Association, 61:1.

Albarran, I and Garcia-Zamor, Jean-Claude. (2010). Decentralizing Cuba’s Health Care System. Journal of International Studies and Development, 10: 132-157.

Almond, G. A. and S. Verba. (1963).The Civic Culture. Princeton, N.J.: Princeton University Press.

Alvarez, Rosangel M. (1997). “Redefinición del Ámbito de 'Lo Publico’ en el Marco del Proceso de Descentralización Adelantando en Venezuela: El Caso del MunicipioLibertador (1993 1995)." Master’s Thesis, School of Sociology, Universidad Central de Venezuela, Caracas.

Angotti, Thomas. (Fall 1996). "Latin American Urbanization and Planning: Inequality and Unsustainability in North and South" Latin American Perspectives, Issue 91, 23:4.

Argyriades, Demetrios. (2010). From Bureaucracy to Debureaucratization. Public Organization Review, 10, 275-297.

Aylwin, Patricio. (July 1998). "Democracy in the Americas” Journal of Democracy, 8:3.

Bava, Silvio Caccia. (1995). "Dilemas de Gestao Municipal Democratica” in Valladares and

Coelho(eds.). Governabilidade e Pobreza no Brasil (Rio de Janeiro: Civilizacao Brasilera).

Bava, Silvio Caccia. (Jul-Sep 1996). "Desenvolvimento Local: Uma Alternativa para a Crise Social?” Sao Paulo em Prespectiva, 10:3.

Bazdresch Prada, M. (1994).Gestión municipal y cambio político. In M. Merino (Ed.). En busca de la democracia municipal. México City: Colegio de México: pp. 25-60.

Beneria, Lourdes and Mendoza Breny (1995). "Structural Adjustment and Social Emergency Funds: The cases of Honduras, México and Nicaragua.” In Jessica 
Vivian Ed. Adjustment and Social Sector Restructuring (53-76) (London: Frank Cass and Company Limited)

Berry, Jeffrey M., Kent E. Portney, and Ken Thomson. (1993). Rebirth of Urban Democracy (Washington, DC: The Brookings Institution).

Bingham, L. B., T. Nabatchi, and R. O’Leary. (2005). "The New Governance: Practices and Processes for Stakeholder and Citizen Participation in the Work of Government." Public Administration Review 65 (5): 547-558.

Borja, Jordi. (March 1996). "The city, democracy and governability: the case of Barcelona." International Social Science Journal, "Cities of the Future: Managing Social Transformations,” Vol. 48, Issue 147.

Borja, Jordi and Manuel Castells. (1997) Local \& Global: Management of Cities in the Information Age (London: United Nations Centre for Human Settlements and Earthscan Publications Ltd.).

Bossert, T. (1998). "Analyzing the Decentralization of Health Systems in Developing Countries: Decision Space, Innovation and Performance.” Social Science Medicine 47: 1513-1527.

Bowler, Shaun and Hiskey, J.T. (2005). Local Context and Democratization in México. American Journal of Political Science, 49: Draft of Forthcoming Article.

Box, Richard C.. (1998). Citizen Governance, Leading Communities into the $21^{\text {st }}$ Century. Thousand Oaks: SAGE Publications.

Bradford, Colin I. Jr., ed. (1994). Redefining the state in Latin America (Washington, DC: OECD Publications \& Information Centre).

Burki, Javed, and Sebastian Edwards. (1996) Dismantling the Populist State: The Unfinished Revolution in America and the Caribbean (Washington DC: The World Bank).

Cabrero, E.M. (1995). La nueva gestión municipal en México: Análisis de experiencias innovadoras en gobiernos locales. (México City: Miguel Ángel Porrúa).

Cabrero E. M. (Ed.). (1996). Los dilemas de la modernización municipal: Estudios sobre la gestión hacendaria en municipios urbanos de México. México City: Miguel Ángel Porrúa.

Camp, Roderic Ai (1997). Crossing Swords: Politics and Religion in México. New York: Oxfort University Press Inc. 
Carpenter, Daniel P. (2001). The Forging of Bureaucratic Autonomy, Reputations, Networks, and Policy Innovation in Executive Agencies, 1862-1928. (Princeton: Princeton University Press).

Chinos, Luis. (Dec 1986). "Gobierno Local y Participación Vecinal; el Caso de Lima Metropolitana,” Socialismo y Participación, v. 36.

Chance, John K. \& William B. Taylor. (1985). "Cofradías and Cargos: An Historical Perspective on the Mesoamerican Civil-Religious Hierarchy," American Ethnologist 12(1): 1-26.

Collier, Ruth Berins and David Collier. (1991). Shaping the Political Arena : Critical Junctures, the Labor Movement, and Regime Dynamics in Latin America (Princeton: Princeton University Press).

Colman, K. M. and C. L. Davis, (1983). "Preemptive Reform and the Mexican Working Class,” Lain American Research Review XVIII,: 22, 24.

Crow, David B. (2009) "Citizen disenchantment in new democracies: the case of México," Dissertation found in the University of Texas Digital Repository: http://repositories.lib.utexas.edu/bitstream/handle/2152/7144/crowd14688.pdf?seq uence $=2$

Dahl, R. A. (1989). Democracy and Its Critics. New Haven, CT: Yale University Press.

Dahl, R. A. (1992) “The Problem of Civic Competence.” Journal of Democracy 3 (4):2 45-59.

Dewalt, Billie R. (1975). "Changes in the Cargo Systems of MesoAmerica," Anthropological Quarterly, 48(2): 87-105.

Díaz Montes, F., Zafra, G., \& González Melchor, S. (1994). Oaxaca: diversidad municipal y participación ciudadana. In M. Merino (Ed.) En busca de la democracia municipal (pp. 135-162) México City: Colegio de México.

Dietz, Henry, and Gil Shidlo (eds.) (1998). Urban Elections in Democratic Latin America (Wilmington: Scholarly Resources, Inc.).

Dillinger, William. (1994). Decentralization and its Implications for Service Delivery (Washington DC: The World Bank).

Dowbor, Ladislau. (Jan 1998). "Decentralization and Governance," Latin American Perspectives, 98:2, pp. 28-44). 
Ebdon, C. and A. L. Franklin. (2004). "Searching for a Role for Citizens in the Budget Process.” Public Budgeting and Finance 24(1): 32-49.

Ebdon, C. and A. L. Franklin. (2006). "Citizen Participation in Budgeting Theory." Public Administration Review 66 (3): 437-447.

Evans, Peter. (1996a). "Introduction: Development Strategies across the Public-Private Divide,” World Development, 24:6, pp. 1033-37.

Evans, Peter. (1996b). "Government Action, Social Capital and Development: Reviewing the Evidence on Synergy,” World Development, 24:6, pp. 1119-32.

Evans Peter. (Oct 1997).“The Eclipse of the State? Reflections on Stateness in an Era of Globalization” World Politics, 50:1.

Evans, Peter. "Looking for Agents of Urban Livability in a Globalized Political Economy" (forthcoming).

Falleti, T. (2005). "A sequential theory of decentralization: Latin American cases in comparative perspective.” American Political Science Review. 99 (3): pp. 327345.

Farazmand, Ali. (2010). Bureaucracy and Democracy: A theoretical Analysis. Public Organization Review, 10: 245-258.

Felicissimo, Jose Roberto. (1994). "A Descentralizacao do Estado Frente as Novas Practicas e formas de Acao Colectiva,” Sao Paulo em Prespectiva, 8:2.

Fernandez Mejia, Ramon. (Febrero 2012). El Papel de la Contraloria Social Social en el Programa Federal Vivienda Rural. El Caso de San Jose del Rincón. Estado de México. (Toluca: Instituto de Administración Pública del Estado de México, A.C.)

Friedlander, Judith. (1981) "The Secularization of the Cargo System: An Example from Postrevolutionary Central México.” Latin American Research Review, 16(2) 132143.

FUNDAR (Febrero de 2006). Monitoreo de Programas Sociales and Contextos Electorales: Fondo de Infraestructura Social Municipal (FISM) -Monitoreo de las obras aprobadas y de los recursos ejercidos- In: http://www.fundar.org.mx/programassociales/8MonFISM.pdf

GACETA (2014) Periodico Official del Estado Libre y Soberano de México, registro DGC NUM. 0011021 CARACTERISTICAS 13282802 Director: Lic. Roberto Gonzalez Cantellano, Toluca de Laredo, Mex. Jueves 8 de mayo de 2014 No. 83 
Garcia-Zamor, Jean-Claude, (1985). An Introduction to Participative Planning and Management. In J-C Garcia-Zamor (Ed.) Public Participation in Development Planning and Managment, Cases from Africa and Asia (pp. 3-11). Boulder and London: Westview Press.

Guo, H. and M. Neshkova. (2009). "Public Involvement and Organizational Performance: Evidence from State Agencies.” Paper prepared for delivery at the $10^{\text {th }}$ Research Conference of the Public Management Research Association. John Glenn School of Public Affairs, Ohio State University, October 1-3.

Goldfrank, Ben (1998). Decentralization and Citizen Participation in Latin America: Deepening or Dooming Democracy. Retrieved October 23, 2012 from University of California Berkeley, Institute of International Studies Web Site : http://iis.berkeley.edu/sites/default/files/Decentralization_Goldfrank,\%20Ben.pdf

Harbers, Imke. (2007). Democratic Deepening in Third Wave Democracies: Experiments with Participation in México City. Political Studies, Vol. 55, pp. 38-58.

Habermas, Jürgen. (1996). Between Facts and Norms: Contributions to a Discourse Theory of Law and Democracy. William Rehg, Trans. Cambridge, MA: MIT Press.

Hagedorn, John M. (1995). Foresaking Our Children: Bureaucracy and Reform in the Child Welfare System (Chicago: Lakeview Press).

Han Handler, Joel. (1996). Down From Bureaucracy: The Ambiguity of Privatization and Empowerment (Princeton: Princeton University Press).

Hayek, F. (1945). “The Use of Knowledge in Society.” American Economic Review 35: $519-530$.

Hernandez, Louis, and Jonathan Fox. (1993) “México’s Difficult Democracy: Grassroots Movements, NGOs, and Local Government” in Reilly ed., New Paths to Democratic Development in Latin America (Boulder: Lynne Reiner Publishers).

Huntington, Samuel. (1975). “The United States,” in Michel Crozier, Samuel P. Huntington, and Joji Watanuki, The Crisis of Democracy: Report on the Governability of Democracies to the Trilateral Commission (New York: New York University Press).

IPMCS, (Institute For Public Management and Community Service), Overview of the first "Inter-American Democracy Conference: Democratic Governance and Effective Policy Development” February 27 - 28, 2014 Hyatt Regency Hotel, Coral Gables, FL 
Jacobi, Pedro. (Jul - Aug 1994). "Alcances y Limites de Governos Locais Progressistas no Brasil: As Prefeituras Petistas,” Cadernos de CEAS, n. 152.

Kernaghan, K. (1992). "Empowerment and Public Administration: Revolutionary Advance or Passing Fancy?” Canadian Public Administration. 35: 194-214.

Lane, R. E. (1959). Political Life. Glencoe, Ill.: The Free Press.

LAPOP, Proyecto de Opinión Pública de América Latina (Latin American Public Opinion Project in English) (2010). Cultura política de la democracia en México, Consolidación democrática en las Américas en tiempos difíciles: Pablo Paras García, Carlos López Olmedo, Dinorah Vargas López, Dr. Mitchell A. Seligson, Vanderbult University.

Levaggi, R. and P. Smith. (2003). "Decentralization in Health Care: Lessons From Public Economics.” Paper presented at the Conference on Economics and Health Policy Center for Health Economics, University of York: 1-18.

Linder, S. H., and B.G. Peters. (1995). "A Design Perspective on the Structure of Public Organizations.” In David Weimer, ed., The structure of Public Institutions. Dordrecht: Kluwer.

Lovan, W.R., Murray, M. and Shaffer, R. (2004). Participatory Governance, Planning, Conflict Mediation and Public Decision-Making in Civil Society. Burlington: Ashgate Publishing Company.

Mainwaring, Scott, \& Scully, Timothy R. (2003). Christian Democracy in Latin America, Electoral Competitions and Regime Conflicts. Stanford: Stanford University Press.

Manor, J. (1999). The Political Economy of Democratic Decentralization. Washington, D.C.: The World Bank.

Martins Filho, Joao Roberto. (Jan 1998). "Critical Sociology or Social Engineering? Commentary on Ladislau Dowbor's 'Decentralization and Governance," Latin American Perspectives, 98:2 pp. 45-48.

McCarney, Patricia. (1996). "New Considerations on the Notion of 'Governance'-New DirectionsFor Cities in the Developing World," in McCarney (ed.), Cities and Governance: New Directions in Latin America, Asia and Africa (Toronto: Centre for Urban and Community Studies).

McConnel, Grant. (1966). Private Power and American Democracy (New York: Knopf). 
McGuire, M. and M. Olson. (1996). "The Economics of Autocracy and Majority Rule: The Invisible Hand and the Use of Force.” IRS Reprint No. 72. Reprint, Journal of Economic Literature 34: 72-96.

Melo, Marcus Andre. (Jul-Sep 1996). "Crise Federativa, Guerra Fiscal e 'Hobbesianismo Municipal': Perverse Effects of Decentralization?” Sao Paulo em Perspectiva, 10:3.

Mendez, P. and A. Moreno. (2002). "Attitudes Toward Democracy: México in Comparative Perspective.” Journal of Comparative Sociology 43:350-367.

Milbrath, L. W. (1965) Political Participation. Chicago: Rand, McNally.

Montero, A. and D. Samuels. (2004). Decentralization and Democracy in Latin America. Notre Dame Press: Helen Kellogg Institute for International Studies.

Moynihan, Daniel P. (1969). Maximum Feasible Misunderstanding: Community Action in the War on Poverty (New York: Free Press).

Musgrave, R. A. (1959). The Theory of Public Finance. New York: McGraw-Hill.

Nabatchi T (2012). A Manager's Guide to Evaluating Citizen Participation. Washington, D.C.: IMD Center for the Business of Government. pp. 6-7.

Neuman, W. L. (2000). Social Research Methods: Qualitative and Quantitative Approaches. $4^{\text {th }}$ ed. Boston, MA: Allyn and Bacon.

Nickson, R. A. (1995). Local Government in Latin America. Boulder and London: Lynne Rienner.

North, D. (1990). Institutions, Institutional Change and Economic Performance. Cambridge, UK: Cambridge University Press.

Nunes, Edison. (Jul- Sep 1996). "Poder Local, Descentralizacao e Democratizacao: Um Encontro Dificil” Sao Paulo em Perspectiva, 10:3.

Nylen, William R. (1998). "The Worker’s Party Confronts the Happy Poor: Popular Participation vs. Social Sufficiency," (forthcoming, NACLA: Report on the Americas).

Oates, W. E. (1999). “An Essay on Fiscal Federalism.” Journal of Economic Literature XXXVII: $1120-1149$.

O’Donnell, Guillermo. (1997) "Polyarchies and the (Un)Rule of Law in Latin America." Paper Presented at the ASPA Meeting in Washington, DC. 
Olsen, J.P. (1986). Organized Democracy. Oslo: Universitetsforlaget.

Olson, M. (1993). “Dictatorship, Democracy, and Development.” IRS Reprint No. 32 Reprint, American Political Science Review 10: 567-576.

Olson, M. E. (August 1970). "Social and Political Participation of Blacks," American Sociological Review, Vol. 35, No. 4, pp. 682-697.

ORIFIS Organo de Fiscalizacion Superior (2013) http://www.orfis.gob.mx/guias2013/guia3.pdf

Ostrom, E., L. Schroeder and Wynne. (1993). Institutional Incentives and Sustainable Development: infrastructure Policies in Perspective. Boulder: Westview Press.

Pateman, Carole. (1970). Participation and Democratic Theory (Cambridge: Cambridge University Press).

Patton, M. Q. (2002). Qualitative Research and Evaluation Methods. $3^{\text {rd }}$ ed. Thousand Oaks, CA: Sage Publications, Inc.

Perez Piera, Adolfo. (1992). "La Decentralizacion en Montevideo: Itinerario Innovador,” in Cuadernos del CLAEH, n. 62, 2nd series, 17th year, /2.

Peters, Guy P.. (2010). Bureaucracy and Democracy. Public Organization Review, 10: 209-222.

Peterson, P. (1996). The Price of Federalism. New York: Brookings Institution Press.

Portillo, Alvaro. (1991) “Montevideo: la Primera Experiencia del Frente Amplio,” in Ziccardi (ed.), Ciudades y Gobiernos Locales en la America Latina de los Noventa (México: FLACSO, Instituto Mora, and Grupo Editorial M.A. Porrua).

Prates Coelho, Magda. (1996). "Urban Governance in Brazil” in McCarney (ed.). Cities and Governance: New Directions in Latin America, Asia, and Africa (Toronto: Center for Urban and Community Studies).

Prud'homme, Remy. (Aug 1995) "Dangers of Decentralization," The World Bank Research Observer, 10:2, pp. 201-220.

Ramírez Saiz J. M. (Ed.). (1998). Como gobiernan Guadalajara? Demandas ciudadanas y respuestas de los ayuntamientos. México City: Miguel Ángel Porrúa, UNAM. 
Reilly, Charles. (1995). "Public Policy and Citizenship" in Reilly (ed.), New Paths to Democratic Development in Latin America: The Rise of NGO-Municipal Collaboration (Boulder: Lynne Reiner Publishers).

Ribeiro, Luiz Cesar de Queiroz. (1995). "A (In)Governabilidade da Cidade? Avancos e Desafios da Reforma Urbana” in Valladares and Coelho (eds.). Governabilidade e Pobreza no Brasil (Rio de Janeiro: Civilizacao Brasileira).

Ribot, Jesse C. (2/6/98). "Decentralization and Participation in Sahelian Forestry: Legal Instruments of Central Political-Administrative Control?” Paper Presented in the Environmental Politics Seminar, Institute of International Studies, U.C. Berkeley.

Riedel, J.A. (1972). "Citizen Participation: Myths and Realities.” Public Administration Review. Vol. 33, No. 3. pp. 211-220.

Roberts, N. (1997). "Public Deliberation: An Alternative Approach to Crafting Policy and Setting Direction.” Public Administration Review 57(2): 124-132.

Rodriguez, V. E. (1997). Decentralization in México, From Reforma Municipal to Solidaridad to Nuevo Federalismo. Boulder, CO: Westview Press.

Rodríguez, V. E. \& Ward P. M. (Eds.) (1995). Opposition government in México. Albuquerque: University of New México Press.

Rondinelli, Dennis A., James S. McCullough and Ronald W. Johnson. (Jan 1989). "Analyzing Decentralization Policies in Developing Countries: a PoliticalEconomy Framework” in Development and Change, 20:1.

Rosenbloom, D. H. (1995). “The Use of Case Studies in Public Administration Education in the USA.” Journal of Management History, Vol. 1, No. 1: pp.33-46.

Rowe, G. \& Frewer, L.J. (Winter 2000). Public Participation Methods: A Framework for Evaluation. Science, Technology \& Human Values, Vol. 25 No. 1, pp. 3-29.

Rowland, Allison M. (2001). Population as a Determinant of Local Outcomes under Decentralization: Illustrations from Small Municipalities in Bolivia and México. World Development, Vol. 29, No. 8, pp. 1373-1389.

Salamon, L., ed. (2002). The Tools of Government: A Guide to the New Governance. NewYork: Oxford University Press.

Schleifer, A. and R. Vishny. "Corruption.” Quarterly Journal of Economics 108: 599617. 
Schonwalder, Gerd. (1998) "Local Politics and the Peruvian Left," Latin American Research Review, 33:2.

Secretaría de la Función Pública (SFP): http://www.funcionpublica.gob.mx/index.php/ministry-of-publicadministration.html

Shifter, Michael. (April 1997). “Tensions and Trade-offs in Latin America” Journal of Democracy, 8:2.

Shuman, Michel H. (1998). Going Local: Creating Self-Reliant Communities in a Global Age (New York: The Free Press).

Sistema Integral de Contraloría Social (SICS). (2004) Extracto del "Informe del Programa de Trabajo 2004" elaborado por la Dirección General de Operación Regional y Contraloría Social, perteneciente a la Subsecretaría de Control y Auditoría de la Gestión Pública de la Secretaría de la Función Pública de México: http://www.clad.org/siare_isis/innotend/control/sics.html

Slater, David. (Jul 1989). "Territorial Power and the Peripheral State: The Issue of Decentralization” in Development and Change, 20:3.

Slater, David. (Jul 1990). "Debating Decentralization-A Reply to Rondinelli" in Development and Change, 21:3.

Slater, David. (Jul 1989). "Territorial Power and the Peripheral State: The Issue of Decentralization" in Development and Change, 20:3.

Slater, David. (Jul 1990). "Debating Decentralization—A Reply to Rondinelli" in Development and Change, 21:3.

Stepan, Alfred. (Autumn 1997). "Democratic Opposition and Democratization Theory," Government and Opposition, 32:4, pp. 657-673.

Stivers, Camila. (1990). "The Public Agency as Polis: Active Citizenship in the Administrative State.” Administration and Society 22 (1): 86-105.

Skowroneck, Stephen. (1982). Building a new American state, the expansion of national administrative capacities; 1877-1920 (Cambridge: Cambridge University Press).

Tendler, Judith. (1997). Good Government in the Tropics (Baltimore and London: The John Hopkins University Press).

Tiebout, C. (1956). “A Pure theory of Local Expenditures.” Journal of Political Economy 64: 416-424. 
Trejos, C.L, et al (2008). "Domestic Wastewater Management in a Rural Community in Colombia.” Comparative Technology Transfer and Society, 6:3, pp. 212-35

Truman, D. (1951). The Governmental Process. New York: Alfred A. Knopf, Inc..

Tulchin, J.S., \& Selee, A., Ed. (2004). Decentralization and Democratic Governance in Latin America, Woodrow Wilson International Center for Scholars, Ch. 5, 'México: Decentralization from Above' by Yemile Mizrahi.

Turner, Fredrick C. and John D. Martz. (Fall 1997). "Institutional Confidence and Democratic Consolidation in Latin America," Studies in Comparative International Development, 32:3.

Urbinati, N. and M. E. Warren. (2008). "The Concept of Representation in Contemporary Democratic Theory.” Annual Review of Political Science 11: 387-412.

Waldo, D. (1948). The Administrative State. New York: Ronald Press Co..

Wilder, M. \& P. R. Lankao. (2006). "Paradoxes of Decentralization: Water Reform and Social Implications in México.” World Development 34:11, pp. 1977-1995, www.elsevier.com/locate/worlddev doi: 10.1016/j.worlddev.2005.11.026

Woolcock, Michael. (April 1998). "Social Capital and Economic Development: Toward a Theoretical Synthesis and Policy Framework.” Theory and Society, 27:2.

Ziccardi, A. (Ed.). (1991). Ciudades y Gobiernos Locales en América Latina de los Noventa (México: FLACSO, Instituto Mora, and Grupo Editorial M.A. Porrúa).

Ziccardi A. (Ed.) (1995). La tarea de gobernar: Gobiernos locales y demandas ciudadanas. México City: Miguel Ángel Porrúa. 
VITA

ILYANA ALBARRAN

Born, México City, México

B.A., Economics

Cornell University

Ithaca, New York

2009-2010

Vice President

Pi Alpha Alpha Honor Society

Florida International University

2011

2011-2012

David Gould Scholar, (SICA)

American Society for Public Administration

Doctoral Evidence Acquisition Fellow

Florida International University

2011-2014

Board Member, (SICA)

American Society for Public Administration

2014-2015

IPMCS Research Fellow

Inst. for Public Management and Community Service Florida International University

\section{PUBLICATIONS AND PRESENTATIONS}

Albarrán, I., and J.C. Garcia-Zamor (2010). Decentralizing Cuba's Health Care System, Journal of International Studies and Development, 1: 132-157.

Albarrán, Ilyana (2011). Vaughan-Whitehead, Daniel (2010). Fair Wages, Strengthening Corporate Social Responsibility, Public Organization Review, 1: 132-157.

Albarrán, I., and A. Caraballo (August 2011). Fair Wages and Corporate Responsibility, Council for Corporate Responsibility Newsletter.

Albarrán, Ilyana (Sep. 2014). Decentralization and Citizen Participation in Mexico. Paper presented at the EGPA Annual Conference PhD Symposium in Speyer, Germany. 